\title{
Wholesale Banking and Bank Runs in Macroeconomic Modeling of Financial Crises
}

Gertler, Mark, Nobuhiro Kiyotaki and Andrea Prestipino

Please cite paper as:

Gertler, Mark, Nobuhiro Kiyotaki and Andrea Prestipino

(2016). Wholesale Banking and Bank Runs in Macroeconomic

Modeling of Financial Crises. International Finance Discussion

Papers 1156.

http://dx.doi.org/10.17016/IFDP.2016.1156

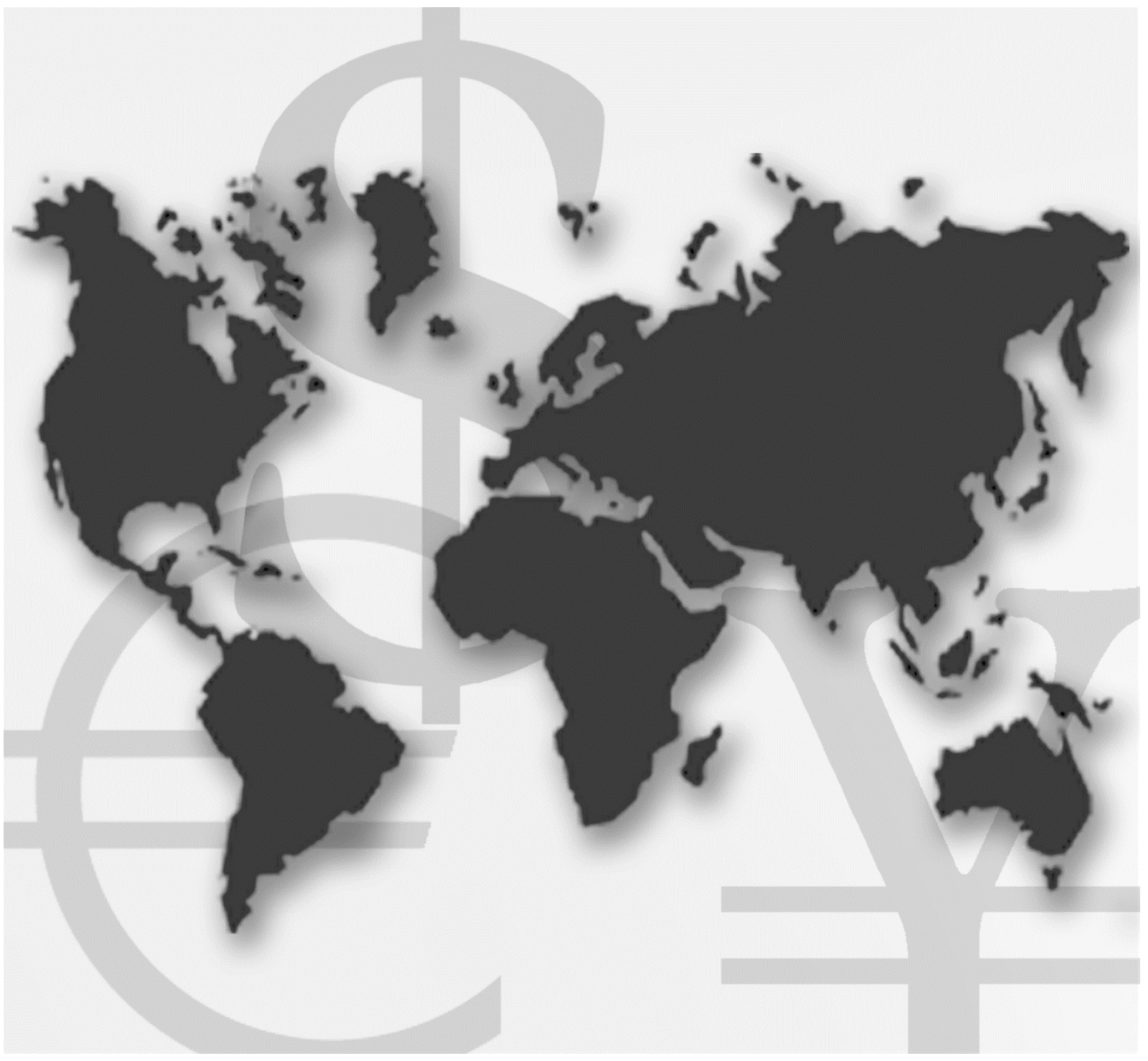

\section{International Finance Discussion Papers}

Board of Governors of the Federal Reserve System

Number 1156

January 2016 
Board of Governors of the Federal Reserve System

International Finance Discussion Papers

Number 1156

January 2016

\title{
Wholesale Banking and Bank Runs in Macroeconomic Modeling of Financial Crises
}

\author{
Mark Gertler, Nobuhiro Kiyotaki and Andrea Prestipino
}

NOTE: International Finance Discussion Papers are preliminary materials circulated to stimulate discussion and critical comment. References to International Finance Discussion Papers (other than an acknowledgment that the writer has had access to unpublished material) should be cleared with the author or authors. Recent IFDPs are available on the Web at www.federalreserve.gov/pubs/ifdp/. This paper can be downloaded without charge from the Social Science Research Network electronic library at www.ssrn.com. 


\title{
Wholesale Banking and Bank Runs in Macroeconomic Modelling of Financial Crises
}

\author{
Mark Gertler, Nobuhiro Kiyotaki and Andrea Prestipino* \\ NYU, Princeton University and Federal Reserve Board of Governors
}

January 2016

\begin{abstract}
There has been considerable progress in developing macroeconomic models of banking crises. However, most of this literature focuses on the retail sector where banks obtain deposits from households. In fact, the recent financial crisis that triggered the Great Recession featured a disruption of wholesale funding markets, where banks lend to one another. Accordingly, to understand the financial crisis as well as to draw policy implications, it is essential to capture the role of wholesale banking. The objective of this paper is to characterize a model that can be seen as a natural extension of the existing literature, but in which the analysis is focused on wholesale funding markets. The model accounts for both the buildup and collapse of wholesale banking, and also sketches out the transmission of the crises to the real sector. We also draw out the implications of possible instability in the wholesale banking sector for lender-of-last resort policy as well as for macroprudential policy.

Keywords: financial crises, wholesale banking, interbank markets, rollover risk

JEL Classsification: E44
\end{abstract}

*Prepared for Handbook of Macroeconomics, edited by John B. Taylor and Harald Uhlig. Thanks to Behzad Diba, Stavros Panageas, John B. Taylor, Harald Uhlig, Ivan Werning and Randall Wright for helpful comments 


\section{Introduction}

One of the central challenges for contemporary macroeconomics is adapting the core models to account for why the recent financial crisis occurred and for why it then devolved into the worst recession of the postwar period. On the eve of the crisis the basic workhorse quantitative models used in practice largely abstracted from financial market frictions. These models were thus largely silent on how the crisis broke out and how the vast array of unconventional policy interventions undertaken by the Federal Reserve and Treasury could have worked to mitigate the effects of the financial turmoil. Similarly, these models could not provide guidance for the regulatory adjustments needed to avoid another calamity.

From the start of the crisis there has been an explosion of literature aimed at meeting this challenge. Much of the early wave of this literature builds on the financial accelerator and credit cycle framework developed in Bernanke and Gertler (1989) and Kiyotaki and Moore (1997). This approach stresses the role of balance sheets in constraining borrower spending in a setting with financial market frictions. Procyclical movement in balance sheet strength amplifies spending fluctuations and thus fluctuations in aggregate economic activity. A feedback loop emerges as conditions in the real economy affect the condition of balance sheets and vice-versa. Critical to this mechanism is the role of leverage: The exposure of balance sheets to systemic risk is increasing in the degree of borrower leverage.

The new vintage of macroeconomic models with financial frictions makes progress in two directions: First, it adapts the framework to account for the distinctive features of the current crisis. In particular, during the recent crisis, it was highly leveraged financial institutions along with highly leveraged households that were most immediately vulnerable to financial distress ${ }^{1}$. The conventional literature featured balance sheet constraints on non-financial firms. Accordingly, a number of recent macroeconomic models have introduced balance sheet constraints on banks, while others have done so for households. ${ }^{2}$ The financial accelerator remains operative, but the classes of agents most directly affected by the financial market disruption differ from earlier work.

Another direction has involved improving the way financial crises are modeled. For example, financial crises are inherently nonlinear events, often featuring a simul-

\footnotetext{
${ }^{1}$ To be sure, the financial distress also directly affected the behavior of non-financial firms. See Giroud and Mueller (2015) for evidence of firm balance sheet effects on employment during the crisis.

${ }^{2}$ See Gertler and Karadi (2011), Gertler and Kiyotaki (2010) and Curdia and Woodford (2010) for papers that incorporate banking and Eggertsson and Krugman (2012), Geurreri and Lorenzoni (2011) and Midrigan and Philippon (2011) for papers that incuded household debt.
} 
taneous sudden collapse in asset prices and rise in credit spreads. ${ }^{3}$ A sharp collapse in output typically ensues. Then recovery occurs only slowly, as it is impeded by a slow process of develeraging. A number of papers have captured this nonlinearity by allowing for the possibility that the balance sheet constraints do not always bind. ${ }^{4}$ Financial crises are then periods where the constraints bind, causing an abrupt contraction in economic activity. Another approach to handling the nonlinearity is to allow for bank runs. ${ }^{5}$ Indeed, runs on the shadow banking system were a salient feature of the crisis, culminating with the collapse in September 2008 of Lehman Brothers, of some major money market funds and ultimately of the entire investment banking sector. Yet another literature captures the nonlinearity inherent in financial crises by modeling network interactions (see, e.g., Garleanu, Panegeas, and $\mathrm{Yu}, 2015)$.

One area the macroeconomics literature has yet to address adequately is the distinctive role of the wholesale banking sector in the breakdown of the financial system. Our notion of wholesale banks corresponds roughly, though not exactly, to the shadow banking sector on the eve of the 2007-2009 financial crisis. Shadow banking includes all financial intermediaries that operated outside the Federal Reserve's regulatory framework. By wholesale banking, we mean the subset that (i) was highly leveraged, often with short term debt and (ii) relied heavily on borrowing from other financial institutions in "wholesale" markets, as opposed to borrowing from households in "retail" markets for bank credit.

When the crisis hit, the epicenter featured malfunctioning of the wholesale banking sector. Indeed, retail markets remained relatively stable while wholesale funding markets experienced dry-ups and runs. By contrast, much of the macroeconomic modeling of banking features traditional retail banking. In this respect it misses some important dimensions of both the run-up to the crisis and how exactly the crisis played out. In addition, by omitting wholesale banking, the literature may be missing some important considerations for regulatory design.

In this Handbook chapter we present a simple canonical macroeconomic model of banking crises that (i) is representative of the existing literature; and (ii) extends this literature to feature a role for wholesale banking. The model will provide some insight both into the growth of wholesale banking and into how this growth led to a build-up of financial vulnerabilities that ultimately led to a collapse. Because the

\footnotetext{
${ }^{3}$ See He and Krishnamurthy (2014) for evidence in support of the nonlinearity of financial crises.

${ }^{4}$ See Brunnermeier and Sannikov (2014), He and Krishnamurthy $(2013,2014)$ and Mendoza (2010).

${ }^{5}$ See Gertler and Kiyotaki (2015), Ferrante (2015a), Robatto (2014) and Martin, Skeie and Von Thadden $(2014 \mathrm{a}, \mathrm{b})$.
} 
model builds on existing literature, our exposition of the framework will permit us to review the progress that is made. However, by turning attention to wholesale banks and wholesale funding markets, we are able to chart a direction we believe the literature should take.

In particular, the model is an extension of the framework developed in Gertler and Kiyotaki (2011), which had a similar two-fold objective: first, present a canonical framework to review progress that has been made and, second, chart a new direction. That paper characterized how existing financial accelerator models that featured firm level balance sheet constraints could be extended to banking relationships in order to capture the disruption of banking during the crisis. The model developed there considered only retail banks which funded loans mainly from household deposits. While it allowed for an inter-bank market for credit among retail banks, it did not feature banks that relied primarily on wholesale funding, as was the case with shadow banks.

For this Handbook chapter we modify the Gertler and Kiyotaki framework to incorporate wholesale banking alongside retail banking, where the amount credit intermediated via wholesale funding markets arises endogenously. Another important difference is that we allow for the possibility of runs on wholesale banks. We argue that both these modifications improve the ability of macroeconomic models to capture how the crisis evolved. They also provide insight into how the financial vulnerabilities built up in the first place.

As way to motivate our emphasis on wholesale banking, Section 2 presents descriptive evidence on the growth of this sector and the collapse it experienced during the Great Recession. Section 3 presents the baseline macroeconomic model with banking, where a wholesale banking sector arises endogenously. Sector 4 conducts a set of numerical experiments. While the increased size of the wholesale banking improves the efficiency of financial intermediation, it also raises the vulnerability of this sector to runs. Section 5 considers the case where runs in the wholesale sector might be anticipated. It illustrates how the model can capture some of the key phases of the financial collapse, including the slow run period up to Lehman and the ultimate "fast run" collapse. In section 6 we introduce a second asset in which retail banks have a comparative advantage in intermediating. We then show how a crisis in wholesale banking can spill over and affect retail banking, consistent with what happened during the crisis. Section 7 analyzes government policy to contain financial crises, including both ex post lender of last resort activity and ex ante macroprudential regulation. Finally, we conclude in section 8 with some directions for future research. 


\section{The Growth and Fragility of Wholesale Banking}

In this section we provide some background motivation for the canonical macroeconomic model with wholesale funding markets that we develop in the following section. We do so by presenting a brief description of the growth and ultimate collapse of wholesale funding markets during the Great Recession. We also describe informally how the disruption of these markets contributed to the contraction of the real economy.

Figure 1 illustrates how we consider the different roles of retail and wholesale financial intermediaries, following the tradition of Gurley and Shaw (1960). ${ }^{6}$ The arrows indicate the direction that credit is flowing. Funds can flow from households (ultimate lenders) to non-financial borrowers (ultimate borrowers) through three different paths: they can be lent directly from households to borrowers $\left(K^{h}\right)$; they can be intermediated by retail banks that raise deposits $(D)$ from households and use them to make loans to non-financial borrowers $\left(K^{r}\right)$; alternatively, lenders' deposits can be further intermediated by specialized financial institutions that raise funds from retail banks in wholesale funding markets $(B)$ and, in turn, make loans to ultimate borrowers $\left(K^{w}\right)$. In what follows we refer to these specialized financial institutions as wholesale banks. We think of wholesale banks as highly leveraged shadow banks that rely heavily on credit from other financial institutions, particularly short term credit. We place in this category institutions that financed long term assets, such as mortgaged back securities, with short term money market instruments, including commercial paper and repurchase agreements. Examples of these kinds of financial institutions are investment banks, hedge funds and conduits. We focus attention on institutions that relied heavily on short term funding in wholesale markets to finance longer term assets because it was primarily these kinds of entities that experienced financial turmoil.

Our retail banking sector, in turn, includes financial institutions that rely mainly on household saving for external funding and provide a significant amount of short

\footnotetext{
${ }^{6}$ Gurley and Shaw (1960) consider that there are two ways to transfer funds from ultimate lenders (with surplus funds) to ultimate borrowers (who need external funds to finance expenditure): direct and indirect finance. In direct finance, ultimate borrowers sell their securities directly to ultimate lenders to raise funds. In indirect finance, financial intermediaries sell their own securities to raise funds from ultimate lenders in order to buy securities from ultimate borrowers. By doing so, financial intermediaries transform relatively risky, illiquid and long maturity securities of ultimate borrowers into relatively safe, liquid and short maturity securities of intermediaries. Here we divide financial intermediaries into wholesale and retail financial intermediaries, while both involve asset transformation of risk, liquidity and maturity. We refer to intermediaries as "banks" and to ultimate lenders as "households" for short.
} 


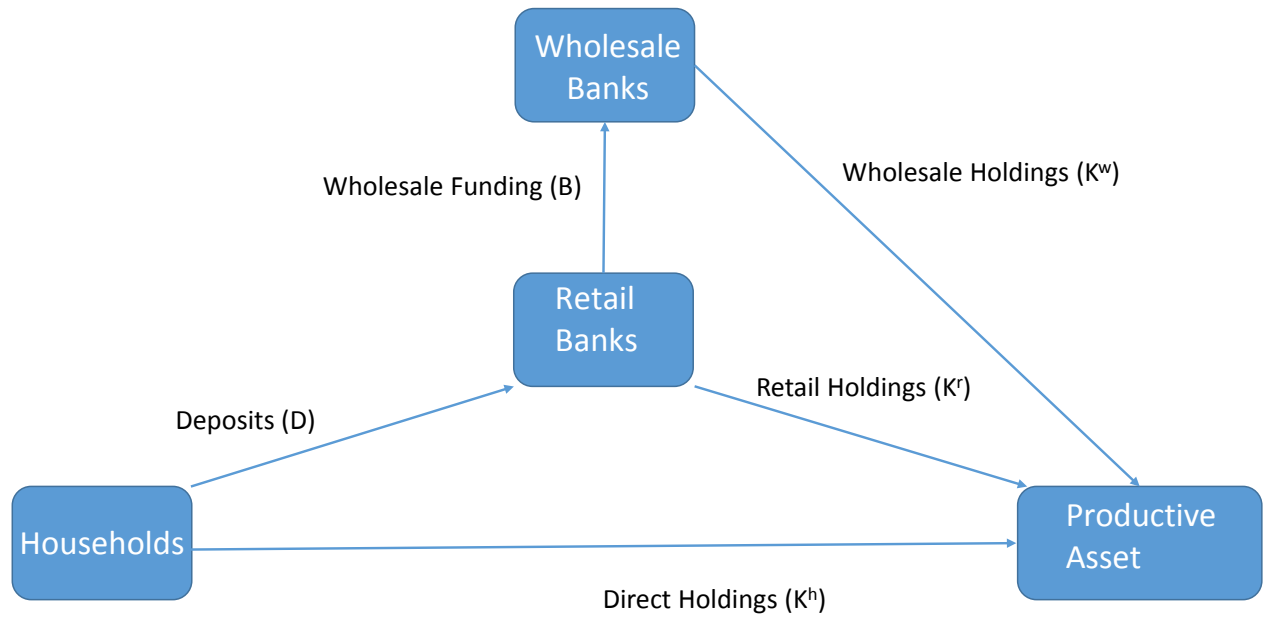

Figure 1: Modes of Financial Intermediation

term financing to the wholesale banks. Here we have in mind commercial banks, money market funds and mutual funds that raised funds mainly from households and on net provided financing to wholesale banks.

Figure 1 treats wholesale banking as if it is homogenous. In order to understand how the crisis spread, it is useful to point out that there are different layers within the wholesale banking sector. While the intermediation process was rather complex, conceptually we can reduce the number of layers to three basic ones: (1) origination; (2) securitization; (3) and funding. Figure 2 illustrates the chain. First there are "loan originators," such as mortgage origination companies and finance companies, that made loans directly to non-financial borrowers. At the other end of the chain were shadow banks that held securitized pools of the loans made by originators. In between were brokers and conduits that assisted in the securitization process and provided market liquidity. Dominant in this group were the major investment banks (e.g., Goldman Sachs, Morgan Stanley, Lehman Brothers, etc.). Each of these layers relied on short term funding, including commercial paper, asset-backed commercial paper and repurchase agreements. While there was considerable inter-bank lending among wholesale banks, retail banks (particularly money market funds) on net provided short term credit in wholesale credit markets.

We next describe a set of facts about wholesale banking. We emphasize three 


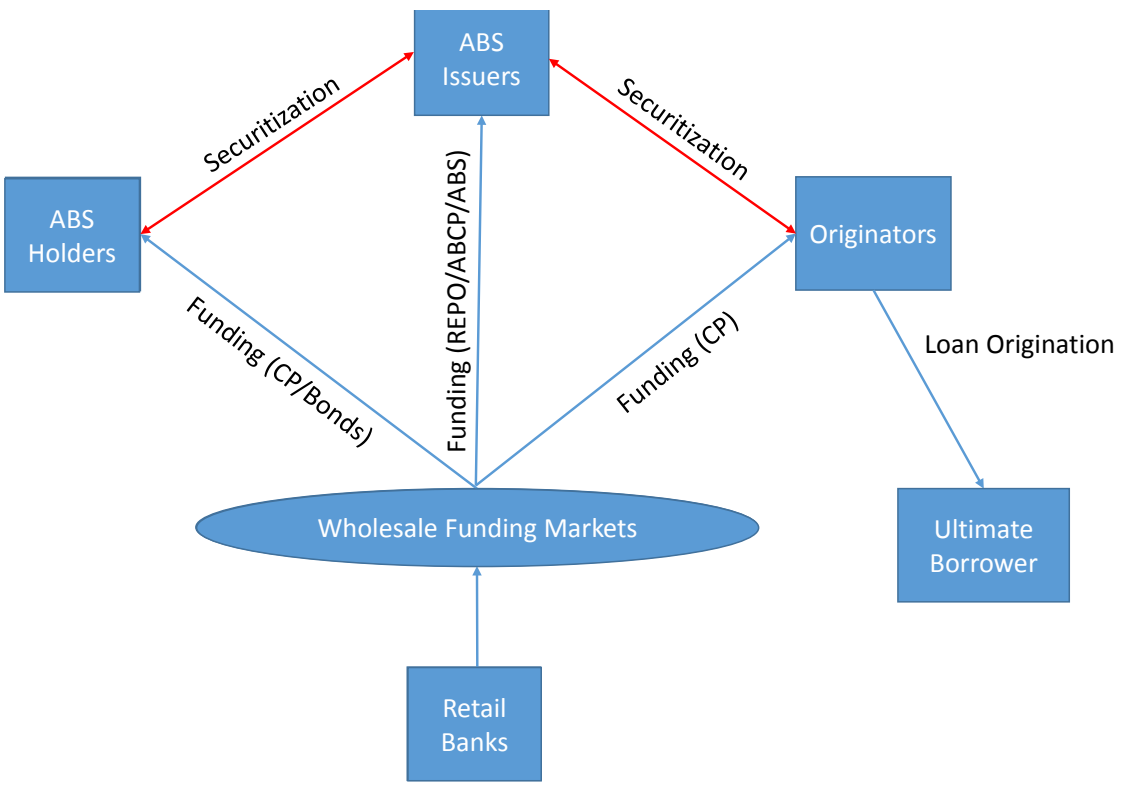

Figure 2: Wholesale Intermediation

sets of facts in particular: (1) wholesale banking grew in relative importance over the last four decades; (2) leading up to the crisis wholesale banks were highly exposed to systemic risk because they were highly leveraged and relied heavily on short term debt; and (3) the subsequent disruption of wholesale funding markets raised credit costs and contracted credit flows, likely contributing in a major way to the Great Recession.

1. Growth in Wholesale Banking

We now present measures of the scale of wholesale banking relative to retail banking as well as to household's direct asset holdings. Table 1 describes how we construct measures of assets held by wholesale versus retail banks. In particular it lists how we categorized the various types of financial intermediaries into wholesale versus retail banking. ${ }^{7,8}$ As the table indicates, the wholesale banking sector aggregates financial institutions that originate loans, that help securitize them and that ultimately fund

\footnotetext{
${ }^{7}$ The Appendix provides details about measurement of the time series shown in this section from Flow of Funds data.

${ }^{8}$ It is important to notice that the measures we report are broadly in line with analogous measures computed for shadow banking. See, e.g., Adrian and Ashcraft (2012), for an alternative definition of shadow banking that yields very simlar conclusions and Pozsar et al (2013), for a detailed description of shadow banking.
} 
them. A common feature of all these institutions, though, is that they relied heavily on short term credit in wholesale funding markets.

\begin{tabular}{|c|c|c|}
\hline \multicolumn{3}{|c|}{ Table 1} \\
\hline Retail Sector & $\begin{array}{r}\text { Priv } \\
\text { Mo }\end{array}$ & $\begin{array}{l}\text { te Depository Institutions } \\
\text { ey Market Mutual Funds } \\
\text { Mutual Funds }\end{array}$ \\
\hline Wholesale Sector & $\begin{array}{l}\text { Origination } \\
\text { Securitization } \\
\text { Funding }\end{array}$ & $\begin{array}{c}\text { Finance Companies } \\
\text { Real Estate Investment Trusts } \\
\text { Government Sponsored Enterprises } \\
\text { Security Brokers Dealers } \\
\text { ABS Issuers } \\
\text { GSE Mortgage Pools } \\
\text { Funding Corporations } \\
\text { Holding Companies }\end{array}$ \\
\hline
\end{tabular}

Figure 3 portrays the log level of credit to non-financial sector provided by wholesale banks, by retail banks, and directly by households from the early 1980s until the present. ${ }^{9}$ The figure shows the rapid increase in wholesale banking relative to the other means of credit supply to non-financial sector. Wholesale banks went from holding under fifteen percent of total credit in the early 1980s to roughly forty percent on the eve of the Great Recession, an amount on par with credit provided by retail banks.

Two factors were likely key to the growth of wholesale banking. The first is regulatory arbitrage. Increased capital requirements on commercial banks raised the incentive to transfer asset holding outside the commercial bank system. Second, financial innovation improved the liquidity of wholesale funding markets. The securitization process in particular improved the (perceived) safety of loans by diversifying idiosyncratic risks as well as by enhancing the liquidity of secondary markets for bank assets. The net effect was to raise the borrowing capacity of the overall financial intermediary sector.

2. Growth in Leverage and Short Term Debt in Wholesale Banking

Wholesale banking not only grew rapidly, it also became increasingly vulnerable to systemic disturbances. Figure 4 presents evidence on the growth in leverage in the investment banking sector. Specifically it plots the aggregate leverage multiple

\footnotetext{
${ }^{9}$ The measure we present also include nonfinancial corporate equities. Excluding equities, households would become negligible but the relative size of wholesale and retail banks would evolve very similarly. See the Appendix for details on how we construct the measures reported.
} 


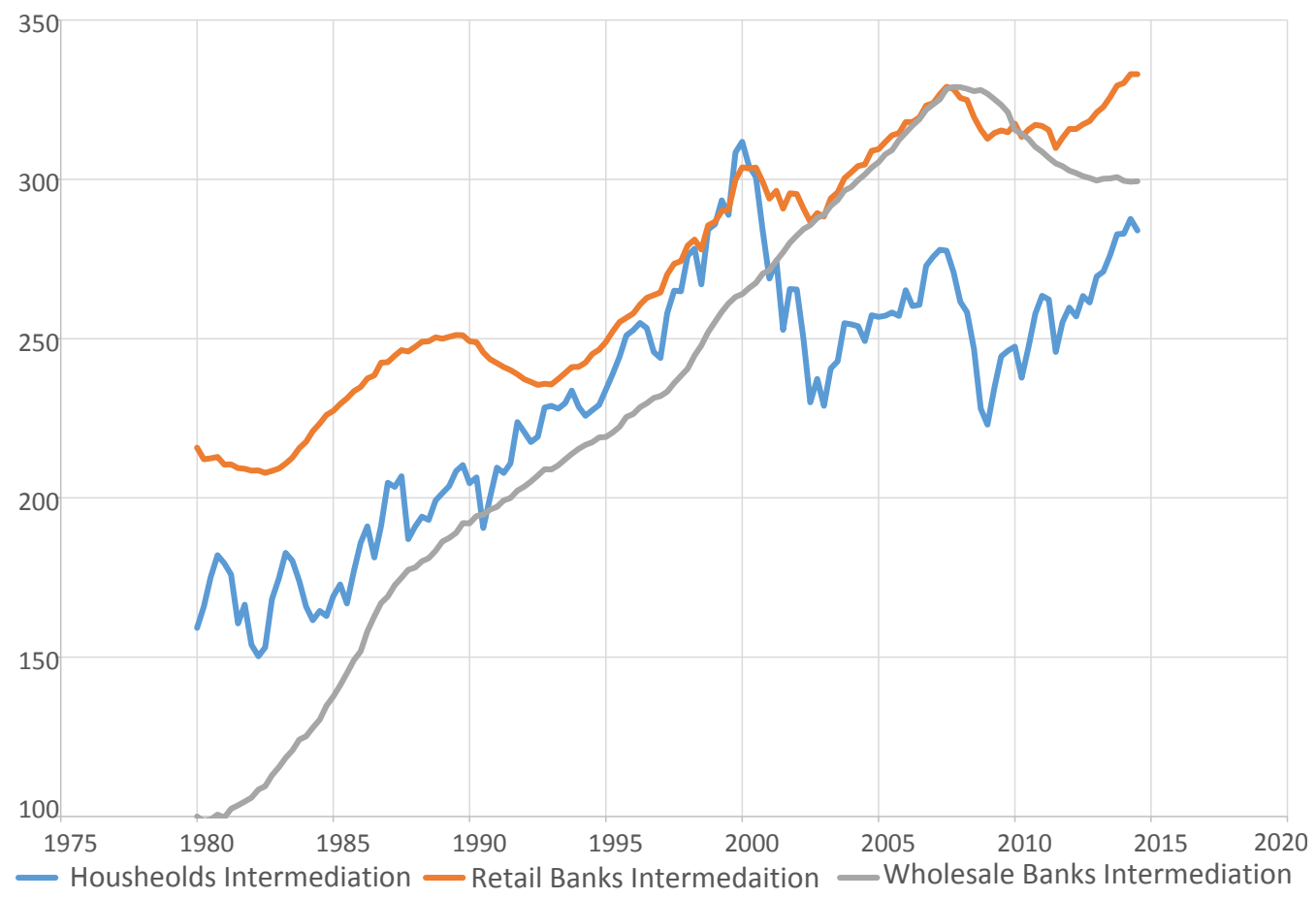

Figure 3: Intermediation by Sector

The graph shows the evolution of credit intermediated by the three different sectors. Nominal data from the flow of funds are deflated using the CPI and normalized so that the log of the normalized value of real wholesale intermediation in 1980 is equal to 1 . The resulting time series are then multiplied by 100

for broker dealers (primarily investment banks) from 1980 to the present. We define the leverage multiple as the ratio of total assets held to equity. ${ }^{10}$ The greater is the leverage multiple, the higher is the reliance on debt finance relative to equity. The key takeaway from Figure 4 is that the leverage multiple grew from under five in the early 1980s to over forty at the beginning of the Great Recession, a nearly tenfold increase.

Arguably, the way securitization contributed to the overall growth of wholesale banking was by facilitating the use of leverage. By constructing assets that appeared safe and liquid, securitization permitted wholesale banks to fund these assets by issuing debt. At a minimum debt finance had the advantage of being cheaper due to

\footnotetext{
${ }^{10}$ The data is from the Flow of Funds and equity is measured by book value. We exclude nonfinancial assets from measurement as they are not reported in the Flow of Funds.
} 


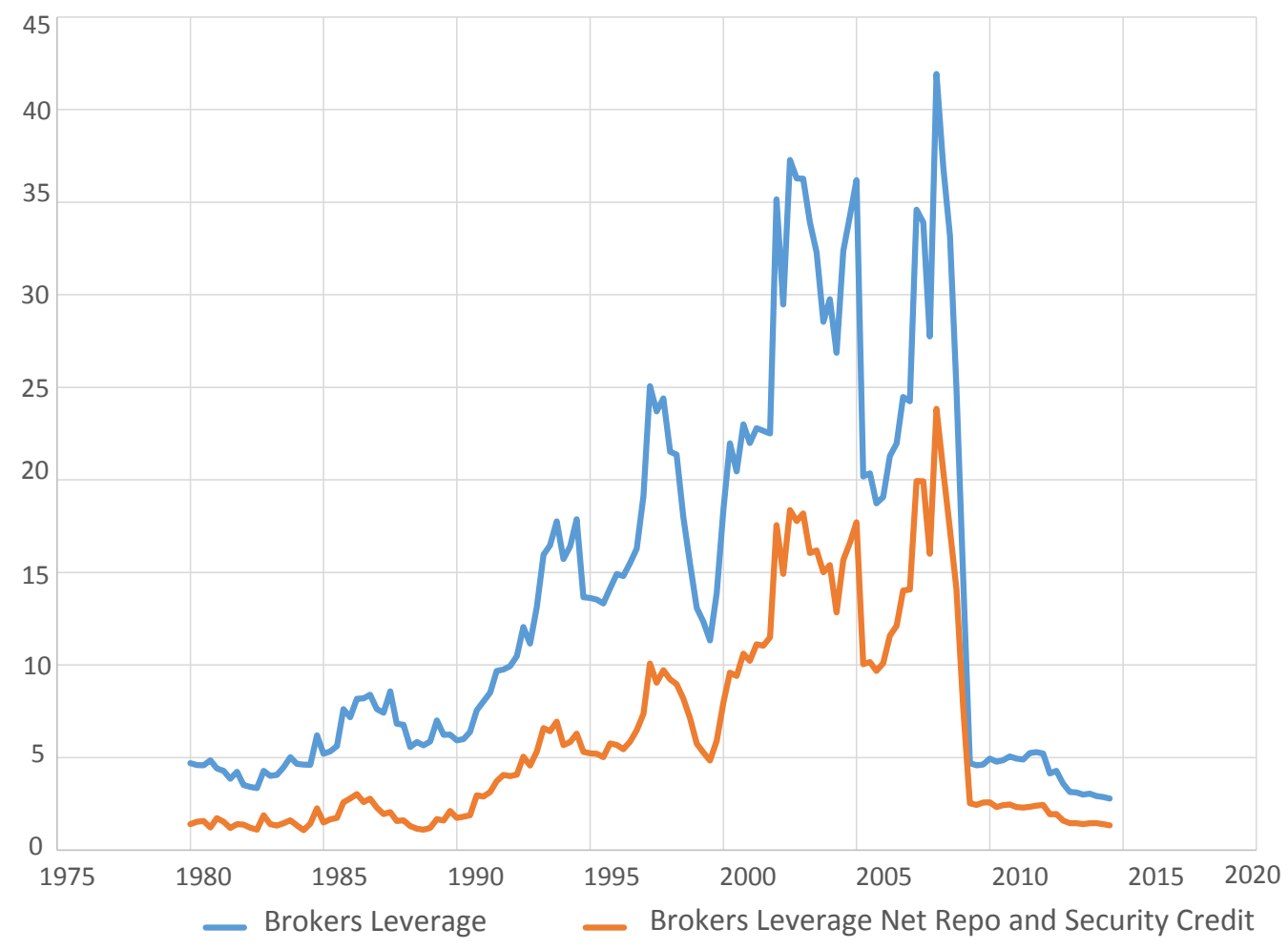

Figure 4: Brokers Leverage

Leverage is given by the ratio of total financial assets over equity. Equity is computed from the flow of funds by subtracting total financial liabilities from total financial assets. The net position leverage computes assets by netting out long and short positions in REPO and Security Credit. See the Appendix for details.

the tax treatment. Debt financing was also cheaper to the extent the liabilities were liquid and thus offered a lower rate due to a liquidity premium.

Why were these assets funded in wholesale markets as opposed to retail markets? The sophistication of these assets required that creditors be highly informed to evaluate payoffs, especially given the absence of deposit insurance. The complicated asset payoff structure also suggests that having a close working relationship with borrowers is advantageous. It served to reduce the possibility of any kind of financial malfeasance. Given these considerations, it makes sense that wholesale banks obtain funding in inter-bank markets. In these markets lenders are sophisticated financial institutions as opposed to relatively unsophisticated households in the retail market.

Figure 5 shows that much of the growth in leverage in wholesale banking involved short term borrowing. The figure plots the levels of asset backed commercial pa- 


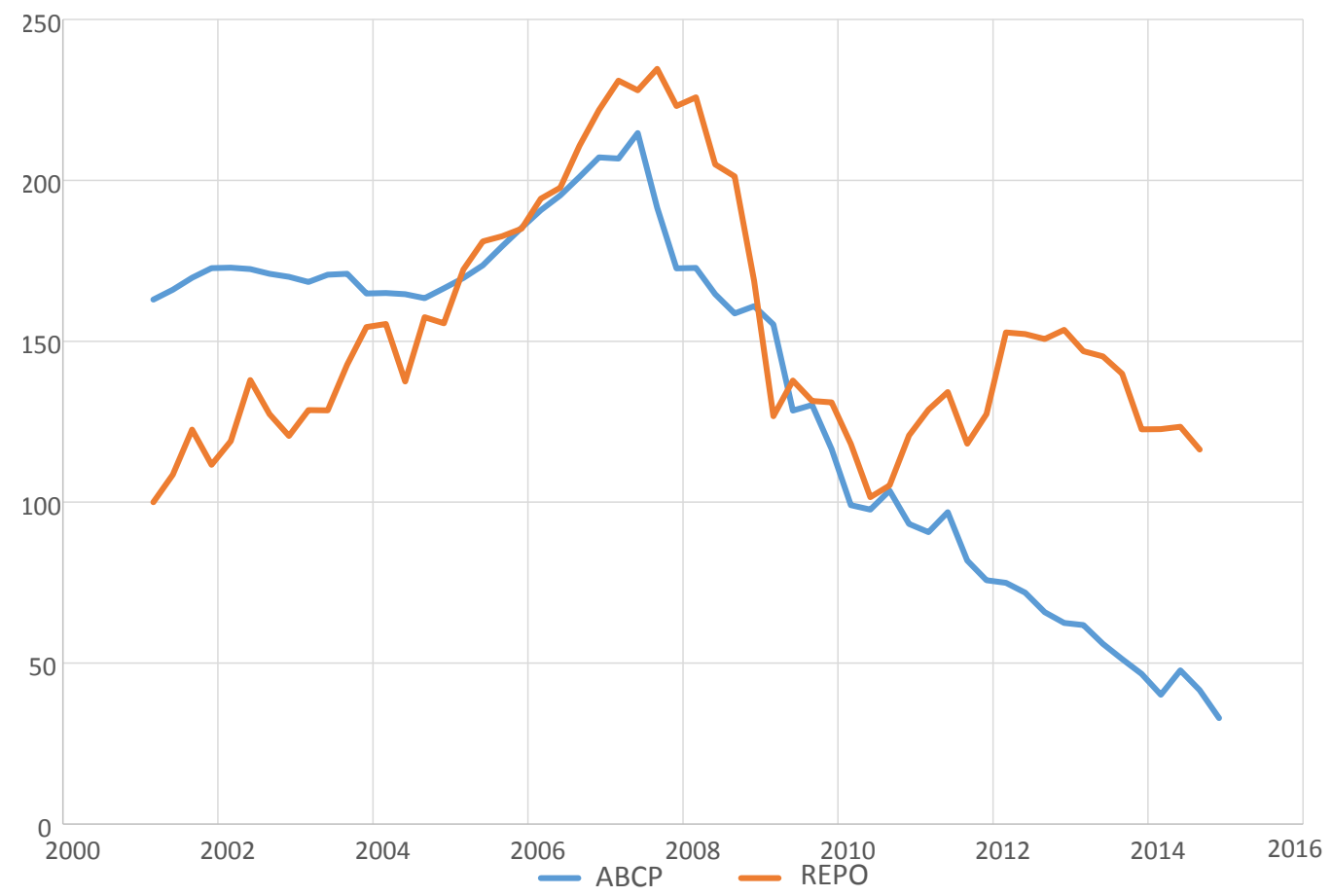

Figure 5: Short Term Wholesale Funding

The graph shows the logarithm of the real value outstanding. Nominal values from Flow of FUnds are deflated using the CPI

per $(\mathrm{ABCP})$ and repurchase agreements (Repo). This growth reflected partly the growth in assets held by wholesale banks and partly innovation in loan securitization that made maturity transformation by wholesale banks more efficient. Also relevant, however, was a shift in retail investors demand from longer term security tranches towards short term credit instruments as the initial fall in housing prices in 2006 raised concerns about the quality of existing securitized assets. ${ }^{11,12}$ As we discuss next, the combination of high leverage and short term debt is what made the wholesale banking system extremely fragile.

\footnotetext{
${ }^{11}$ See Brunnermeier and Oemke (2013) for a model in which investors prefer shorter maturities when realease of information could lead them not to roll over debt.

${ }^{12}$ It is not easy to gather direct evidence on this from the aggregate composition of liabilities of wholesale banks since data from the Flow of Funds excludes the balance sheets of SIVs and CDOs from the ABS Issuers category. Our narrative is based on indirect evidence coming from ABX spreads as documented for example in Gorton (2009).
} 


\section{The Crisis: The Unraveling of Wholesale Bank Funding Markets}

The losses suffered by mortgage originators due to falling housing prices in 2006 eventually created strains in wholesale funding markets. Short term wholesale funding markets started experiencing severe turbulence in the summer of 2007. In July 2007 two Bear Sterns investment funds that had invested in subprime related products declared bankruptcy. Shortly after, BNP Paribas had to suspend withdrawals from investment funds with similar exposure. These two episodes led investors to reassess the risks associated with the collateral backing commercial paper offered by asset backed securities issuers. In August 2007 a steady contraction of Asset Backed Commercial Paper (ABCP) market began, something akin to a "slow run", in Bernanke's terminology. ${ }^{13}$ The value of Asset Backed Commercial Paper outstanding went from a peak of 1.2 trillion dollars in July 2007 to 800 billion dollars in December of the same year and continued its descent to its current level of around 200 billion dollars.

The second significant wave of distress to hit wholesale funding markets featured the collapse of Lehman Brothers in September of 2008. Losses on short term debt instruments issued by Lehman Brothers led the Reserve Primary Fund, a large Money Market Mutual Fund (MMMF), to "break the buck": the market value of assets fell below the value of its non-contingent liabilities. An incipient run on MMMFs was averted only by the extension of Deposit Insurance to these types of institutions. Wholesale investors ${ }^{14}$ however, reacted by pulling out of the Repo market, switching off the main source of funding for Security Broker Dealers. Figure 5 shows the sharp collapse in repo financing around the time of the Lehman collapse. Indeed if the first wave of distress hitting the ABCP market had the features of a "slow run", the second, which led to the dissolution of the entire investment banking system had the features of a traditional "fast run."

We emphasize that a distinctive feature of these two significant waves of financial distress is that they did not involve traditional banking institutions. In fact, the retail sector as a whole was shielded thanks to prompt government intervention that halted the run on MMMFs in 2008 as well as the Troubled Asset Relief Program and other subsequent measures that supplemented the traditional safety net. In fact, total short term liabilities of the retail sector were little affected overall (See Figure 19). This allowed the retail banking sector to help absorb some of the intermediation

\footnotetext{
${ }^{13}$ Covitz, Liang and Suarez (2013) provide a detailed description of the run on ABCP programs in 2007. A very clear description of the role of commercial paper during the 2007-2009 crisis is presented by Kacperczyk and Schnabl (2010).

${ }^{14}$ The poor quality of available data makes it difficult to exactly identify the identity of the investors running on Repo's. See Gorton (2012) and Krishnamurthy Nagel and Orlov (2014).
} 


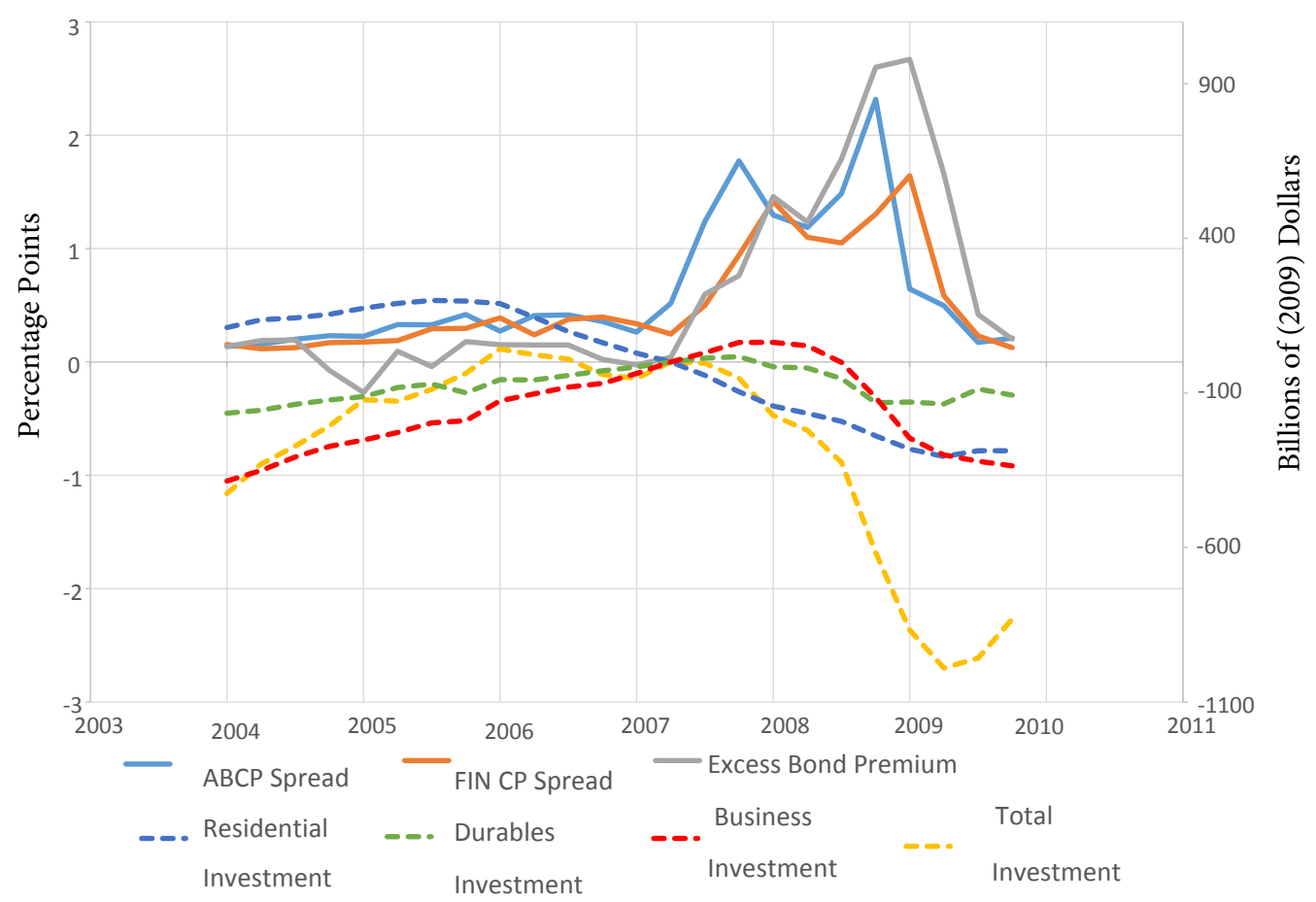

Figure 6: Credit Spreads and Investment

previously performed by wholesale banks.

Despite the unprecedented nature and size of government intervention and the partial replacement of wholesale intermediation by retail bank lending, the distress in wholesale bank funding markets led to widespread deterioration in credit conditions. Figure 6 plots the behavior of credit spreads and investment from 2004 to 2010 . We focus on three representative credit spreads: (1) The spread between the three month ABCP rate and three month Treasury spread; (2) The financial company commercial paper spread; and (3) The Gilchrist and Zakrajsek (2012) excess bond premium. In each case the spread is the difference between the respective rate on the private security and a similar maturity treasury security rate. The behavior of the spreads lines up with the waves of financial distress that we described. The ABCP spread jumps by 1.5\% in August 2007, the beginning of the unraveling of this market. The increase in this spread implies a direct increase in credit costs for borrowing funded by $\mathrm{ABCP}$ including mortgages, car loans, and credit card borrowing. As problems spread to broker dealers, the financial commercial paper spread increases reaching a peak at more than $1.5 \%$ at the time of the Lehman collapse. Increasing costs 
of credit for these intermediaries, in turn, helped fuel increasing borrowing costs for non-financial borrowers. The Gilchrist and Zakrajsek's corporate excess bond spread jumps more than $2.5 \%$ from early 2007 to the peak in late 2008 .

It is reasonable to infer that the borrowing costs implied by the increased credit spreads contributed in an important way to the slowing of the economy at the onset of the recession in 2007:Q4, as well as to the sharp collapse following the Lehman failure. As shown in Figure 7, the contraction in business investment, residential investment, durable consumption and their sum - total investment, moves inversely with credit spreads.

In our view, there are three main conclusions to be drawn from the empirical evidence presented in this section. First, the wholesale banking sector grew into a very important component of financial intermediation by relying on securitization to reduce the risks of lending and expand the overall borrowing capacity of the financial system. Second, higher borrowing capacity came at the cost of increased fragility as high leverage made wholesale banks' net worth very sensitive to corrections in asset prices. Third, the disruptions in wholesale funding markets that took place in 2007 and 2008 seem to have played an important role in the unfolding of the Great Recession. These observations motivate our modeling approach below and our focus on interbank funding markets functioning and regulation.

\section{Basic Model}

\subsection{Key Features}

Our starting point is the infinite horizon macroeconomic model with banking and bank runs developed in Gertler and Kiyotaki (2015). In order to study recent financial booms and crises, in this chapter we disaggregate banking into wholesale and retail banks. Wholesale banks make loans to the non-financial sector funded primarily by borrowing from retail banks. The latter use deposits from households to make loans both to the non-financial sector and to the wholesale financial sector. Further, the size of the wholesale banking market arises endogenously. It depends on two key factors: (1) the relative advantage wholesale banks have in managing assets over retail banks; and (2) the relative advantage of retail banks over households in over-coming an agency friction that impedes lending to wholesale banks. ${ }^{15}$

\footnotetext{
${ }^{15}$ Our setup bears some resemblance to Holmstrom and Tirole (1997), which has non-financial firms that face costs in raising external funds from banks that in turn face costs in raising deposits from households. In our case it is constrained wholesale banks that raise funds from constrained retail banks.
} 
In the previous section we described the different layers of the wholesale sector, including origination, securitization and funding. For tractability, in our model we consolidate these various functions into a single type of wholesale bank. Overall, our model permits capturing financial stress in wholesale funding markets which was a key feature of the recent financial crisis.

There are three classes of agents: households, retail banks, and wholesale banks. There are two goods, a nondurable good and a durable asset, "capital." Capital does not depreciate and the total supply of capital stock is fixed at $\bar{K}$. Wholesale and retail banks use borrowed funds and their own equity to finance the acquisition of capital. Households lend to banks and also hold capital directly. The sum of total holdings of capital by each type of agent equals the total supply:

$$
K_{t}^{w}+K_{t}^{r}+K_{t}^{h}=\bar{K},
$$

where $K_{t}^{w}$ and $K_{t}^{r}$ are the total capital held by wholesale and retail bankers and $K_{t}^{h}$ is the amount held by households.

Agents of type $j$ use capital and goods as inputs at $t$ to produce output and capital at $t+1$, as follows:

$$
\left.\begin{array}{cc}
\text { date } t & \text { date } t+1 \\
K_{t}^{j} \text { capital } \\
F^{j}\left(K_{t}^{j}\right) \text { goods }
\end{array}\right\} \rightarrow\left\{\begin{array}{c}
Z_{t+1} K_{t}^{j} \text { output } \\
K_{t}^{j} \text { capital }
\end{array}\right.
$$

where type $j=w, r$ and $h$ stands for wholesale banks, retail banks, and households, respectively. Expenditure in terms of goods at date $t$ reflects the management cost of screening and monitoring investment projects. In the case of retail banks, the management costs might also reflect various regulatory constraints. We suppose this management cost is increasing and convex in the total amount of capital, as given by the following quadratic formulation:

$$
F^{j}\left(K_{t}^{j}\right)=\frac{\alpha^{j}}{2}\left(K_{t}^{j}\right)^{2} .
$$

In addition we suppose the management cost is zero for wholesale banks and highest for households (holding constant the level of capital):

$$
\alpha^{w}=0<\alpha^{r}<\alpha^{h} .
$$

This assumption implies that wholesale bankers have an advantage over the other 
agents in managing capital. ${ }^{16}$ Retail banks in turn have a comparative advantage over households. Finally, the convex cost implies that it is increasingly costly at the margin for retail banks and households to absorb capital directly. As we will see, this cost formulation provides a simple way to limit agents with wealth but lack of expertise from purchasing assets during a firesale.

In our decentralization of the economy, a representative household provides capital management services both for itself and for retail banks. For the latter, the household charges retail banks a competitive price $f_{t}^{r}$ per unit of capital managed, where $f_{t}^{r}$ corresponds to the marginal cost of providing the service:

$$
f_{t}^{r}=F^{r^{\prime}}\left(K_{t}^{r}\right)=\alpha^{r} K_{t}^{r}
$$

Households obtain the profit from this activity $f_{t}^{r} K_{t}^{r}-F^{r}\left(K_{t}^{r}\right)$.

\subsection{Households}

Each household consumes and saves. Households save either by lending funds to bankers or by holding capital directly in the competitive market. They may deposit funds in either retail or wholesale banks. In addition to the returns on portfolio investments, every period each household receives an endowment of nondurable goods, $Z_{t} W^{h}$, that varies proportionately with the aggregate productivity shock $Z_{t}$.

Deposits held in a bank from $t$ to $t+1$ are one period bonds that promise to pay the non-contingent gross rate of return $\bar{R}_{t+1}$ in the absence of a run by depositors. In the event of a deposit run, depositors only receive a fraction $x_{t+1}^{r}$ of the promised return, where $x_{t+1}^{r}$ is the total liquidation value of retail banks assets ${ }^{17}$ per unit of promised deposit obligations. Accordingly, we can express the household's return on deposits, $R_{t+1}$, as follows:

$$
R_{t+1}=\left\{\begin{aligned}
\bar{R}_{t+1} & \text { if no deposit run } \\
x_{t+1}^{r} \bar{R}_{t+1} & \text { if deposit run occurs }
\end{aligned}\right.
$$

where $0 \leq x_{t}^{r}<1$. Note that if a deposit run occurs all depositors receive the same pro rata share of liquidated assets.

\footnotetext{
${ }^{16}$ In general we have in mind that wholesale and retail banks specialize in different types of lending and, as a consequence, each has developed relative expertise in managing the type of assets they hold. We subsequently make this point clearer by introducing a second asset in which retail banks have a comparative advantage in intermediating. Also relevant are regulatory distortions, though we view this as a factor that leads to specialization in the first place.

${ }^{17}$ Under our calibration only retail banks choose to issue deposits. See below.
} 
Household utility $U_{t}$ is given by

$$
U_{t}=E_{t}\left(\sum_{i=0}^{\infty} \beta^{i} \ln C_{t+i}^{h}\right)
$$

where $C_{t}^{h}$ is household consumption and $0<\beta<1$. Let $Q_{t}$ be the market price of capital. The household then chooses consumption, bank deposits $D_{t}$ and direct capital holdings $K_{t}^{h}$ to maximize expected utility subject to the budget constraint

$$
C_{t}^{h}+D_{t}+Q_{t} K_{t}^{h}+F^{h}\left(K_{t}^{h}\right)=Z_{t} W^{h}+R_{t} D_{t-1}+\left(Z_{t}+Q_{t}\right) K_{t-1}^{h}+f_{t}^{r} K_{t}^{r}-F^{r}\left(K_{t}^{r}\right) .
$$

Here, consumption, saving and management costs are financed by the endowment, the returns on savings, and the profits from providing management services to retail bankers.

For pedagogical purposes, we begin with a baseline model where bank runs are completely unanticipated events. Accordingly, in this instance the household chooses consumption and saving with the expectation that the realized return on deposits, $R_{t+i}$, equals the promised return, $\bar{R}_{t+i}$, with certainty, and that asset prices, $Q_{t+i}$, are those at which capital is traded when no bank run happens. In a subsequent section, we characterize the case where agents anticipate that a bank run may occur with some likelihood.

Given that the household assigns probability zero to a bank run, the first order condition for deposits is given by

$$
E_{t}\left(\Lambda_{t, t+1}\right) R_{t+1}=1
$$

where the stochastic discount factor $\Lambda_{t, \tau}$ satisfies

$$
\Lambda_{t, \tau}=\beta^{\tau-t} \frac{C_{t}^{h}}{C_{\tau}^{h}} .
$$

The first order condition for direct capital holdings is given by

$$
E_{t}\left(\Lambda_{t, t+1} R_{k t+1}^{h}\right)=1
$$

with

$$
R_{k t+1}^{h}=\frac{Q_{t+1}+Z_{t+1}}{Q_{t}+F^{h \prime}\left(K_{t}^{h}\right)}
$$

where $F^{h \prime}\left(K_{t}^{h}\right)=\alpha^{h} K_{t}^{h}$ and $R_{t+1}^{h}$ is the household's gross marginal rate of return from direct capital holdings. 


\subsection{Banks}

There are two types of bankers, retail and wholesale. Each type manages a financial intermediary. Bankers fund capital investments (which we will refer to as "nonfinancial loans") by issuing deposits to households, borrowing from other banks in an interbank market and using their own equity, or net worth. Banks can also lend in the interbank market.

As we describe below, bankers may be vulnerable to runs in the interbank market. In this case, creditor banks suddenly decide to not rollover interbank loans. In the event of an interbank run, the creditor banks receive a fraction $x_{t+1}^{w}$ of the promised return on the interbank credit, where $x_{t+1}^{w}$ is the total liquidation value of debtor bank assets per unit of debt obligations. Accordingly, we can express the creditor bank's return on interbank loans, $R_{b t+1}$, as follows:

$$
R_{b t+1}=\left\{\begin{aligned}
\bar{R}_{b t+1} & \text { if no interbank run } \\
x_{t+1}^{w} \bar{R}_{b t+1} & \text { if interbank run occurs }
\end{aligned}\right.
$$

where $0 \leq x_{t}^{w}<1$. If an interbank run occurs, all creditor banks receive the same pro rata share of liquidated assets. As in the case of deposits, we continue to restrict attention to the case where bank runs are completely unanticipated, before turning in a subsequent section to the case of anticipated runs in wholesale funding markets.

Due to financial market frictions that we specify below, bankers may be constrained in their ability to raise external funds. To the extent they may be constrained, they will attempt to save their way out of the financing constraint by accumulating retained earnings in order to move toward one hundred percent equity financing. To limit this possibility, we assume that bankers have a finite expected lifetime: Specifically, each banker of type $j$ (where $j=w$ and $r$ for wholesale and retail bankers) has an i.i.d. probability $\sigma^{j}$ of surviving until the next period and a probability $1-\sigma^{j}$ of exiting. This setup provides a simple way to motivate "dividend payouts" from the banking system in order to ensure that banks use leverage in equilibrium.

Every period new bankers of type $j$ enter with an endowment $w^{j}$ that is received only in the first period of life. This initial endowment may be thought of as the start up equity for the new banker. The number of entering bankers equals the number who exit, keeping the total constant.

We assume that bankers of either type are risk neutral and enjoy utility from consumption in the period they exit. The expected utility of a continuing banker at 
the end of period $t$ is given by

$$
V_{t}^{j}=E_{t}\left[\sum_{i=1}^{\infty} \beta^{i}\left(1-\sigma^{j}\right)\left(\sigma^{j}\right)^{i-1} c_{t+i}^{j}\right],
$$

where $\left(1-\sigma^{j}\right)\left(\sigma^{j}\right)^{i-1}$ is the probability of exiting at date $t+i$, and $c_{t+i}^{j}$ is terminal consumption if the banker of type $j$ exits at $t+i$.

The aggregate shock $Z_{t}$ is realized at the start of $t$. Conditional on this shock, the net worth of "surviving" bankers $j$ is the gross return on non-financial loans net the cost of deposits and borrowing from the other banks, as follows:

$$
n_{t}^{j}=\left(Q_{t}+Z_{t}\right) k_{t-1}^{j}-R_{t} d_{t-1}^{j}-R_{b t} b_{t-1}^{j},
$$

where $d_{t-1}^{j}$ is deposit and $b_{t-1}^{j}$ is interbank borrowing at $t-1$. Note that $b_{t-1}^{j}$ is positive if bank $j$ borrows and negative if $j$ lends in the interbank market.

For new bankers at $t$, net worth simply equals the initial endowment:

$$
n_{t}^{j}=w^{j}
$$

Meanwhile, exiting bankers no longer operate banks and simply use their net worth to consume:

$$
c_{t}^{j}=n_{t}^{j}
$$

During each period $t$, a continuing bank $j$ (either new or surviving) finances nonfinancial loans $\left(Q_{t}+f_{t}^{j}\right) k_{t}^{j}$ with net worth, deposit and interbank debt as follows:

$$
\left(Q_{t}+f_{t}^{j}\right) k_{t}^{j}=n_{t}^{j}+d_{t}^{j}+b_{t}^{j}
$$

where $f_{t}^{r}$ is given by (4) and $f_{t}^{w}=0$. We assume that banks can only accumulate net worth via retained earnings. While this assumption is a reasonable approximation of reality, we do not explicitly model the agency frictions that underpin it. ${ }^{18}$

To derive a limit on the bank's ability to raise funds, we introduce the following moral hazard problem: After raising funds and buying assets at the beginning of $t$, but still during the period, the banker decides whether to operate "honestly" or to divert assets for personal use. Operating honestly means holding assets until the payoffs are realized in period $t+1$ and then meeting obligations to depositors and interbank creditors. To divert means to secretly channel funds away from investments in order to consume personally.

\footnotetext{
${ }^{18}$ See Bigio (2015) for a model that explains why banks might find it hard to raise external equity during crises in the presence of adverse selection problems.
} 
To motivate the use of wholesale funding markets along with retail markets, we assume that the banker's ability to divert funds depends on both the sources and uses of funds. The banker can divert the fraction $\theta$ of non-financial loans financed by retained earnings or funds raised from households, where $0<\theta<1$. On the other hand, he/she can divert only the fraction $\theta \omega$ of non-financial loans financed by interbank borrowing, where $0<\omega<1$. Here we are capturing in a simple way that bankers lending in the wholesale market are more effective at monitoring the banks to which they lend than are households that supply deposits in the retail market. Accordingly, the total amount of funds that can be diverted by a banker who is a net borrower in the interbank market is given by

$$
\theta\left[\left(Q+f^{j}\right) k_{t}^{j}-b_{t}^{j}+\omega b_{t}^{j}\right]
$$

where $\left(Q+f^{j}\right) k_{t}^{j}-b_{t}^{j}$ equals the value of funds invested in non-financial loans that is financed by deposits and net worth and where $b_{t}^{j}>0$ equals the value of non-financial loans financed by inter-bank borrowing.

For bankers that lend to other banks, we suppose that it is more difficult to divert interbank loans than non-financial loans. Specifically, we suppose that a banker can divert only a fraction $\theta \gamma$ of its loans to other banks, where $0<\gamma<1$. Here we appeal to the idea that interbank loans are much less idiosyncratic in nature than non-financial loans and thus easier for outside depositors to monitor. Accordingly, the total amount a bank that lends on the interbank market can divert is given by

$$
\theta\left[\left(Q_{t}+f_{t}^{j}\right) k_{t}^{j}+\gamma\left(-b_{t}^{j}\right)\right]
$$

with $b_{t}^{j}<0$. As we will make clear shortly, key to operation of the inter-bank market are the parameters that govern the moral hazard problem in this market, $\omega$ and $\gamma$.

We assume that the process of diverting assets takes time: The banker cannot quickly liquidate a large amount of assets without the transaction being noticed. For this reason the banker must decide whether to divert at $t$, prior to the realization of uncertainty at $t+1$. The cost to the banker of the diversion is that the creditors can force the intermediary into bankruptcy at the beginning of the next period.

The banker's decision at $t$ boils down to comparing the franchise value of the bank $V_{t}^{j}$, which measures the present discounted value of future payouts from operating honestly, with the gain from diverting funds. In this regard, rational lenders will not supply funds to the banker if he has an incentive to cheat. Accordingly, any financial arrangement between the bank and its lenders must satisfy the following set of incentive constraints, which depend on whether the bank is a net borrower or 
lender in the interbank market:

$$
\begin{aligned}
& V_{t}^{j} \geq \theta\left[\left(Q+f^{j}\right) k_{t}^{j}-b_{t}^{j}+\omega b_{t}^{j}\right], \text { if } b_{t}^{j}>0 \\
& V_{t}^{j} \geq \theta\left[\left(Q_{t}+f_{t}^{j}\right) k_{t}^{j}+\gamma\left(-b_{t}^{j}\right)\right], \text { if } b_{t}^{j}<0 .
\end{aligned}
$$

As will become clear shortly, each incentive constraint embeds the constraint that the net worth $n_{t}^{j}$ must be positive for the bank to operate: This is because the franchise value $V_{t}^{j}$ will turn out to be proportional to $n_{t}^{j}$.

Overall, there are two basic factors that govern the existence and relative size of the interbank market. The first is the cost advantage that wholesale banks have in managing non-financial loans, as described by Assumption 1. The second is the size of the parameters $\omega$ and $\gamma$ which govern the comparative advantage that retail banks have over households in lending to wholesale banks . Observe that as $\omega$ and $\gamma$ decline, it becomes more attractive to channel funds through wholesale bank funding markets relative to retail markets. As $\omega$ declines below unity, a bank borrowing in the wholesale market can relax its incentive constraint by substituting inter-bank borrowing for deposits. Similarly, as $\gamma$ declines below unity, a bank lending in the wholesale market can relax its incentive constraint by shifting its composition of assets from non-financial loans to inter-bank loans.

In what follows, we restrict attention to the case in which

$$
\omega+\gamma>1
$$

(Assumption 2)

In this instance the parameters $\omega$ and $\gamma$ can be sufficiently small to permit an empirically reasonable relative amount of inter-bank lending. However, the sum of these parameters cannot be so small as to induce a situation of pure specialization by retail banks, where these banks do not make non-financial loans directly but instead lend all their funds to wholesale banks. ${ }^{19,20}$ Since in practice retail banks hold some of the same types of assets held by wholesale banks, we think it reasonable to restrict attention to this case.

We now turn to the optimization problems for both wholesale and retail bankers. Given that bankers simply consume their net worth when they exit, we can restate the bank's franchise value recursively as the expected discounted value of the sum of

\footnotetext{
${ }^{19}$ See Section 9.1 in the Appendix for the formal argument that shows that under Assumption 2 pure specialization of retail bankers cannot be an equilibrium.

${ }^{20}$ Holmstrom and Tirole (1997) make similar assumptions on the levels and sum of the agency distortions for banks and non-financial firms in order to explain why bank finance arises.
} 
net worth conditional on exiting and the value conditional on continuing as:

$$
\begin{aligned}
V_{t}^{j} & =\beta E_{t}\left[\left(1-\sigma^{j}\right) n_{t+1}^{j}+\sigma^{j} V_{t+1}^{j}\right] . \\
& =E_{t}\left[\Omega_{t+1}^{j} n_{t+1}^{j}\right]
\end{aligned}
$$

where

$$
\Omega_{t+1}^{j}=\beta\left(1-\sigma^{j}+\sigma^{j} \frac{V_{t+1}^{j}}{n_{t+1}^{j}}\right) .
$$

The stochastic discount factor $\Omega_{t+1}^{j}$, which the bankers use to value $n_{t+1}^{j}$, is a probability weighted average of the discounted marginal values of net worth to exiting and to continuing bankers at $\mathrm{t}+1$. For an exiting banker at $t+1$ (which occurs with probability $1-\sigma^{j}$ ), the marginal value of an additional unit of net worth is simply unity, since he or she just consumes it. For a continuing banker (which occurs with probability $\sigma^{j}$ ), the marginal value is the franchise value per unit of net worth $V_{t+1}^{j} / n_{t+1}^{j}$ (i.e., Tobin's Q ratio). As we show shortly, $V_{t+1}^{j} / n_{t+1}^{j}$ depends only on aggregate variables and is independent of bank specific factors.

We can express the banker's evolution of net worth as:

$$
n_{t+1}^{j}=R_{k t+1}^{j}\left(Q_{t}+f_{t}^{j}\right) k_{t}^{j}-R_{t+1} d_{t}^{j}-R_{b t+1} b_{t}^{j}
$$

where $R_{k t+1}^{j}$ is the rate of return on non-financial loans, given by

$$
R_{k t+1}^{j}=\frac{Q_{t+1}+Z_{t+1}}{Q_{t}+f_{t}^{j}}
$$

The banker's optimization problem then is to choose $\left(k_{t}^{j}, d_{t}^{j}, b_{t}^{j}\right)$ each period to maximize the franchise value (15) subject to the incentive constraint (14) and the balance sheet constraints (13) and (17).

We defer the details of the formal bank maximization problems to Appendix A. Here we explain the decisions of wholesale and retail banks informally. Because wholesale banks have a cost advantage over retail banks in making non-financial loans, the rate of return on non-financial loans is higher for the former than for the latter (see equation (18)). In turn, retail banks have an advantage over households in lending to wholesale banks due to their relative advantage in recovering assets in default. Therefore, if the interbank market is active in equilibrium, wholesale banks borrow from retail banks in the interbank market to make non-financial loans. Indeed 
the only reason retail banks directly make non-financial loans is because wholesale banks may be constrained in the amount of this type of loan they can make. ${ }^{21}$

In the text, we restrict attention to the case where the interbank market is active, with wholesale banks borrowing from retail banks, and where both types of banks are constrained in raising funds externally.

\subsubsection{Wholesale banks}

In general, wholesale banks may raise funds either from other banks or from households. Since the kinds of financial institutions we have in mind relied exclusively on wholesale markets for funding, we focus on this kind of equilibrium. In particular, we restrict attention to model parameterization which generate an equilibrium where the conditions for the following Lemma 1 are satisfied:

Lemma 1: $d_{t}^{w}=0, b_{t}^{w}>0$ and the incentive constraint is binding iff

$$
0<\omega E_{t}\left[\Omega_{t+1}^{w}\left(R_{k t+1}^{w}-R_{t+1}\right)\right]<E_{t}\left[\Omega_{t+1}^{w}\left(R_{k t+1}^{w}-R_{b t+1}\right)\right]<\theta \omega
$$

We first explain why $d_{t}^{w}=0$ in this instance. The wholesale bank faces the following trade-off in using retail deposits: If the deposit interest rate is lower than the interbank interest rate so that $E_{t}\left[\Omega_{t+1}^{w}\left(R_{k t+1}^{w}-R_{t+1}\right)\right]>E_{t}\left[\Omega_{t+1}^{w}\left(R_{k t+1}^{w}-R_{b t+1}\right)\right]$, then the bank gains from issuing deposits to reduce interbank loans. On the other hand, because households are less efficient in monitoring wholesale bank behavior, they will apply a tighter limit on the amount they are willing to lend than will retail banks. If $\omega$ is sufficiently low so that $\omega E_{t}\left[\Omega_{t+1}^{w}\left(R_{k t+1}^{w}-R_{t+1}\right)\right]<E_{t}\left[\Omega_{t+1}^{w}\left(R_{k t+1}^{w}-R_{b t+1}\right)\right]$, the cost exceeds the benefit. In this instance the wholesale bank does not use retail deposits, relying entirely on interbank borrowing for external finance. Everything else equal, by not issuing retail deposits, the wholesale bank is able to raise its overall leverage in order to make more non-financial loans relative to its equity base. This incentive consideration accounts for why the wholesale bank may prefer interbank borrowing to issuing deposits, even if the interbank rate lies above the deposit rate. ${ }^{22}$

\footnotetext{
${ }^{21}$ We do not mean to suggest that the only reason retail banks make non-financial loans in practice is because wholesalse banks are constrained. Rather we focus on this case for simplicity of the basic model. Later we extend the model to allow for a second type of lending, which we refer to as commercial and industrial leanding, where retail banks have a comparative advantage. In this instance, spillovers emerge where problems in wholesale banking can affect the degree of intermediation of commercial and industrial loans.

${ }^{22}$ Under our baseline parametrization, wholesale banks borrow exclusively from retail banks. We view this as the case that best corresponds to the wholesale banking system on the eve of the Great Recession. Circumstances do exist where wholesale banks will borrow from households as well as retail banks. One might interpret his situation as corresponding to the consolidation of wholesale
} 
Next we explain why the incentive constraint is binding. If $E_{t}\left[\Omega_{t+1}^{w}\left(R_{k t+1}^{w}-\right.\right.$ $\left.R_{b t+1}\right)$ ] $<\theta \omega$, then at the margin the wholesale bank gains by borrowing on the interbank market and then diverting funds to its own account. Accordingly, as the incentive constraint (14) requires, rational creditor banks will restrict lending to the point where the gain from diverting equals the bank franchise value, which is what the wholesale bank would lose if it cheated.

Given Lemma 1 we can simplify the evolution of bank net worth to

$$
n_{t+1}^{w}=\left[\left(R_{k t+1}^{w}-R_{b t+1}\right) \phi_{t}^{w}+R_{b t+1}\right] n_{t}^{w}
$$

where $\phi_{t}^{w}$ is given by

$$
\phi_{t}^{w} \equiv \frac{Q_{t} k_{t}^{w}}{n_{t}^{w}} .
$$

We refer to this ratio of assets to net worth as the leverage multiple.

In turn, we can simplify the wholesale banks optimization problem to choosing the leverage multiple to solve:

$$
V_{t}^{w}=\max _{\phi_{t}^{w}} E_{t}\left\{\Omega_{t+1}^{w}\left[\left(R_{k t+1}^{w}-R_{b t+1}\right) \phi_{t}^{w}+R_{b t+1}\right] n_{t}^{w}\right\}
$$

subject to the incentive constraint

$$
\theta\left[\omega \phi_{t}^{w}+(1-\omega)\right] n_{t}^{w} \leq V_{t}^{w}
$$

Given the incentive constraint is binding under Lemma 1, we can combine the objective with the binding incentive constraint to obtain the following solution for $\phi_{t}^{w}$ :

$$
\phi_{t}^{w}=\frac{E_{t}\left(\Omega_{t+1}^{w} R_{b t+1}\right)-\theta(1-\omega)}{\theta \omega-E_{t}\left[\Omega_{t+1}^{w}\left(R_{k t+1}^{w}-R_{b t+1}\right)\right]}
$$

Note that $\phi_{t}^{w}$ is increasing in $E_{t}\left(\Omega_{t+1}^{w} R_{k t+1}^{w}\right)$ and decreasing in $E_{t}\left(\Omega_{t+1}^{w} R_{b t+1}\right){ }^{23} \mathrm{In}$ tuitively, the franchise value $V_{t}^{w}$ increases when returns on assets are higher and decreases when the cost of funding asset purchases rises, as equation (21) indicates. Increases in $V_{t}^{w}$, in turn, relax the incentive constraint, making lenders will to supply more credit.

Also, $\phi_{t}^{w}$ is a decreasing function of both $\theta$, the diversion rate on non-financial loans funded by net worth, and $\omega$, the parameter that controls the relative ease of

and retail bank in the wake of the crisis, or perhaps the period before the rapid growth of wholesale banking when retail banks were performing many of the same activities as we often observe in continental Europe and Japan.

${ }^{23}$ This is because $E_{t}\left(\Omega_{t+1}^{w} R_{k t+1}^{w}\right)>1>\theta$ in equilibrium as shown in Appendix. 
diverting nonfinancial loans funded by inter-bank borrowing relative to those funded by the other means: Increases in either parameter tighten the incentive constraint, inducing lenders to cut back on the amount of credit they supply. Later we will use the inverse relationship between $\phi_{t}^{w}$ and $\omega$ to help account for the growth in both leverage and size of the wholesale banking sector.

Finally, from equation (21) we obtain an expression from the franchise value per unit of net worth

$$
\frac{V_{t}^{w}}{n_{t}^{w}}=E_{t}\left\{\Omega_{t+1}^{w}\left[\left(R_{k t+1}^{w}-R_{b t+1}\right) \phi_{t}^{w}+R_{b t+1}\right]\right\}
$$

where $\phi_{t}^{w}$ is given by equation (23) and $\Omega_{t+1}^{w}$ is given by equation (16). It is straightforward to show that $\frac{V_{t}^{w}}{n_{t}^{w}}$ exceeds unity: i.e., the shadow value of a unit of net worth is greater than one, since additional net worth permits the bank to borrow more and invest in assets earning an excess return. In addition, as we conjectured earlier, $\frac{V_{t}^{w}}{n_{t}^{w}}$ depend only on aggregate variables and not on bank-specific ones.

\subsubsection{Retail banks}

As with wholesale banks, we choose a parametrization where the incentive constraint binds. In addition, as discussed earlier, we restrict attention to the case where retail banks are holding both non-financial and inter-bank loans. In particular, we consider a parametrization where in equilibrium Lemma 2 is satisfied

Lemma 2: $b_{t}^{r}<0, k_{t}^{r}>0$ and the incentive constraint is binding iff

$$
0<E_{t}\left[\Omega_{t+1}^{r}\left(R_{k t+1}^{r}-R_{t+1}\right)\right]=\frac{1}{\gamma} E_{t}\left[\Omega_{t+1}^{r}\left(R_{b t+1}-R_{t+1}\right)\right]<\theta
$$

For the retail bank to be indifferent between holding non-financial loans versus interbank loans, the rate on interbank loans $R_{b t+1}$ must lie below the rate earned on non-financial loans $R_{k t+1}^{r}$ in a way that satisfies the conditions for the lemma. Intuitively, the advantage for the retail bank to making an interbank loan is that households are willing to lend more to the bank per unit of net worth than for a non-financial loan. Thus to make the retail bank indifferent, $R_{b t+1}$ must be less than $R_{k t+1}^{r}$.

Let $\phi_{t}^{r}$ be a retail bank's effective leverage multiple, namely the ratio of assets to net worth, where assets are weighted by the relative ease of diversion:

$$
\phi_{t}^{r} \equiv \frac{\left(Q_{t}+f_{t}^{r}\right) k_{t}^{r}+\gamma\left(-b_{t}^{r}\right)}{n_{t}^{r}}
$$


The weight $\gamma$ on $\left(-b_{t}^{r}\right)$ is the ratio of how much a retail banker can divert from interbank loans relative to non-financial loans.

Given the restrictions implied by Lemma 2, we can use the same procedure as in the case of wholesale bankers to express the retail banker's optimization problem as choosing $\phi_{t}^{r}$ to solve:

$$
V_{t}^{r}=\max _{\phi_{t}^{r}} E_{t}\left\{\Omega_{t+1}^{r}\left[\left(R_{k t+1}^{r}-R_{t+1}\right) \phi_{t}^{r}+R_{t+1}\right] n_{t}^{r}\right\}
$$

subject to

$$
\theta \phi_{t}^{r} n_{t}^{r} \leq V_{t}^{r}
$$

Given Lemma 2, we can impose that incentive constraint binds, which implies

$$
\phi_{t}^{r}=\frac{E_{t}\left(\Omega_{t+1}^{r} R_{t+1}\right)}{\theta-E_{t}\left[\Omega_{t+1}^{r}\left(R_{k t+1}^{r}-R_{t+1}\right)\right]} .
$$

As with the leverage multiple for wholesale bankers, $\phi_{t}^{r}$ is increasing in expected asset returns on the bank's portfolio and decreasing in the diversion parameter.

Finally, from equation (26) we obtain an expression for the franchise value per unit of net worth

$$
\frac{V_{t}^{r}}{n_{t}^{r}}=E_{t}\left\{\Omega_{t+1}^{r}\left[\left(R_{k t+1}^{r}-R_{t+1}\right) \phi_{t}^{r}+R_{t+1}\right]\right\}
$$

As with wholesale banks, the shadow value of a unit of net worth exceeds unity and depends only on aggregate variables.

\subsection{Aggregation and Equilibrium without Bank Runs}

Given that the ratio of assets and liabilities to net worth is independent of individual bank-specific factors and given a parametrization where the conditions in Lemma 1 and 2 are satisfied, we can aggregate across banks to obtain relations between total assets and net worth for both the wholesale and retail banking sectors. Let $Q_{t} K_{t}^{w}$ and $Q_{t} K_{t}^{r}$ be total non-financial loans held by wholesale and retail banks, $D_{t}$ be retail bank deposits, $B_{t}$ be total interbank debt, and $N_{t}^{w}$ and $N_{t}^{r}$ total net worth in each respective banking sector. Then we have:

$$
\begin{gathered}
Q_{t} K_{t}^{w}=\phi_{t}^{w} N_{t}^{w} \\
\left(Q_{t}+f_{t}^{r}\right) K_{t}^{r}+\gamma B_{t}=\phi_{t}^{r} N_{t}^{r}
\end{gathered}
$$


with

$$
\begin{gathered}
Q_{t} K_{t}^{w}=N_{t}^{w}+B_{t} \\
\left(Q_{t}+f_{t}^{r}\right) K_{t}^{r}+B_{t}=D_{t}^{r}+N_{t}^{r},
\end{gathered}
$$

and

$$
E_{t}\left[\Omega_{t+1}^{r}\left(R_{k t+1}^{r}-R_{t+1}\right)\right]=\frac{1}{\gamma} E_{t}\left[\Omega_{t+1}^{r}\left(R_{b t+1}-R_{t+1}\right)\right] .
$$

Equation (33) ensures that the retail bank is indifferent at the margin between holding non-financial loans versus interbank loans (see Lemma 2).

Summing across both surviving and entering bankers yields the following expression for the evolution of $N_{t}$ :

$$
\begin{aligned}
N_{t}^{w} & =\sigma^{w}\left[\left(R_{k t}^{w}-R_{b t}\right) \phi_{t-1}^{w}+R_{b t}\right] N_{t-1}^{w}+W^{w}, \\
N_{t}^{r} & =\sigma^{r}\left[\left(R_{k t}^{r}-R_{t}\right) \phi_{t-1}^{r}+R_{t}\right] N_{t-1}^{r}+W^{r} \\
& +\sigma^{r}\left[R_{b t}-R_{t}-\gamma\left(R_{k t}^{r}-R_{t}\right)\right] B_{t-1},
\end{aligned}
$$

where $W^{j}=\left(1-\sigma^{j}\right) w^{j}$ is the total endowment of entering bankers. The first term is the accumulated net worth of bankers that operated at $t-1$ and survived to $t$, which is equal to the product of the survival rate $\sigma^{j}$ and the net earnings on bank assets.

Total consumption of bankers equals the sum of the net worth of exiting bankers in each sector:

$$
C_{t}^{b}=\left(1-\sigma^{w}\right) \frac{N_{t}^{w}-W^{w}}{\sigma^{w}}+\left(1-\sigma^{r}\right) \frac{N_{t}^{r}-W^{r}}{\sigma^{r}}
$$

Total gross output $\bar{Y}_{t}$ is the sum of output from capital, household endowment $Z_{t} W^{h}$ and bank endowment $W^{r}$ and $W^{i}$ :

$$
\bar{Y}_{t}=Z_{t}+Z_{t} W^{h}+W^{r}+W^{i}
$$

Net output $Y_{t}$, which we will refer to simply as output, equals gross output minus management costs

$$
Y_{t}=\bar{Y}_{t}-\left[F^{h}\left(K_{t}^{h}\right)+F^{r}\left(K_{t}^{r}\right)\right]
$$

Equation (38) captures in a simple way how intermediation of assets by wholesale banks improves aggregate efficiency. Finally, output is consumed by households and bankers:

$$
Y_{t}=C_{t}^{h}+C_{t}^{b}
$$


The recursive competitive equilibrium without bank runs consists of aggregate quantities

$$
\left(K_{t}^{w}, K_{t}^{r}, K_{t}^{h}, B_{t}, D_{t}^{r}, N_{t}^{w}, N_{t}^{r}, C_{t}^{b}, C_{t}^{h}, \bar{Y}_{t}, Y_{t}\right)
$$

, prices

$$
\left(Q_{t}, R_{t+1}, R_{b t+1}, f_{t}^{r}\right)
$$

and bankers' variables

$$
\left(\Omega_{t}^{j}, R_{k t}^{j}, \frac{V_{t}^{j}}{n_{t}^{j}}, \phi_{t}^{j}\right)_{j=w, r}
$$

as a function of the state variables $\left(K_{t-1}^{w}, K_{t-1}^{r}, R_{b t} B_{t-1}, R_{t} D_{t-1}^{w}, R_{t} D_{t-1}^{r}, Z_{t}\right)$, which satisfy equations $(1,4,7,8,16,18,23,24,27-39) .^{24}$

\subsection{Unanticipated Bank Runs}

In this section we consider unanticipated bank runs. We defer an analysis of anticipated bank runs to Section 5. In general three types of runs are conceivable: (i) a run on wholesale banks leaving retail banks intact; (ii) a run on just retail banks; and (iii) a run on both the wholesale and retail bank sectors. We restrict attention to (i) because it corresponds most closely to what happened in practice.

\subsubsection{Conditions for a Wholesale Bank Run Equilibrium}

The runs we consider are runs on the entire wholesale banking system, not on individual wholesale banks. Indeed, so long as an asset firesale by an individual wholesale bank is not large enough to affect asset prices, it is only runs on the system that will be disruptive. Given the homogeneity of wholesale banks in our model, the conditions for a run on the wholesale banking system will apply to each individual wholesale bank.

What we have in mind for a run is a spontaneous failure of the bank's creditors to roll over their short term loans. In particular, at the beginning of period $t$, before the realization of returns on bank assets, retail banks lending to a wholesale bank decide whether to roll over their loans with the bank. If they choose to "run", the wholesale bank liquidates its capital and turns the proceeds over to its retail bank creditors who then either acquire the capital or sell it to households. Importantly, both the retail banks and households cannot seamlessly acquire the capital being liquidated

\footnotetext{
${ }^{24}$ In total we have a system of 23 equations. Notice that $(16,18)$ have two equations. By Walras' law, the household budget constraint (6) is satisfied as long as deposit market clears as $D_{t}=D_{t}^{r}$.
} 
in the firesale by wholesale banks. The retail banks face a capital constraint which limits asset acquisition and are also less efficient at managing the capital than are wholesale banks. Households can only hold the capital directly and are even less efficient than retail banks in doing so.

Let $Q_{t}^{*}$ be the price of capital in the event of a forced liquidation of the wholesale banking system. Then a run on the entire wholesale bank sector is possible if the liquidation value of wholesale banks assets, $\left(Z_{t}+Q_{t}^{*}\right) K_{t-1}^{w}$, is smaller than their outstanding liability to interbank creditors, $R_{b t} B_{t-1}$, so that liquidation would wipe out wholesale banks networth. In this instance the recovery rate in the event of a wholesale bank run, $x_{t}^{w}$, is the ratio of $\left(Z_{t}+Q_{t}^{*}\right) K_{t-1}^{w}$ to $R_{b t} B_{t-1}$ and the condition for a bank run equilibrium to exist is that the recovery rate is less than unity, i.e.

$$
x_{t}^{w}=\frac{\left(Q_{t}^{*}+Z_{t}\right) K_{t-1}^{w}}{R_{b t} B_{t-1}}<1 .
$$

Let $R_{k t}^{w *}$ be the return on bank assets conditional on a run at $t$ :

$$
R_{k t}^{w *} \equiv \frac{Z_{t}+Q_{t}^{*}}{Q_{t-1}}
$$

Then from (40), we can obtain a simple condition for a wholesale bank run equilibrium in terms of just two endogenous variables: (i) the ratio of $R_{k t}^{w *}$ to the interbank borrowing rate $R_{b t}$; and (ii) the leverage multiple $\phi_{t-1}^{w}$ :

$$
x_{t}^{w}=\frac{R_{k t}^{w *}}{R_{b t}} \cdot \frac{\phi_{t-1}^{w}}{\phi_{t-1}^{w}-1}<1
$$

A bank run equilibrium exists if the realized rate of return on bank assets conditional on liquidation of assets $R_{k t}^{w *}$ is sufficiently low relative to the gross interest rate on interbank loans, $R_{b t}$, and the leverage multiple is sufficiently high to satisfy condition (41). Note that the expression $\frac{\phi_{t-1}^{w}}{\phi_{t-1}^{w}-1}$ is the ratio of bank assets $Q_{t-1} K_{t-1}^{w}$ to interbank borrowing $B_{t-1}$, which is decreasing in the leverage multiple. Also note that the condition for a run does not depend on individual bank-specific factors since $R_{k t}^{w *} / R_{b t}$ and $\phi_{t-1}^{w}$ are the same for all in equilibrium.

Since $R_{k t}^{w *}, R_{b t}$ and $\phi_{t-1}^{w}$ are all endogenous variables, the possibility of a bank run may vary with macroeconomic conditions. The equilibrium absent bank runs (that we described earlier) determines the behavior of $R_{b t}$ and $\phi_{t-1}^{w}$. The value of $R_{k t}^{w *}$, instead, depends on the liquidation price $Q_{t}^{*}$, whose determination is described in the next sub-section. 


\subsubsection{The Liquidation Price}

To determine $Q_{t}^{*}$ we proceed as follows. A run by interbank creditors at $t$ induces all wholesale banks that carried assets from $t-1$ to fully liquidate their asset positions and go out of business. ${ }^{25}$ Accordingly they sell all their assets to retail banks and households, who hold them at $t$. The wholesale banking system then re-builds itself over time as new banks enter. For the asset firesale during the panic run to be quantitatively significant, we need there to be at least a modest delay in the ability of new banks to begin operating. Accordingly, we suppose that new wholesale banks cannot begin operating until the period after the panic run. ${ }^{26}$

Accordingly, when wholesale banks liquidate, they sell all their assets to retail banks and households in the wake of the run at date $t$, implying

$$
\bar{K}=K_{t}^{r}+K_{t}^{h} .
$$

The wholesale banking system then rebuilds its equity and assets as new banks enter at $\mathrm{t}+1$ onwards. Given our timing assumptions and Equation (34), bank net worth evolves in the periods after the run according to

$$
\begin{aligned}
N_{t+1}^{w} & =\left(1+\sigma^{w}\right) W^{w}, \\
N_{t+i}^{w} & =\sigma^{w}\left[\left(Z_{t+i}+Q_{t+i}\right) K_{t+i-1}^{w}-R_{b t+i} B_{t+i-1}\right]+W^{w}, \text { for all } i \geq 2 .
\end{aligned}
$$

Rearranging the Euler equation for the household's capital holding (8) yields the following expression for the liquidation price in terms of discounted dividends $Z_{t+i}$ net the marginal management $\operatorname{cost} \alpha^{h} K_{t+i}^{h}$.

$$
Q_{t}^{*}=E_{t}\left[\sum_{i=1}^{\infty} \Lambda_{t, t+i}\left(Z_{t+i}-\alpha^{h} K_{t+i}^{h}\right)\right]-\alpha^{h} K_{t}^{h} .
$$

Everything else equal, the longer it takes for the banking sector to recapitalize (measured by the time it takes $K_{t+i}^{h}$ to fall back to steady state), the lower will be the liquidation price. Note also that $Q_{t}^{*}$ will vary with cyclical conditions. In particular, a negative shock to $Z_{t}$ will reduce $Q_{t}^{*}$, possibly moving the economy into a regime where bank runs are possible.

\footnotetext{
${ }^{25}$ See Uhlig (2010) for an alternative bank run model with endogenous liquidation prices.

${ }^{26}$ Suppose for example that during the run it is not possible for retail banks to identify new wholesale banks that are financially independent of the wholesale banks being run on. New wholesale banks accordingly wait for the dust to settle and then begin raising fund in the interbank market in the subsequent period. The results are robust to alternative timing assumptions about the entry of new banks.
} 


\section{Table 2: Baseline Parameters}

\begin{tabular}{|c|c|c|}
\hline \multicolumn{3}{|c|}{ PARAMETERS } \\
\hline \multicolumn{3}{|c|}{ Households } \\
\hline$\beta$ & discount rate & .99 \\
\hline$\alpha^{h}$ & Intermediation cost & .03 \\
\hline$W^{h}$ & Endowment & .006 \\
\hline \multicolumn{3}{|c|}{ Retail Banks } \\
\hline$\sigma^{r}$ & Survival Probability & .96 \\
\hline$\alpha^{r}$ & Intermediation cost & .0074 \\
\hline$W^{r}$ & Endowment & .0008 \\
\hline$\theta$ & Divertable proportion of assets & .25 \\
\hline$\gamma$ & Shrinkage of Divertable proportion of interbank loans & 67 \\
\hline \multicolumn{3}{|c|}{ Wholesale Banks } \\
\hline$\sigma^{w}$ & Survival Probability & .88 \\
\hline$\alpha^{w}$ & Intermediation cost & 0 \\
\hline$W^{w}$ & Endowment & .0008 \\
\hline$\omega$ & Shrinkage of divertable proportion of assets & .46 \\
\hline \multicolumn{3}{|c|}{ Production } \\
\hline $\mathrm{Z}$ & Steady State productivity & .016 \\
\hline$\rho_{z}$ & Serial correlation of productivity shocks & .9 \\
\hline
\end{tabular}

\section{Table 3: Baseline Steady State}

\begin{tabular}{l||l||l}
\hline \multicolumn{2}{c}{ STEADY STATE } \\
\hline$Q$ & price of capital & 1 \\
$K^{r}$ & retail intermediation & .4 \\
$K^{w}$ & wholesale intermediation & .4 \\
$R^{b}$ & Annual interbank rate & 1.048 \\
$R_{r}^{k}$ & Annual retail return on capital & 1.052 \\
$R$ & Annual deposit rate & 1.04 \\
$R_{w}^{k}$ & Annual wholesale return on capital & 1.064 \\
$\phi^{w}$ & wholesale leverage & 20 \\
$\phi^{r}$ & retail leverage & 10 \\
$Y$ & output & .0229 \\
$C^{h}$ & consumption & .0168 \\
$N^{r}$ & retail banks networth & .0781 \\
$N^{w}$ & wholesale banks networth & .02
\end{tabular}

\section{Numerical Experiments}

In this section we examine how the long-run properties of the model can account for the growth of the wholesale banking sector and then turn to studying the cyclical responses to macroeconomic shocks that may or may not induce runs. Overall these numerical examples provide a description of the tradeoff between growth and stability associated with an expansion of the shadow banking sector and illustrate the real effects of bank runs in our model.

\subsection{Calibration}

Here we describe our baseline calibration. This is meant to capture the state of the economy at the onset of the financial crisis in 2007.

There are 13 parameters in the model:

$$
\left\{\theta, \omega, \gamma, \beta, \alpha^{h}, \alpha^{r}, \sigma^{r}, \sigma^{w}, W^{h}, W^{r}, W^{w}, \sigma_{z}, \rho_{z}\right\}
$$

their values are reported in Table 2 , while Table 3 shows the steady state values of the equilibrium allocation. 
We take the time interval in the model to be a quarter. We use conventional values for households' discount factor, $\beta=.99$, and the parameters governing the stochastic process for dividends, $\sigma_{z}=.05$ and $\rho_{z}=.9$. We set $W^{h}$ so that households endowment income is twice as big as their capital income.

We calibrate managerial costs of intermediating capital for households and retail bankers, $\alpha^{h}$ and $\alpha^{r}$, in order to obtain the spread between deposit and interbank interest rates as well as the spread between interbank and non-financial loan rates both to be $0.8 \%$ and $1.6 \%$ in annual in steady state.

The fraction of divertible assets purchased by raising deposits, $\theta$, and interbank loans, $\omega \theta$, are set in order to get leverage ratios for retail bankers and wholesale bankers of 10 and 20 respectively.

Our retail banking sector comprises of commercial banks, open end Mutual Funds and Money Market Mutual Funds (MMMF). In the case of Mutual Funds and MMMF the computation of leverage is complicated by the peculiar legal and economic details of the relationship between these institutions, their outside investors and sponsors. ${ }^{27}$ Hence, our choice of 10 quite closely reflects the actual leverage ratios of commercial banks, which is the only sector for which a direct empirical counterpart of leverage can be easily computed.

To set our target for wholesale leverage we decided to focus on private institutions within the wholesale banking sector that relied mostly on short term debt. A reasonable range for the leverage multiple for such institutions goes from around 10 for some ABCP issuers ${ }^{28}$ to values of around 40 for brokers dealers in 2007. Our choice of 20 is a conservative target within this range.

The survival rates of wholesale and retail bankers, $\sigma^{w}$ and $\sigma^{r}$, are set in order for the distribution of assets across sectors to match the actual distribution in 2007. Finally, we set $W^{r}$ to make new entrants net worth being equal to $1 \%$ of total retail banks net worth and $W^{w}$ to ensure that wholesale bankers are perfectly specialized.

\subsection{Long Run Effects of Financial Innovation}

As mentioned in Section 2, the role of wholesale banks in financial intermediation has grown steadily from the 1980's to the onset of the financial crisis. This growth was largely accomplished through a series of financial innovations that enhanced the borrowing capacity of the system by relying on securitization to attract funds from

\footnotetext{
${ }^{27}$ On the relationship between MMFs and their sponsors see, for instance, Parlatore (2015) and McCabe (2010).

${ }^{28}$ The same caveat as in the case of MMFs applies here because it is very complicated to factor in the various lines of credit that were provided by the sponsors of these programs.
} 

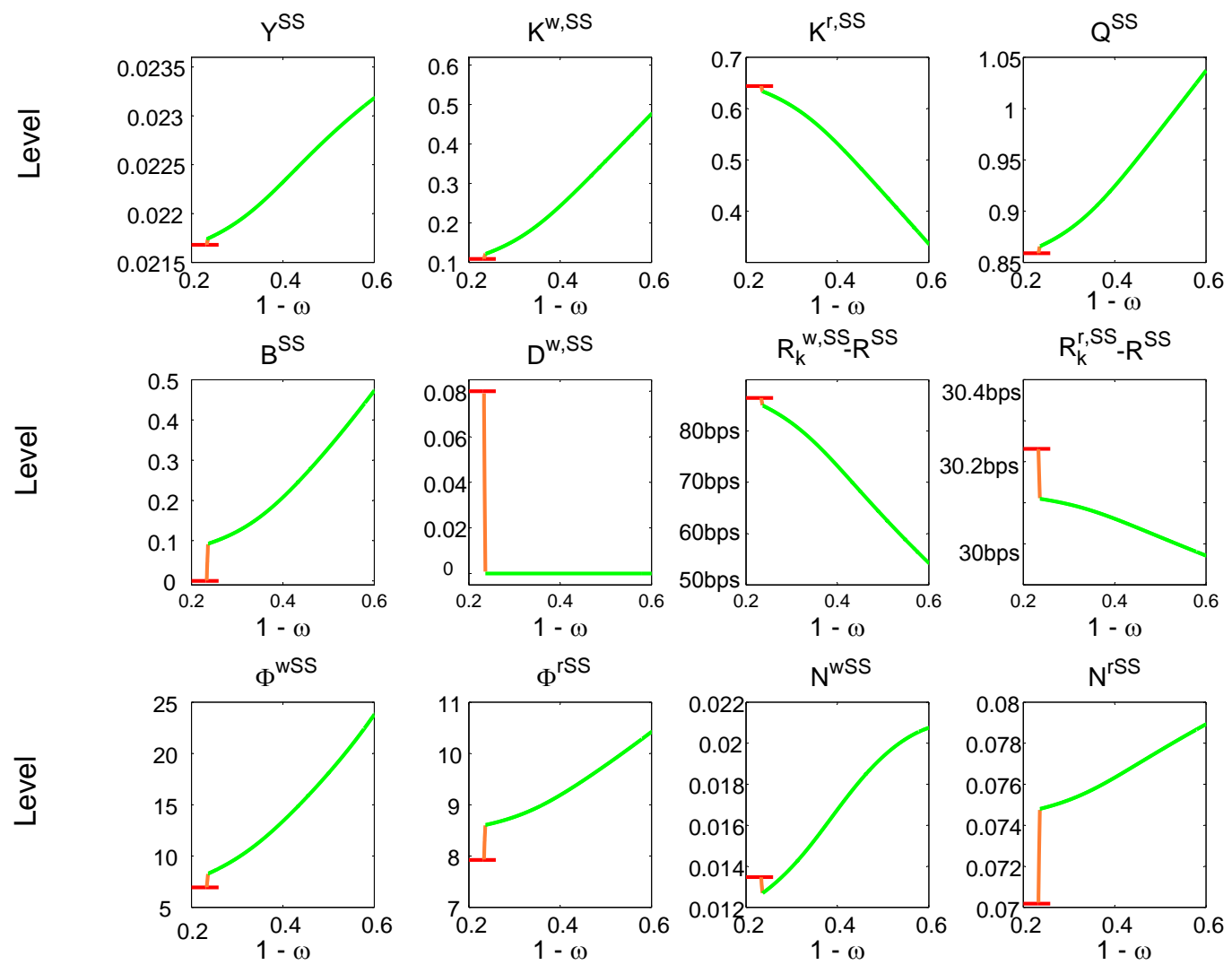

No Interbank — Active Interbank with Imperfect Specializaiotn — Baseline Equilibrium

Figure 7: Comparative Statics: a reduction in $\omega$

institutional investors. While our model abstracts from the details of the securitization process, we capture its direct effects on wholesale banks' ability of raising funds in interbank markets with a reduction in the severity of the agency friction between retail banks and wholesale banks, which is captured by parameter $\omega$. Hence, in this section we study the long run behavior of financial intermediation in response to a decrease in $\omega$ and compare it to the low frequency dynamics in financial intermediation documented in Section 2.

The direct effect of ameliorating the agency problem between wholesale and retail banks is a relaxation of wholesale banks' incentive constraints. The improved ability of retail banks to seize the assets of wholesale bankers in the case of cheating allows wholesale bankers to borrow more aggressively from retail bankers. 
Figure 7 shows how some key variables depend upon $\omega$ in the steady state. ${ }^{29}$ The general equilibrium effects of a lower $\omega$ work through various channels. For an economy with a lower interbank friction $\omega$, the leverage multiple of the wholesale banking sector is higher, with a larger capital $K^{w}$ and a larger amount interbank borrowing $B$ by wholesale banking sector. Conversely, capital intermediated by retail banks $K^{r}$ and households $K^{h}$ tends to be lower. In the absence of bank runs, the relative shift of assets to the wholesale banking sector implies a more efficient allocation of capital and consequently a higher capital price $Q_{t}$. The flow of assets into wholesale banking, further, reduces the spread between the return on capital for wholesale banks and the interbank rate, as well as the spread between interbank and deposit rates. Despite lower spreads, both wholesale and retail banks enjoy higher franchise values thanks to the positive effect of higher leverage on total returns on equity. A unique aspect of financial innovation due to a lower friction in the interbank market is that the borrowing and lending among banks tends to be larger relative to the flow-of-funds from ultimate lenders (households) to ultimate non-financial borrowers. (See Appendix B).

Figure 8 compares the steady state effect of financial innovations on some key measures of financial intermediation with the observed low frequency trends in their empirical counterparts. In particular, we assume that the value of $\omega$ in our baseline calibration results from a sequence of financial innovations that took place gradually from the 1980's to the financial crisis. For simplicity, we divide our sample into 2 periods of equal length and assign a value of $\omega$ to each subsample in order to match the observed percentage of intermediation of wholesale bankers over the period. In order to compute leverage of wholesale banks in Figure 8, we compute leverage of the three sectors within the wholesale banking sector that were mainly responsible for the growth of wholesale intermediation. Overall, the steady state comparative statics capture quite well the actual low frequency dynamics in financial intermediation observed over the past few decades. ${ }^{30}$

\footnotetext{
${ }^{29}$ Notice that as $\omega$ increases above a certain threshold, two other types of equilibria arise: one in which wholesale bankers are imperfectly specialized and raise funds in both wholesale and retail markets; and one in which the interbank market shuts down completely. See the Appendix for details.

${ }^{30}$ The model overstatement of the role of retail intermediation relative to household direct holding of assets can be rationalized by the lack of heterogeneity in ultimate borrowers' funding sources since, in the data, households mainly hold equities while intermediaries are responsible for most debt intermediation. Introducing a different type of asset for which intermediaries have a smaller advantage would then help to reconcile the evolution of the distribution of capital across sectors predicted by the model in response to financial innovation with the empirical one.
} 


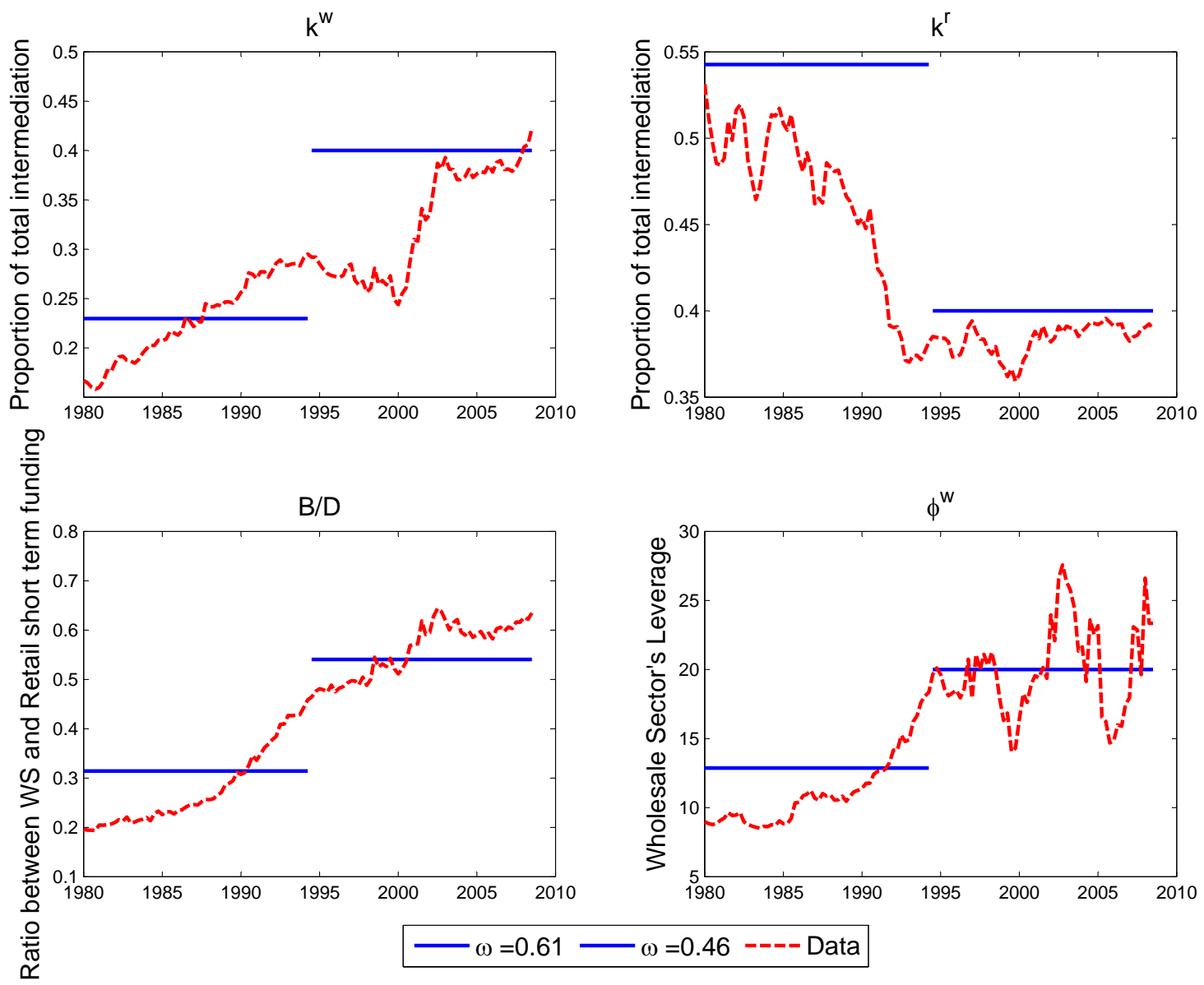

Figure 8: Low Frequency Dynamics in Financial Intermediation

\subsection{Recessions and Runs}

We now turn to the cyclical behavior of our model economy. Figure 9 shows the response of the economy to an unanticipated negative six percent shock to productivity $Z_{t}$, assuming that a run does not happen. ${ }^{31}$ To capture the effects of financial liberalization on the cyclical properties of the economy, we consider both our baseline parameterization and one with a higher $\omega$ which we set to be equal to the one associated with the early 1980's in Figure 10. In both cases the presence of financial constraints activates the familiar financial accelerator mechanism of Bernanke and

\footnotetext{
${ }^{31}$ We choose the size of the shock to generate a fall in output similar to the one that occurred during the Great Recession.
} 

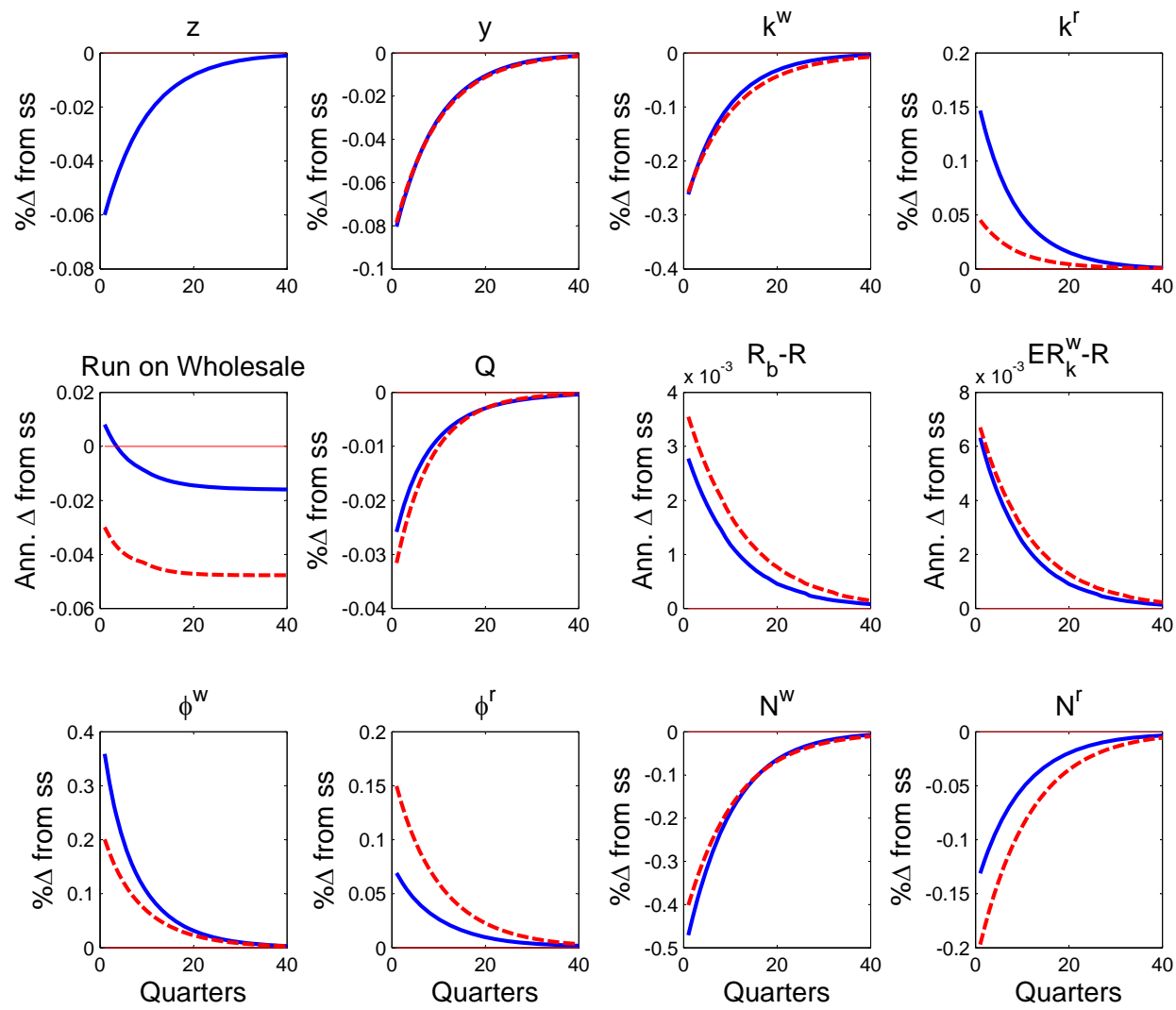

Recession $\quad$ Recession Before Financial Innovation

Figure 9: A recession before and after financial innovation (NO RUN EQUILIBRIUM)

Gertler (1989) and Kiyotaki and Moore (1997). Leverage amplifies the effects of the drop in $Z_{t}$ on bankers' net worth, inducing a tightening of financial constraints, as reflected by an increase in credit spreads. In turn, wholesale banks sell off loans, which reduces asset prices and feeds back into lower net worth. Higher exposure to variations in $Z_{t}$ and higher leverage make this effect stronger for wholesale banks that are forced into a firesale liquidation of their assets, which in turn leads them to reduce their demand for interbank loans. As a result, retail bankers increase their asset holdings and absorb, together with households, the capital flowing out of the wholesale banking sector. However, the relative inefficiency of these agents in intermediating assets makes this process costly as shown by the rise in the cost of bank credit and the amplification in the drop in output. Under our baseline calibration, 
spreads between gross borrowing costs for non financial borrowers and the risk free rate increase by sixty basis points and output drops by eight percent, which is two percentage points greater than the drop in $Z_{t}{ }^{32}$

As we noted earlier, financial innovation makes the economy operate more efficiently in steady state. Figure 11 shows that, absent bank runs, it also makes the economy more stable as the financial accelerator weakens. In response to the drop in $Z_{t}$, the economy with financial innovation features smaller increases in credit spreads and a smaller drop in assets prices. Intuitively, with financial innovation, retail banks provide a stronger buffer to absorb loan sales by wholesale banks, which helps stabilize asset prices. At the same time, the economy with financial innovation is more vulnerable to a bank run.

This is illustrated by the panel titled "Run on Wholesale" in Figure 9. In this panel we plot a variable that indicates at each time $t$ whether a run is possible at time $t+1$. To construct this variable we define

$$
\operatorname{Run}_{t}^{w}=1-x_{t}^{w}
$$

where $x_{t}^{w}$ is the recovery rate on wholesale debt. Hence, in order for a run to exist the run variable must be positive.

As shown by the Run wariable, a run on wholesale banks is not possible in the steady state under both parameterization considered. With a six percent drop in $Z_{t}$, a run equilibrium remains impossible in the economy absent financial innovation, i.e., the one with a high value of $\omega$. However, for the economy with financial innovation (i.e. a low $\omega$ ), the same drop in $Z_{t}$ is big enough to make a run on wholesale banking possible. Intuitively, in the low $\omega$ economy, wholesale bank leverage ratios are higher than would be otherwise, and asset liquidation values are lower, which raises the likelihood that the conditions for a bank run equilibrium will be satisfied.

Figure 10 describes the effects of bank runs. In particular we assume that two periods after the unanticipated drop in $Z_{t}$, retail investors stop rolling over short term debt issued by wholesale banks, inducing them to liquidate all of their assets and go bankrupt.

As explained in Section 3.5.1, the run on wholesale banks forces them into bankruptcy and results in $K^{w}$ dropping to 0 . Households and retail banks are forced to absorb all of the wholesale banks' assets, inducing asset prices to drop by about $7 \%$ in total. The intermediation costs associated with the reallocation of assets to less

\footnotetext{
${ }^{32}$ Observe also that in a production economy with investement and nominal rigidities, the drop in the asset price would reduce investment and thus aggregate demand, magnifying the overall drop in output.
} 

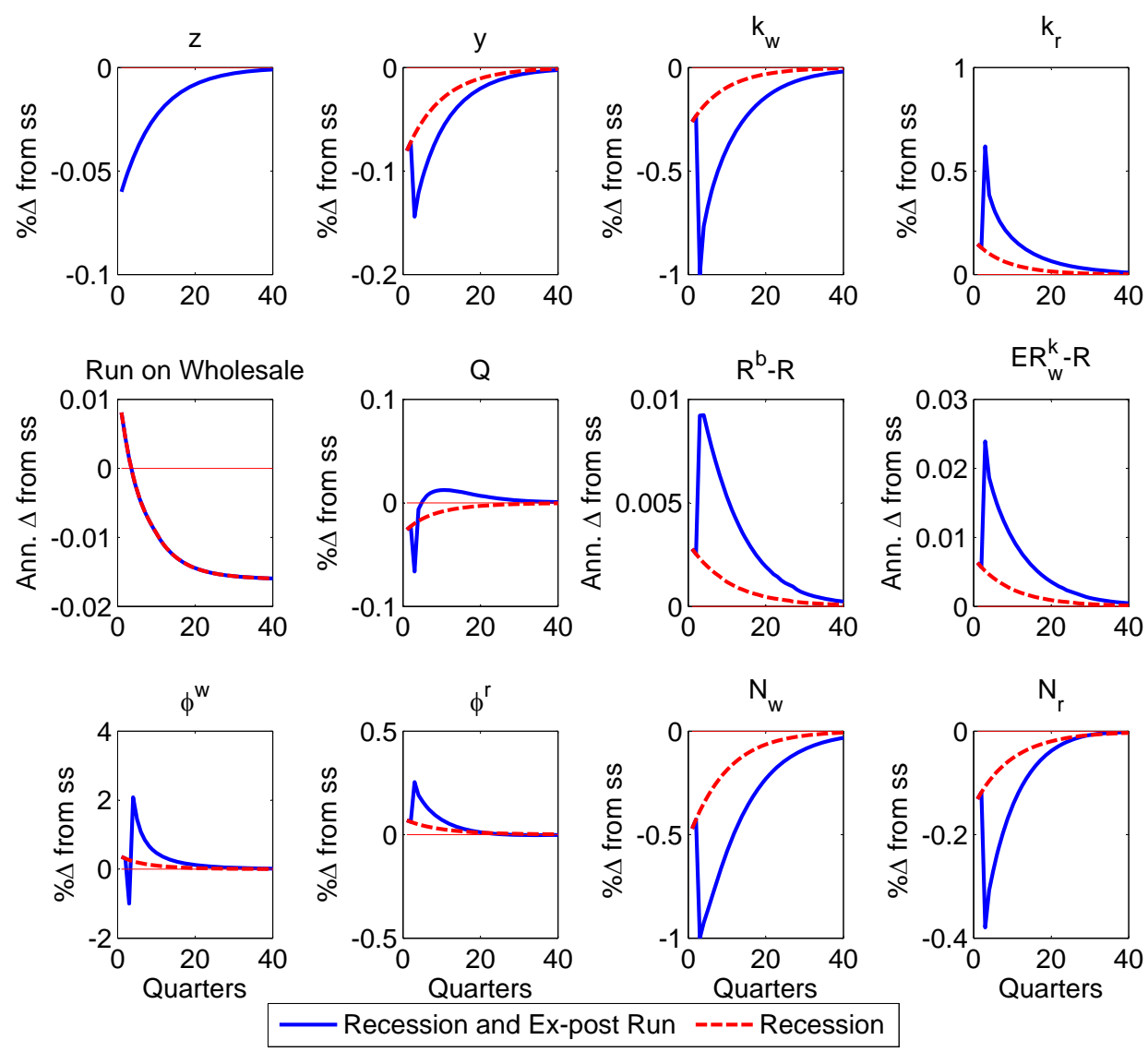

Figure 10: A recession followed by a run on wholesale bankers

efficient agents leads to an additional contraction of output of around $7 \%$, resulting in an overall drop of about $15 \%$.

As new wholesale bankers resume operations from the period after the run, high levels of spreads for both retail and wholesale bankers allow them to increase their leverage and recapitalize financial intermediaries thanks to above average retained earnings. The re-intermediation process however is rather lengthy and output remains depressed for a prolonged period of time.

\section{$5 \quad$ Anticipated Runs}

So far, we have focused on the case in which runs are completely unexpected. In this section we study how the equilibrium changes if agents anticipate that a run 
will occur with positive probability in the future, focusing on the more realistic case of a run on wholesale bankers only. The Appendix contains a detailed description of the equilibrium in this case. ${ }^{33}$ Here we describe the key forces through which anticipation of a run in the future affects financial intermediation. To keep the analysis as simple as possible, we assume that once a negative shock to $Z_{t}$ hits, $Z_{t}$ obeys perfect foresight path back to steady state.

The main difference from the unanticipated case is in the market for interbank loans. In particular, once runs are anticipated, retail bankers internalize how wholesale bankers' leverage affects returns on interbank loans in case of a run and they adjust the required promised rate $\bar{R}_{b t+1}$ accordingly. We denote by $p_{t}$ the time $t$ probability that retail banks will run on wholesale banks at time $t+1 .^{34}$ The indifference condition of the retail bank between making interbank loans and non-financial loans (33) becomes:

$$
\begin{aligned}
& E_{t}\left[\left(1-p_{t}\right) \Omega_{t+1}^{r}\left(\bar{R}_{b t+1}-R_{t+1}\right)+p_{t} \Omega_{t+1}^{r *}\left(x_{t+1}^{w} \bar{R}_{b t+1}-R_{t+1}\right)\right] \\
& =\gamma E_{t}\left[\left(1-p_{t}\right) \Omega_{t+1}^{r}\left(R_{k t+1}^{r}-R_{t+1}\right)+p_{t} \Omega_{t+1}^{r *}\left(R_{k t+1}^{r *}-R_{t+1}\right)\right],
\end{aligned}
$$

where

$$
\Omega_{t+1}^{r *}=\beta\left(1-\sigma+\sigma \frac{V_{t+1}^{r *}}{n_{t+1}^{r *}}\right)
$$

is the value of the stochastic discount factor if a run occurs at $t+1$.

Using equation (41) to substitute for $x_{t+1}^{w}$ in (44) we obtain a menu of promised rates: ${ }^{35}$

$$
\begin{gathered}
\bar{R}_{b t+1}\left(\phi_{t}^{w}\right)=(1-\gamma) R_{t+1}+\gamma \frac{E_{t}\left(\Omega_{t+1}^{r} R_{k t+1}^{r}\right)}{E_{t}\left(\Omega_{t+1}^{r}\right)} \\
+\frac{p_{t}}{\left(1-p_{t}\right) E_{t}\left(\Omega_{t+1}^{r}\right)} E_{t}\left\{\Omega_{t+1}^{r *}\left[(1-\gamma) R_{t+1}+\gamma R_{k t+1}^{r *}-\frac{\phi^{w}}{\phi^{w}-1} R_{k t+1}^{w *}\right]\right\}
\end{gathered}
$$

Notice that $\bar{R}_{b t+1}\left(\phi_{t}^{w}\right)$ is an increasing function $\phi_{t}^{w}$. This is because as leverage increases, retail bankers suffer larger losses on interbank loans if a run occurs. This induces them to require higher returns in the event of no run, to compensate for the larger losses in the event of a run.

When choosing their portfolios, wholesale bankers will now have to factor in that changes in their leverage affect their cost of credit according to equation (45). This

\footnotetext{
${ }^{33}$ The analysis of anticipated runs draws heavily on Gertler and Kiyotaki (2015).

${ }^{34}$ The determination of this probability of "observing a sunspot" will be discussed below.

${ }^{35}$ This is the relevant function for values of leverage high enough to induce bankruptcy in case of a run.
} 
preserves homogeneity of the problem but the franchise value of the firm will change to reflect that with probability $p_{t}$ the bank will be forced to liquidate assets at price $Q_{t+1}^{*}$ in the subsequent period. This will have the effect of reducing the franchise value of wholesale banks, hence tightening their financial constraints.

In particular the franchise value of a wholesale bank will be given by ${ }^{36}$

$$
\frac{V_{t}^{w}}{n_{t}^{w}}=\left(1-p_{t}\right) E_{t}\left\{\Omega_{t+1}^{w}\left[\phi_{t}^{w}\left(R_{t+1}^{w}-\bar{R}_{b t+1}\left(\phi_{t}^{w}\right)\right)+\bar{R}_{b t+1}\left(\phi_{t}^{w}\right)\right]\right\} .
$$

An increase in $p_{t}$ reduces the franchise value through two channels: First, it decreases the likelihood that the bank will continue to operate next period. Second, it leads to an increase in the interbank loan rate each individual bank faces, $\bar{R}_{b t+1}\left(\phi_{t}^{w}\right)$, which reduces the franchise value even if the bank continues to operate.

In order to pin down a state dependent probability of a run, we follow Gertler and Kiyotaki (2015). In particular we assume that at each time $t$ the probability of transitioning to a state where a run on wholesale banks occurs is given by a reduced form decreasing function of the expected recovery rate $E_{t} x_{t+1}^{w}$ as follows,

$$
p_{t}=\left[1-E_{t}\left(x_{t+1}^{w}\right)\right]^{\delta} \text {. }
$$

Although we don't endogenize the functional dependence of $p_{t}$ on the state of the economy, the above formulation allows us to capture the idea that as wholesale balance sheet positions weaken, the likelihood of a run increases. This same qualitative conclusion would follow, for example, if the probability of a run was determined endogenously by introducing imperfect information, as in the global games approach developed by Morris and Shin (1998).

Figure 11 demonstrates how anticipation effects work to increase financial amplification of shocks in the model. The solid line is the response of the economy to an unanticipated six percent shock to $Z_{t}$ when agents anticipate that a run can happen at each time $t+1$ with probability $p_{t}$ as determined in equation (47). ${ }^{37}$ As we noted earlier, we assume that after the shock $Z_{t}$ follows a perfect foresight path back to steady state. To isolate the effect of the anticipation of the run, we suppose in this case that the run never actually occurs ex-post. For comparison, the dotted line reports the responses of the baseline economy in which individuals assign probability zero to a bank run.

\footnotetext{
${ }^{36}$ Here we are already assuming that wholesale bankers will choose a leverage high enough to result in bankruptcy when a run occurs. See the Appendix for a detailed description of hte wholesale banker's problem when runs are anticipated. There, we derive the conditions that ensure that it is optimal for wholesale bankers to default in the event of a run.

${ }^{37}$ In the numerical simulations below we pick $\delta$ to be $\frac{1}{2}$.
} 

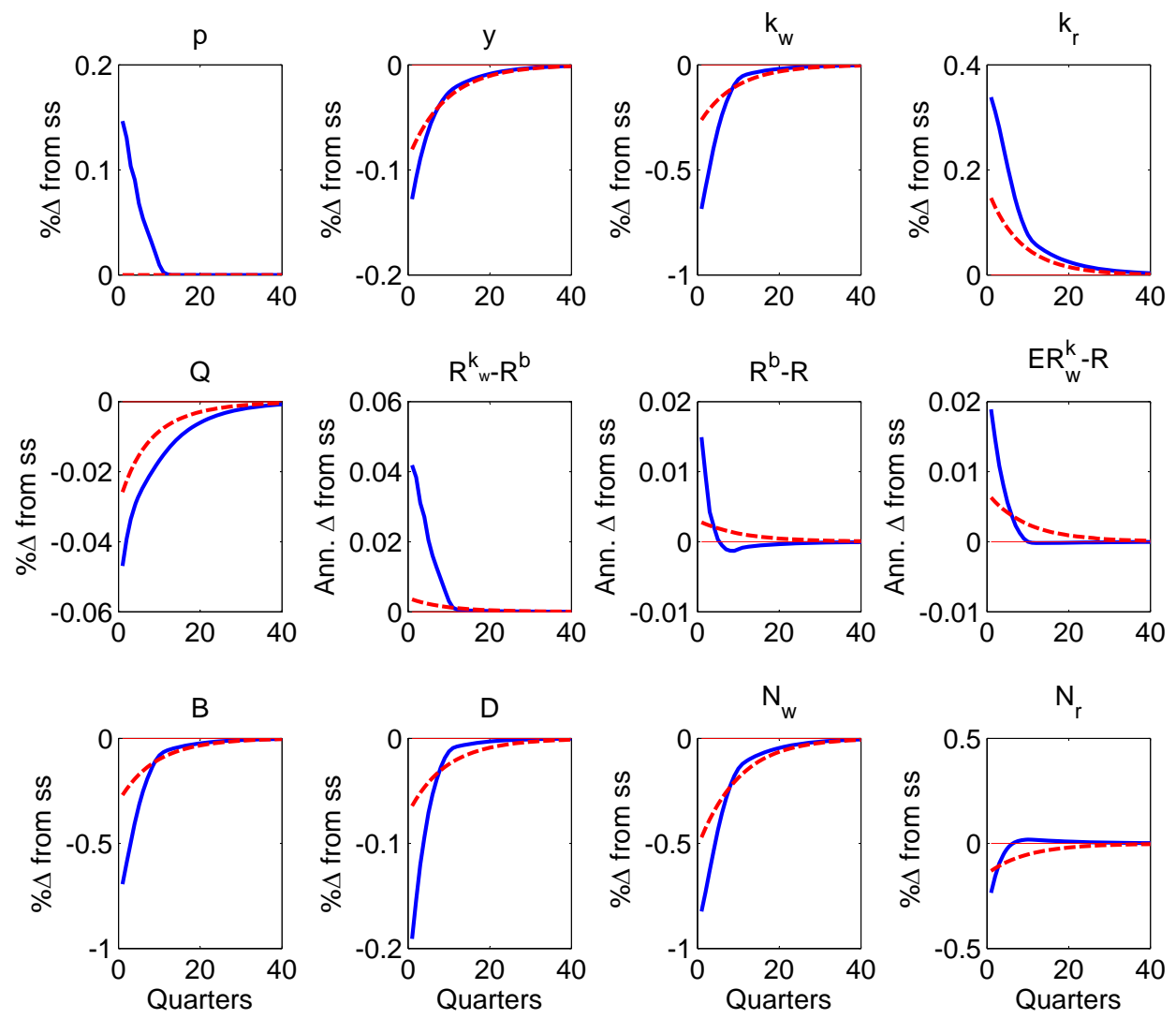

Recession with Positive Run Probability ---- Recession

Figure 11: A recession in the model with anticipated runs

While it is still the case that in steady state a run cannot occur, the shock to $Z_{t}$ leads the probability of a run to increase to $15 \%$. As wholesale bankers' balance sheets weaken and the liquidation price decreases, retail bankers expect more losses on interbank loans in case of a run and the probability of coordinating on a run equilibrium increases as a result. The increase in $p_{t}$ leads to a sharp contraction in the supply of interbank credit and a further tightening of wholesale bankers financial constraints. This, in turn, results in an overall reduction in their net worth of about $80 \%$ compared to a $50 \%$ in the baseline and to a spike in spreads between nonfinancial loan and interbank loan rates that increase by 400 basis points compared to only 30 in the baseline. As wholesale banks are forced to downsize their operations, total interbank credit falls by about $70 \%$, more than twice the percentage drop in the baseline. These massive withdrawals of funds from wholesale markets is the model 

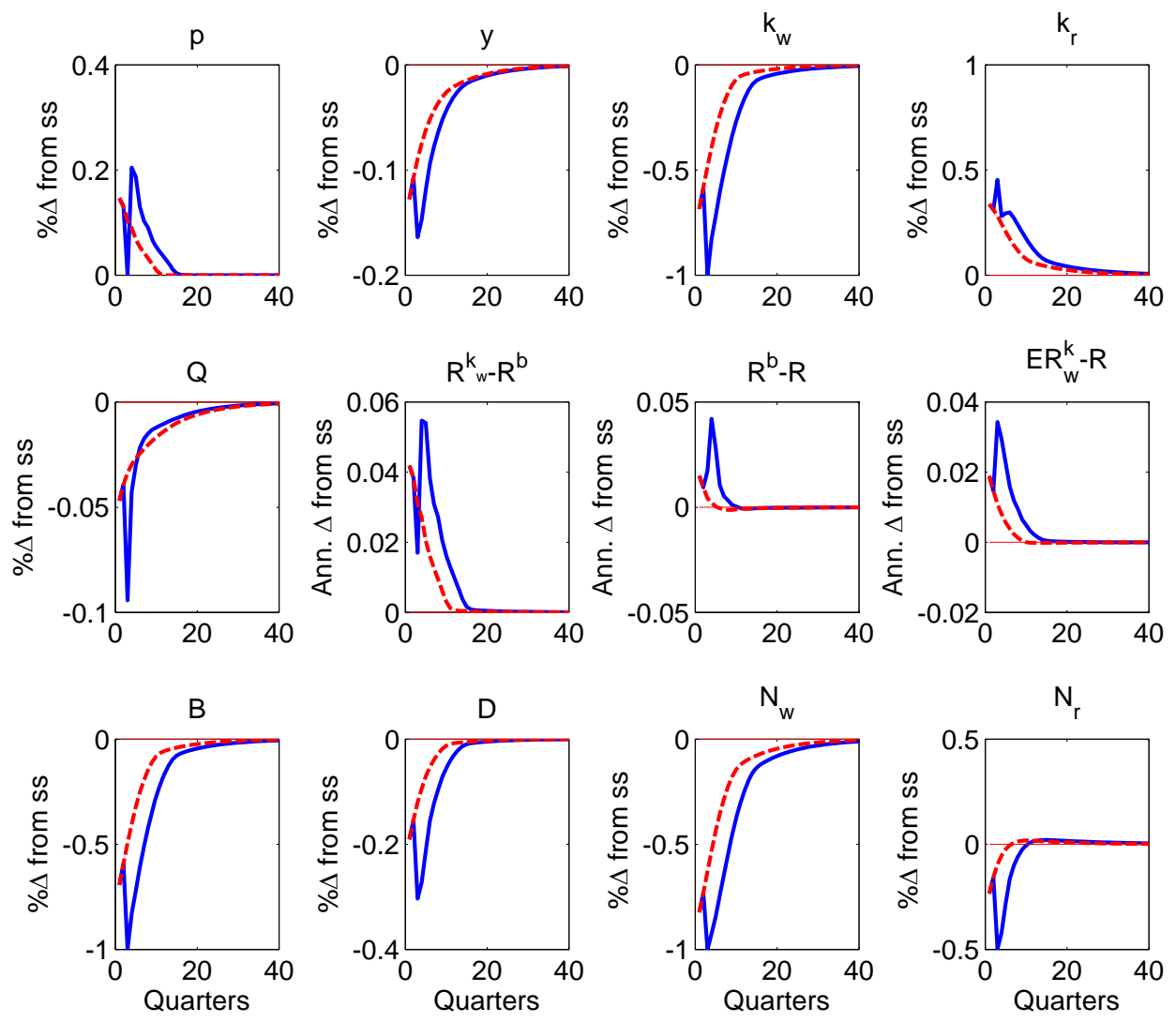

- Recession with Anticipated Run Happening ex-post ---- Recession with Positive Run Probability

Figure 12: A recession followed by a run in the model with anticipated runs

counterpart to the "slow runs" on the ABCP market in 2007. These disruptions in wholesale funding markets are then transmitted to the rest of the economy inducing a drop in asset prices of five percent and a total contraction of output of thirteen percent.

Figure 12 shows the case in which the run actually occurs two periods after the realization of the shock to $Z_{t}$. There are two main differences with respect to the analogous experiment performed in the case of unanticipated runs depicted in Figure 10 . First, the initial increase in the probability of a run that precedes the actual run allows the model to capture the "slow runs" followed by "fast runs" in wholesale funding markets that was a central feature of the financial crisis, as discussed in the Introduction. Second, the run induces a further increase in the probability of additional runs in the future, that goes back to about $20 \%$ the period after the 


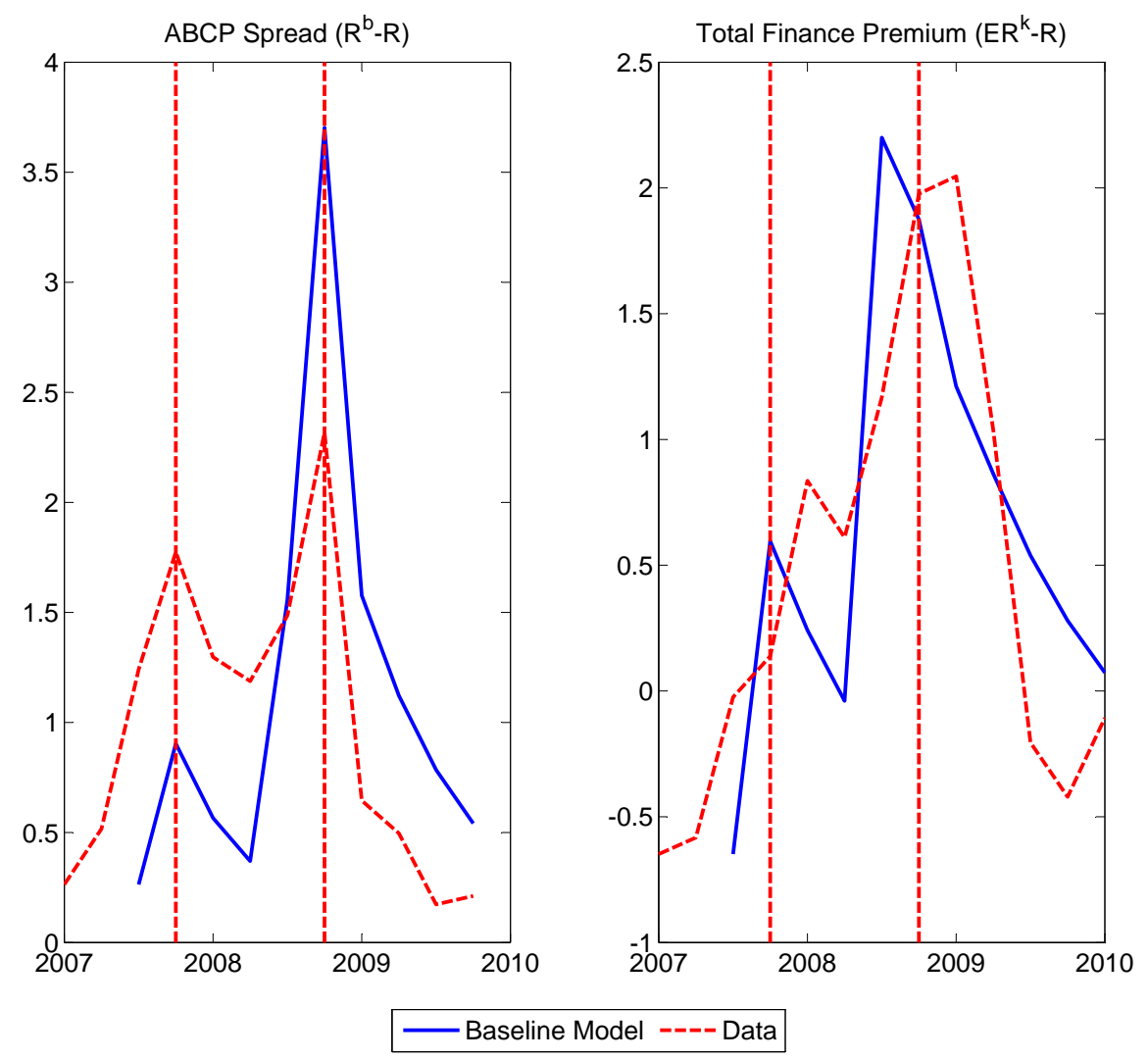

Figure 13: Total Credit Spreads and Interbank Spreads in the Model and in the Data

run occurs. This hampers wholesale bankers ability to increase their leverage and generates higher spreads in the interbank market preventing the relatively smooth increase in asset prices that characterizes the recovery in the baseline model.

Figure 13 shows how the model with anticipated runs can reproduce some key features of the financial disruptions that occurred in 2007 and 2008. In particular, we compare the model predicted path for interbank spreads, $\bar{R}_{t+1}^{b}-R_{t+1}$, and excess finance premium, $E R_{k, t+1}^{w}-R_{t+1}$, with their empirical counterparts over the period going from 2007Q2 to 2009Q4. For the interbank spreads we choose the ABCP spread, since the first "slow runs" in wholesale funding markets in the third quarter of 2007 took place in the ABCP market. The measure of excess borrowing costs is the Excess Bond Premium of Gilchrist and Zakrajsek (2012). We assume that the economy is in steady state in 2007Q2 and the unanticipated shock hits in 2007Q3 
followed by a run on wholesale banks in 2008Q3. ${ }^{38}$ In the data excess borrowing costs lag financial spreads, so the model predicts a stronger initial increase in $E R_{k, t+1}^{w}-R_{t+1}$ and attributes a slightly smaller proportion of the increase to interbank spreads, probably due to the behavior of the risk free rate. On the other hand, the faster decline in spreads in the data after 2009 can be attributed to the effects of government intervention in this period. Overall, the experiment can capture the credit spreads and bank equity dynamics reasonably well.

\section{Two Productive Assets and Spillover Effects}

In our baseline model there is only one type of capital. Wholesale banks have an efficiency advantage in holding this capital. Retail banks exist mainly because wholesale banks may be constrained by their net worth; otherwise the latter would hold all the capital. In this section we introduce a second type of capital which retail banks have an efficiency advantage in intermediating. In addition to providing a stronger motivation for the existence of retail banking, the second asset allows us to illustrate spillover effects from a crisis in wholesale banking into retail banking.

In particular, one of the salient features of the recent crisis was the strong contagion effect through which the collapse in subprime mortgage related products within the wholesale banking sector led to a deterioration in financial conditions within the commercial banking sector, ultimately affecting the flow credit through these institutions. Even though on the eve of the crisis, much of the credit provided by the retail sector had no direct reliance on shadow banks, the collapse of the latter ultimately disrupted commercial bank lending, enhancing the downturn.

As is the case with the first type of capital, we suppose the second type is fixed in supply and denote the total as $\bar{L}$. We refer to bank loans made to finance this capital as "C\&I" loans (for" commercial and industrial" loans). What we have in mind are the kinds of information-intensive loans that are not easily securitized, which retail banks have historically specialized in intermediating. This contrasts with the kinds of securitized assets, involving mortgages, car loans, credit card debt, trade credit and so on, that were principally held by wholesale banks.

For simplicity, we assume that only retail banks and households fund the second type of capital. Given $L_{t}^{r}$ and $L_{t}^{h}$ are the amounts funded by retail banks and households, we have:

$$
L_{t}^{h}+L_{t}^{r}=\bar{L}
$$

\footnotetext{
${ }^{38}$ To be closer to the observed dynamics of spreads we resize the innovation to $Z_{t}$ to five percentage points.
} 
We model retail banks' comparative advantage in making C\&I loans by assuming that management costs of intermediating these loans are zero for these types of banks. Conversely, we think of management costs for wholesale banks as being infinity. Finally, we allow households to directly fund this asset, where claims on this capital directly held by households may be thought of as corporate bonds. We suppose that households are at disadvantage to retail banks in funding the second type of capital, though at an advantage relative to wholesale banks: They must pay the management fee

$$
F^{L}\left(K_{t}^{L}\right)=\frac{\alpha^{L}}{2}\left(K_{t}^{L}\right)^{2}
$$

with $0<\alpha^{L}<\infty$.

In analogy to the first type of capital, there is an exogenous dividend payout $Z_{t}^{L}$ that obeys a stationary first order stochastic process. In addition, for simplicity we restrict attention to the case where bank runs are completely unanticipated. Accordingly, let $R_{l t+1}^{h}$ be the household's rate of return from funding the second asset. Then the household's first order condition for holding the second asset is given by

$$
E_{t}\left(\Lambda_{t, t+1} R_{l t+1}^{h}\right)=1
$$

with

$$
R_{l t+1}^{h}=\frac{Z_{t+1}^{L}+Q_{t+1}^{L}}{Q_{t}^{L}+\alpha_{h}^{L} L_{t}^{h}}
$$

where $Q_{t}^{L}$ is the asset price and $\alpha_{h}^{L}$ controls the degree of inefficiency of households in directly holding this asset.

The optimization problem of wholesale bankers is unchanged. Accordingly, we focus on retail bankers. Given retail banks now have the option of intermediating the second asset, we can rewrite the balance sheet and flow of funds constraints as

$$
\begin{gathered}
\left(Q_{t}+f_{t}^{r}\right) k_{t}^{r}+Q_{t}^{L} l_{t}^{r}+\left(-b_{t}^{r}\right)=n_{t}^{r}+d_{t}^{r} \\
n_{t+1}^{r}=R_{k t+1}^{r}\left(Q_{t}+f_{t}^{r}\right) k_{t}^{r}+R_{l t+1}^{r} Q_{t}^{L} l_{t}^{r}+R_{b t+1}\left(-b_{t}^{r}\right)-R_{t+1} d_{t}^{r}
\end{gathered}
$$

where $R_{l t+1}^{r}$ is the rate of return on the type $L$ asset and is given by,

$$
R_{l t+1}^{r}=\frac{Z_{t+1}^{L}+Q_{t+1}^{L}}{Q_{t}^{L}} .
$$

Because the incentive constraint is

$$
\theta\left[\left(Q_{t}+f_{t}^{r}\right) k_{t}^{r}+Q_{t}^{L} l_{t}^{r}+\left(-b_{t}^{r}\right)\right] \leq V_{t}^{r},
$$


the effective leverage multiple for this case $\phi_{t}^{r}$ now includes the holdings of the second type of capital:

$$
\phi_{t}^{r} \equiv \frac{\left(Q_{t}+f_{t}^{r}\right) k_{t}^{r}+Q_{t}^{L} l_{t}^{r}+\gamma\left(-b_{t}^{r}\right)}{n_{t}^{r}} .
$$

Proceeding as earlier to solve the retail bank's maximization problem yields a solution for $\phi_{t}^{r}$ which is the same as in the baseline case (see equation (27)). In addition, at the margin the retail bank must be indifferent between holding the types of capital, which implies the following arbitrage condition:

$$
E_{t}\left[\Omega_{t+1}^{r}\left(R_{l t+1}^{r}-R_{k t+1}^{r}\right)\right]=0 .
$$

We now consider a numerical example designed to illustrate the contagion effect. The real world phenomenon that motivates the experiment is the fall in housing prices beginning in 2006 that led to the collapse of the wholesales banking sector that in turn disrupted commercial banking. In particular, we suppose that the dividend to the $L$ asset is fixed at its steady state value $Z^{L}$. Then we consider a negative shock to the dividend on the type $K$ asset and, as in our earlier baseline experiments, allow for an unanticipated run two periods after the initial shock. Tables 4 and 5 describe the changes in the calibration for this experiment.

Figure 14 reports the results from the experiment and demonstrates the spillover effects of shocks to $Z_{t}$ on the market for $L$. The source of contagion in this environment is the balance sheet position of retail bankers. ${ }^{39}$ Losses on their capital investment and, in case of a run, on their interbank loans, result in a decrease in retail bankers' net worth and a tightening of their respective incentive constraints. As long as there are incentive costs associated with intermediating asset $L$, the tightening of financial constraints leads retail bankers to increase required excess returns in both markets, as shown by equation (50). The negative shock to returns on capital and the run on wholesale banks lead to a costly reallocation of assets to households and to an increase in spreads between returns on $L_{t}^{r}$ and the deposit rate of about 60 basis points.

\section{Government Policy}

In this section we study the effects of two types of policy interventions to combat banking crises: first an ex-post intervention where the central bank acts as a lender of last resort; second, an ex-ante macroprudential regulation that limits banks' risk

\footnotetext{
${ }^{39}$ Other similar models of spillover are Bocola (2015) and Ferrante (2015b). An alternative mechanism based on market fragmentation is developed by Garleanu, Panageas and Yu (2015).
} 


\section{Table 4: Parameters in 2 Assets Table 5: Steady State Model in 2 Assets Model}

\begin{tabular}{|c|c|c|}
\hline \multicolumn{3}{|c|}{ PARAMETERS } \\
\hline \multicolumn{3}{|c|}{ Households } \\
\hline$\beta$ & discount rate & .99 \\
\hline$\alpha^{h}$ & Intermediation cost & .06 \\
\hline$\alpha_{L}^{h}$ & Intermediation cost for $\mathrm{Cl}$ loans & .006 \\
\hline$W^{h}$ & Endowment & .016 \\
\hline \multicolumn{3}{|c|}{ Retail Banks } \\
\hline$\sigma^{r}$ & Survival Probability & .96 \\
\hline$\alpha^{r}$ & Intermediation cost & .01 \\
\hline$\alpha_{L}^{r}$ & Intermediation cost for $\mathrm{Cl}$ loans & 0 \\
\hline$W^{r}$ & Endowment & .0014 \\
\hline$\theta$ & Divertable proportion of assets & .27 \\
\hline$\gamma$ & Shrinkage of Divertable proportion of interbank loans & 67 \\
\hline \multicolumn{3}{|c|}{ Wholesale Banks } \\
\hline$\sigma^{w}$ & Survival Probability & .88 \\
\hline$\alpha^{w}$ & Intermediation cost & 0 \\
\hline$\alpha_{L}^{w}$ & Intermediation cost for $\mathrm{Cl}$ loans & $\infty$ \\
\hline$W^{w}$ & Endowment & .0012 \\
\hline$\omega$ & Shrinkage of divertable proportion of assets & .47 \\
\hline \multicolumn{3}{|c|}{ Production } \\
\hline $\mathrm{Z}$ & Steady State productivity & .016 \\
\hline$\rho_{z}$ & Serial correlation of productivity shocks & .9 \\
\hline
\end{tabular}

\begin{tabular}{l||l||l||}
\hline \multicolumn{2}{c|}{ STEADY STATE } \\
\hline$Q$ & price of capital & 1 \\
$Q^{L}$ & price of Cl loans & 1 \\
$K^{r}$ & retail intermediation & .3 \\
$K^{w}$ & wholesale intermediation & .6 \\
$L^{r}$ & retail holding of Cl loans & .5 \\
$L^{h}$ & household holding of Cl loans & .5 \\
$R^{b}$ & Annual interbank rate & 1.048 \\
$R_{r}^{k}$ & Annual retail return on capital & 1.052 \\
$R_{r}^{L}$ & Annual retail return on Cl loans & 1.052 \\
$R$ & Annual deposit rate & 1.04 \\
$R_{w}^{k}$ & Annual wholesale return on capital & 1.064 \\
$\phi^{w}$ & wholesale leverage & 20 \\
$\phi^{r}$ & retail leverage & 10 \\
$Y$ & output & .0466 \\
$C^{h}$ & consumption & .0363 \\
$N^{r}$ & retail banks networth & .1371 \\
$N^{w}$ & wholesale banks networth & .03
\end{tabular}

exposure. Within the literature, these policies have largely been studied in the context of dampening negative financial accelerator effects on the economy. Here we emphasize a somewhat different perspective: How these policies might be useful in reducing the likelihood of damaging bank runs? As we show, lender of last resort policy that is anticipated ex ante in the event of an ex post crisis reduces the likelihood of a run by raising asset liquidation prices. Macroprudential does so by reducing bank leverage.

A case for ex ante macroprudential regulation arises because banks tend to choose an inefficiently high level of leverage in the laissez-faire economy. Roughly speaking, because individual banks ignore the consequences of their own borrowing decisions on the level of aggregate risk, their are prone to issue more debt than would be socially desirable. ${ }^{40}$ In addition, as Farhi and Tirole (2012) Chari and Kehoe (2014),

\footnotetext{
${ }^{40}$ See Geanakoplos Polemarchakis (1986) for the original result of generic constrained inefficiency in a model with incomplete markets. Lorenzoni (2008) and Bianchi (2011) are recent applications to environments with financial frictions.
} 

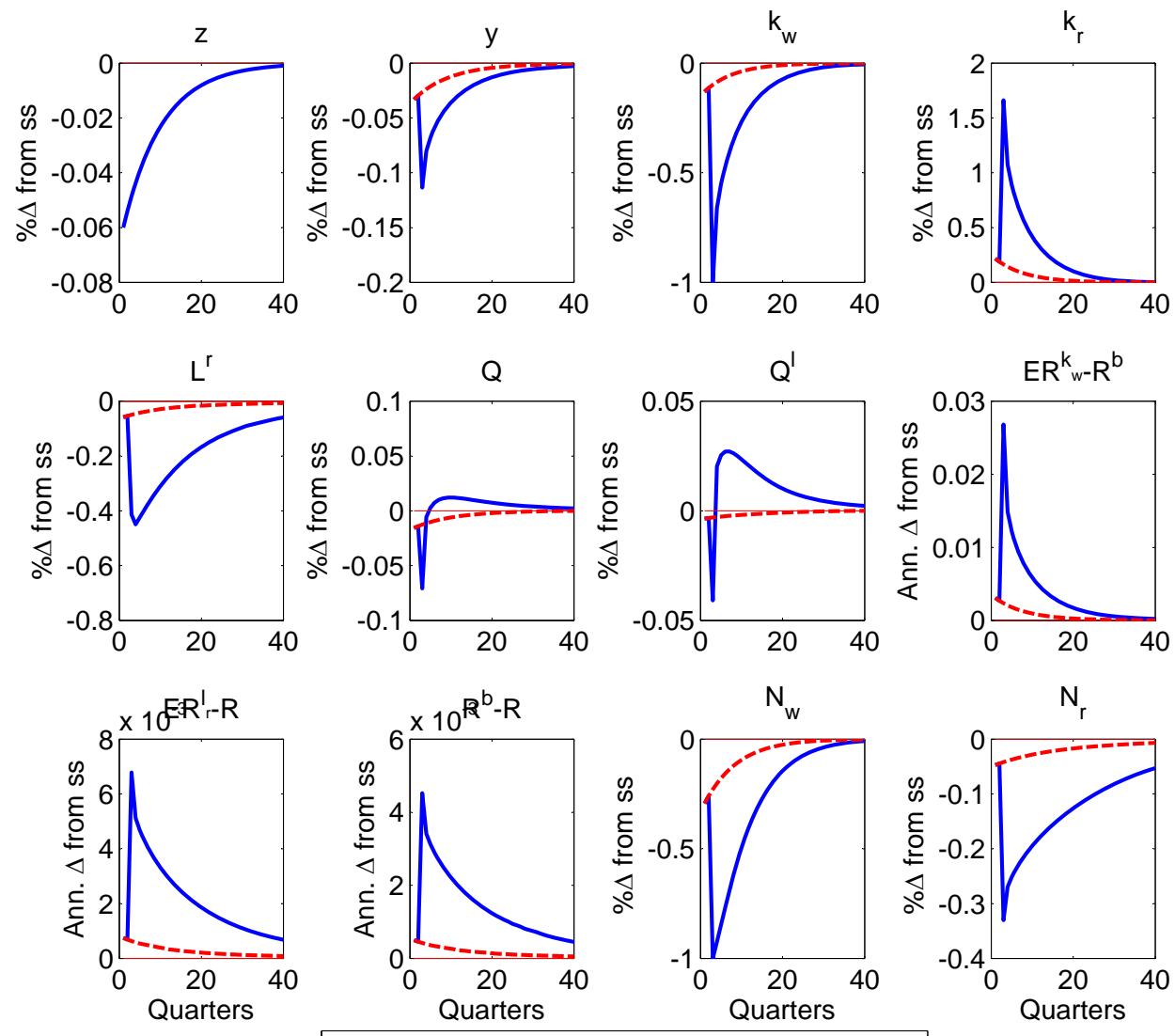

Ex-post run on wholesale ----- Recession

Figure 14: Spillover

and Gertler, Kiyotaki and Queralto (2011) emphasize, the expectations of some type of government interventions ex post will also encourage excessive leverage in the banking system ex ante.

In this section we explore each of this kinds of policy's within our framework of Anticipated Runs of Section 5.

\subsection{Ex-Post Intervention: Lender of the Last Resort}

It is well known that if there are limits to arbitrage in private financial intermediation, then a central bank who plays as the lender of last resort during a financial crisis can enhance the flow of credit and in turn mitigate the economic downturn. What makes the lender of last resort effective is that the central bank can elastically obtain funds by issuing interest bearing reserves, while private financial intermediaries may be 
constrained in their ability to obtain funds by the condition of their balance sheets (Gertler and Karadi, 2011, Gertler and Kiyotaki, 2011).

Following the onset of the recent financial crisis, the Federal Reserve introduced a variety of lender of last resort programs. The most prominent involved large scale asset purchases (LSAPs) of high grade long term debt, including primarily agency mortgage backed securities (AMBS), instruments that were held primarily in the shadow banking sector. The Fed announced this program in December 2008 following the collapse of the shadow banking system and began phasing it in the following March. The objective of this kind of lender of last resort intervention was to reduce the cost and thereby increase the availability of credit to the nonfinancial sector. There is evidence which suggests the Fed achieved this objective. Beyond these considerations, however, by acting as buyers in the secondary market for AMBS, the Fed raised the price and accordingly the liquidation value of these assets. As we noted, the impact of these policies on liquidation prices has important implications for banking stability. (See equation (40), for the condition for a bank run equilibrium.)

To model this type of intervention, we assume that the central bank can directly undertake intermediation by borrowing from retail banks and then making nonfinancial loans. The way the central bank obtains funds from retail banks is to issue interest bearing bank reserves. We assume that retail banks are unable to divert bank reserves, since they are held in an account at the Fed. Given retail banks cannot divert reserves, they are not constrained in their ability to raise deposits to fund reserves. Because there are no limits to arbitrage for banks funding reserves, the interest rate on reserves will equal the deposit rate. Therefore, when the central bank supplies interest-rate bearing reserves to retail banks, it effectively raises funds directly from households by issuing overnight government bond. What gives the central bank an advantage in intermediating assets is that, unlike retail and wholesale banks, it is not balance sheet constrained.

We also assume, following Gertler and Karadi (2011) that the central bank is less efficient than the private sector. As with retail banks and households, the government faces quadratic managerial costs $\frac{1}{2} \alpha^{g}\left(K_{t}^{g}\right)^{2}$, where $K_{t}^{g}$ is the size of central bank's intervention and where $\alpha^{h}>\alpha^{g}>\alpha^{r}$. To ensure that it is desirable for the central bank to intervene only in a crisis, we also allow for inefficiency in the average performance of the government's portfolio: In particular, we assume that the return on government intermediated assets is:

$$
R_{k t+1}^{g}=\varphi \frac{Z_{t+1}+Q_{t+1}}{Q_{t}+\alpha^{g} K_{t}^{g}}
$$

where $\varphi \in(0,1)$ controls the relative inefficiency of central bank's intermediation for 
the average return on assets, independent of scale.

We assume that the central bank intervenes in credit markets whenever expected asset returns exceed its cost of borrowing. That is we posit a policy rule for central bank's intervention given by

$$
\begin{array}{cc}
K_{t}^{g}=0, & \text { if } E_{t}\left(R_{k t+1}^{g}-R_{g t+1}\right)<0 \\
E_{t}\left(R_{k t+1}^{g}-R_{g t+1}\right)=0, & \text { if } K_{t}^{g} \geq 0
\end{array}
$$

where $R_{g t+1}$ is the interest paid on reserves issued to retail banks.

As we just noted, since there is no incentive problem associated with central bank intermediation, in equilibrium the interest rate on reserve $R_{g t+1}$ must equal to the deposit rate: ${ }^{41}$

$$
R_{g t+1}=R_{t+1}
$$

The key variable to which the central bank responds in determining credit market intervention is the spread between the wholesale bank's return on assets and the deposit rate, $R_{k t+1}^{w}-R_{t+1}$, which can be thought of as a measure of the degree of inefficiency in private financial markets. The central bank intervenes when this excess return is high. ${ }^{42}$ In particular, the policy rule (52) prescribes that the Fed starts intermediating assets as soon as the ratio of the credit spread to the deposit rate exceeds a given threshold that varies inversely with the inefficiency parameter $\varphi:$

$$
K_{t}^{g}>0, \text { iff } \frac{E_{t}\left(R_{k t+1}^{w}\right)-R_{t+1}}{R_{t+1}}>\frac{1-\varphi}{\varphi} .
$$

From equation (52), the size of the intervention in the region where $K_{t}^{g}>0$ is then governed by:

$$
K_{t}^{g}=\frac{\varphi}{\alpha^{g}} Q_{t}\left[\frac{E_{t}\left(R_{k t+1}^{w}\right)-R_{t+1}}{R_{t+1}}-\frac{1-\varphi}{\varphi}\right] .
$$

${ }^{41}$ To see formally, first notice that, since retail bankers cannot divert reserves, their incentive constraint (14) is not affected by the amount of reserves held on their balance sheet. Hence the introduction of interest bearing reserves only affects retail bankers' optimization problem by modifying the objective function (26), which becomes

$$
V_{t}^{r}=\underset{\phi_{t}^{r}, d_{g t}^{r}}{\operatorname{Max}} E_{t}\left\{\Omega_{t+1}^{r}\left[\phi_{t}^{r}\left(R_{k t+1}^{r}-R_{t+1}\right)+R_{t+1}+d_{g t}^{r}\left(R_{g t+1}-R_{t+1}\right)\right] n_{t}^{r}\right\}
$$

where $d_{g t}^{r}$ is the amount of reserves per unit of networth held by retail bankers. The optimality condition with respect to $d_{g t}^{r}$ is just given by $R_{g t+1}=R_{t+1}$. Covariance terms are zero since both $R_{g t+1}$ and $R_{t+1}$ are known at date $t$.

${ }^{42}$ Our policy rule, which has the central bank target credit spreads, is consistent with how the central bank behaved throughout the crisis. What motivated an unconventional intervention in a given credit market was typically a sharp increase in the spread wthin that market. 

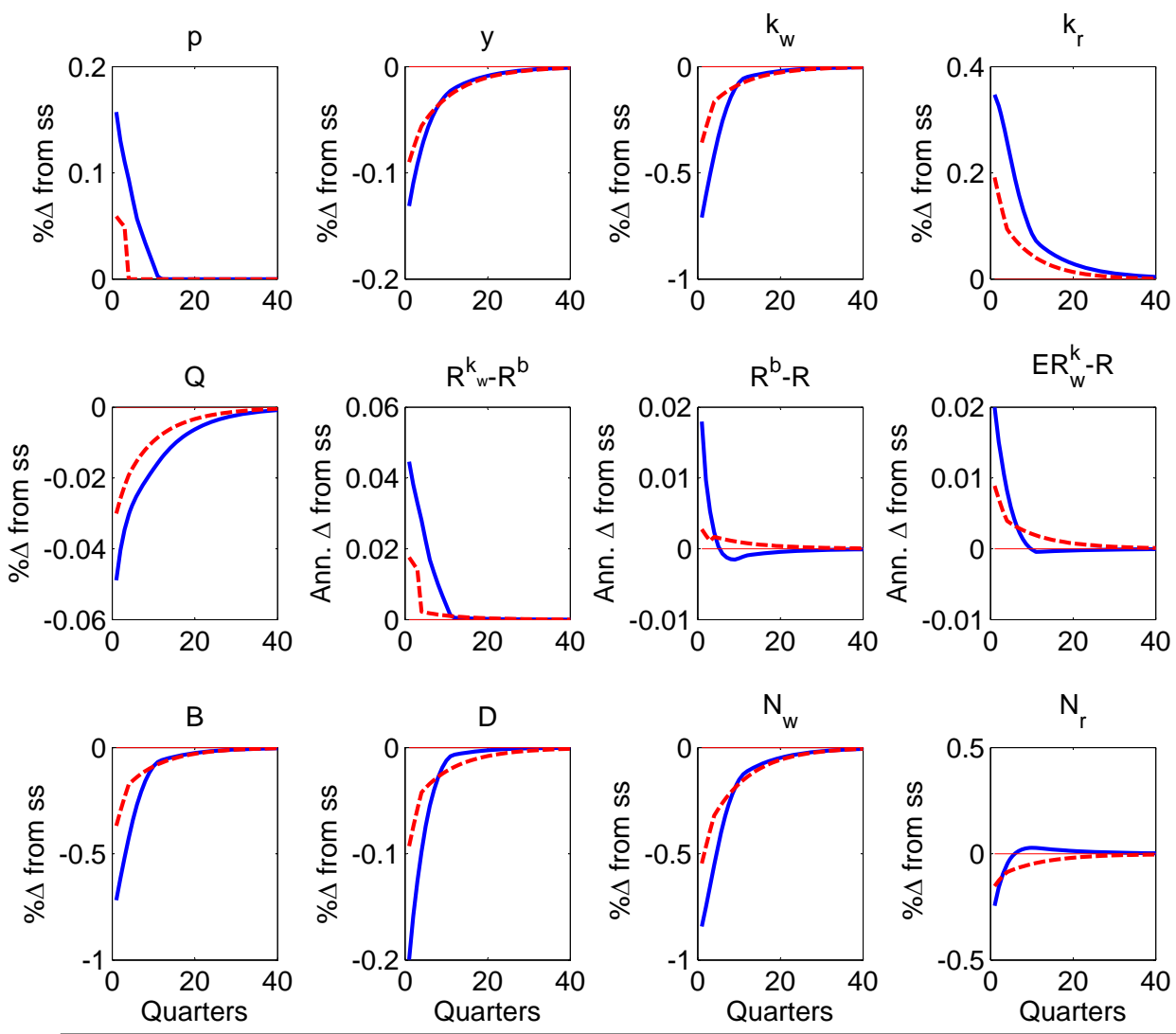

- Recession with Positive Run Probability ---- Recession with Lender of Last Resort

Figure 15: Anticipation Effects of Government intervention

We choose $\varphi$ in order to ensure that the central bank only intervenes after a run happens: that is, the threshold for the credit spread to justify an intervention is reached only in the event of a run. We choose the management cost parameter $\alpha^{g}$ in order for the intervention to be around 5 percent of total capital.

Figure 15 shows the response of the economy to a recession when agents anticipate that, if a run happens, the monetary authority intervenes with large scale asset purchases according to (52). Even though in this experiment the run does not happen and the central bank accordingly does not intervene, the anticipation of the intervention in the event of a run significantly dampens the downturn. It does so by reducing the probability of a run: The central bank's conditional intervention policy increases the liquidation price of wholesale banks assets. In turn, by equation (47), the higher recovery rate associated with higher liquidation prices decreases the prob- 

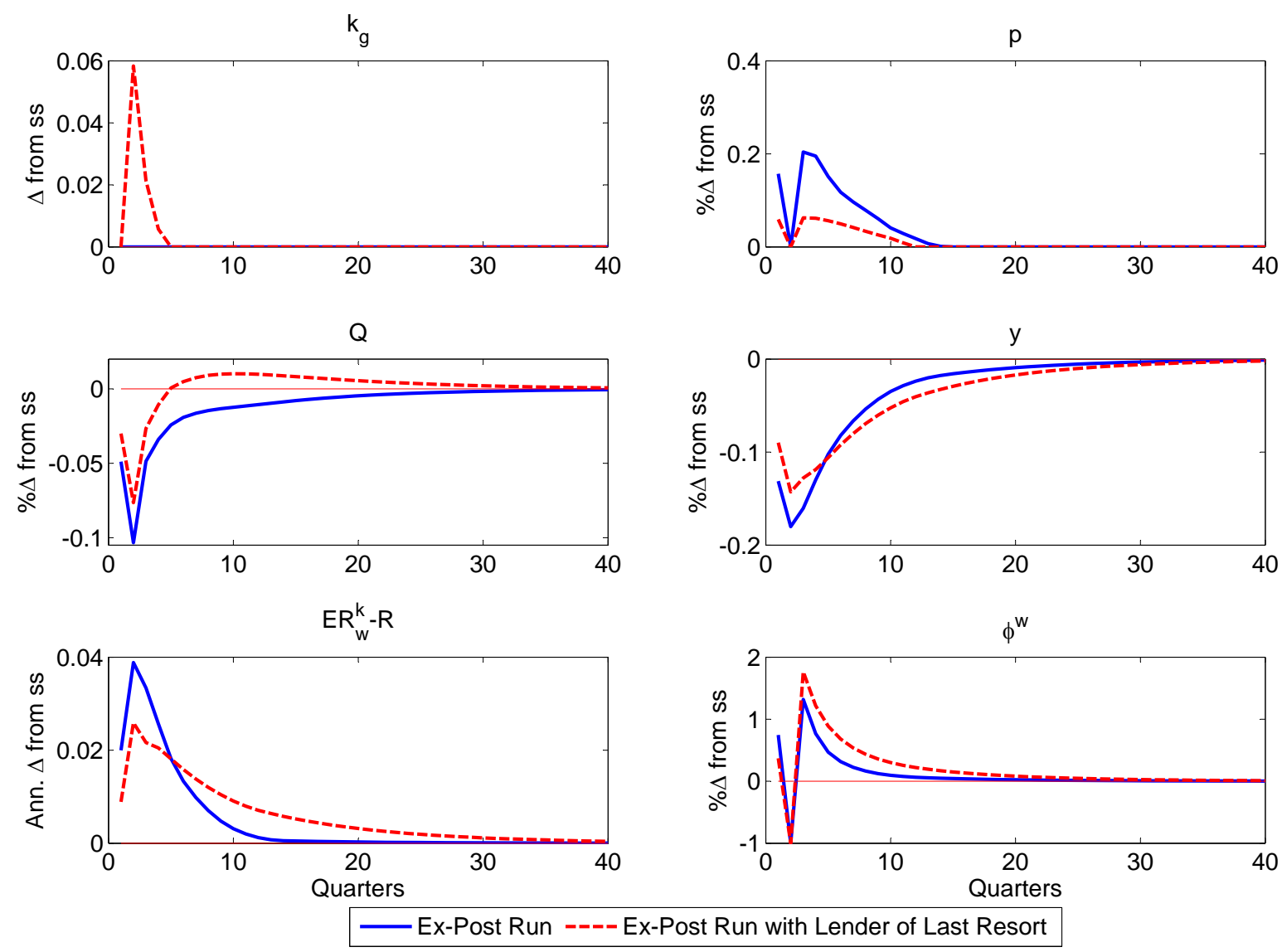

Figure 16: Government intervention when a Run happens at time 2

ability of a run. In the experiment the probability of a run decreases by 10 percent in the first two periods and becomes zero thereafter. This drastic reduction in the run probability implies that, overall, anticipation of government intervention works to stimulate the economy. Notice that, even though the reduction in the run probability relaxes the incentive constraint and hence allows wholesale bankers to increase their leverage for any given level of spreads, the general equilibrium effects of asset prices on their balance sheet results in better capitalization and lower leverage in both the wholesale and retail bank sectors.

Figure 16 illustrates the effect of the intervention when a run happens one period after the shock to $Z$. The intervention is around 5 percent of total capital and reduces the drop in asset prices and output by about 2.5 and 4 percent respectively. 


\subsection{Ex-Ante Intervention: Macroprudential Policy}

One of the most important challenges facing policy makers in the aftermath of the financial crisis is the development of financial regulations that can help prevent the recurrence of similar episodes in the future. In this respect, the most relevant innovation in the policy landscape has been the introduction of various macroprudential measures in the oversight of financial institutions, such as stress tests by central banks and the revised provisions in Basel III. These measures are aimed at ensuring that financial institutions' capital is sufficient to absorb losses during adverse economic conditions.

There is now a significant literature that analyzes the impact of capital requirements on banks for macroeconomic stability (e.g. Christiano and Ikeda (2015), Begenau (2015), Bianchi and Mendoza (2013), Chari and Kehoe (2015)), Gertler, Kiyotaki and Queralto (2012). Most of this literature analyzes how the introduction of leverage restrictions can dampen financial accelerator effects by dampening fluctuations in bank capital. The need for leverage restrictions, or equivalently capital requirements, stems from an externality that leads individual banks to fail to take into account their own borrowing on the stability as a whole. ${ }^{43}$

Our framework offers a somewhat different perspective on the potential benefits of leverage restrictions. Not only can these restrictions dampen financial accelerator effects: Importantly, they can also make the banking system less susceptible to runs. As equation (41) makes clear, a bank run can only happen if the leverage ratio is high enough. Thus, by limiting the leverage ratio sufficiently, the regulatory authority can in principle eliminate the possibility of a run. The question then is what are the tradeoffs. We turn to this issue next.

We capture macroprudential policies in our model economy by introducing leverage restrictions on wholesale banks. In particular, we assume that a financial regulator can impose an upper bound on wholesale banks' leverage, $\bar{\phi}^{w}$. This implies that the effective limit to wholesale banks' leverage will be given by the smaller between the market imposed limit and the regulatory limit. Accordingly, constraint (22) becomes

$$
\phi^{w} \leq \min \left\{\frac{\frac{1}{\theta} \frac{V_{t}^{w}}{n_{t}^{w}}-(1-\omega)}{\omega}, \bar{\phi}^{w}\right\}
$$

In a fully stochastic simulation of the economy, leverage restrictions would trade-

\footnotetext{
${ }^{43}$ Much of the literature, following Lorenzoni (2008), features a pecuniary externality stemming from the presence of asset prices in the borrowing constraint. Fahri and Werning (2015), and Korinek and Simsek (2015) show that if aggregate demand is sensitive to aggregate leverage, a similar kind of externality can emerge.
} 

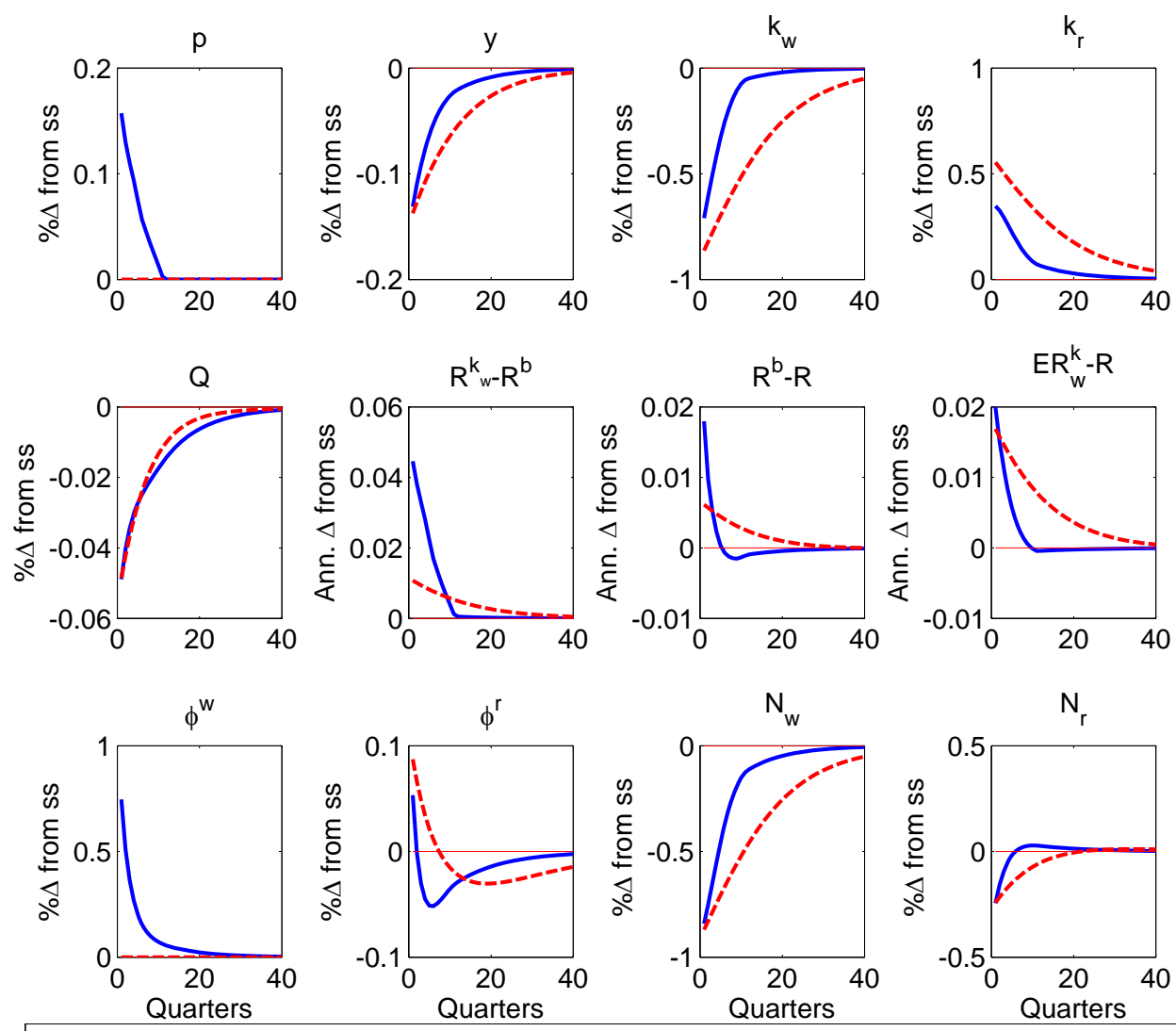

- Recession with Positive Run Probability

---- Recession with (tight) Leverage Restrictions

Figure 17: Macro Prudential Policy: $\phi^{w}=\phi^{s s}$

off lower frequency of crises, resulting from reduced variation of bankers' capital, against lower average output, as the impaired ability of wholesale banks to increase their leverage would induce a costly reallocation of capital to less efficient agents. While our numerical experiments in Sections 7 and 4.3 provide an illustration of the tradeoff between steady state output and fragility associated to changes in the long run level of wholesale bankers' leverage, here we focus on the conditional effects of leverage restrictions upon the occurrence of a recession that would leave the decentralized economy vulnerable to bank runs.

We focus on two possible levels for $\bar{\phi}^{w}$ : the steady state level of wholesale banks' leverage and a level that is higher than steady state but still sufficiently low to prevent a run. Permitting a leverage ratio above the steady state allows banks to issue more debt in a recession, which has the overall effect of dampening the contraction in 

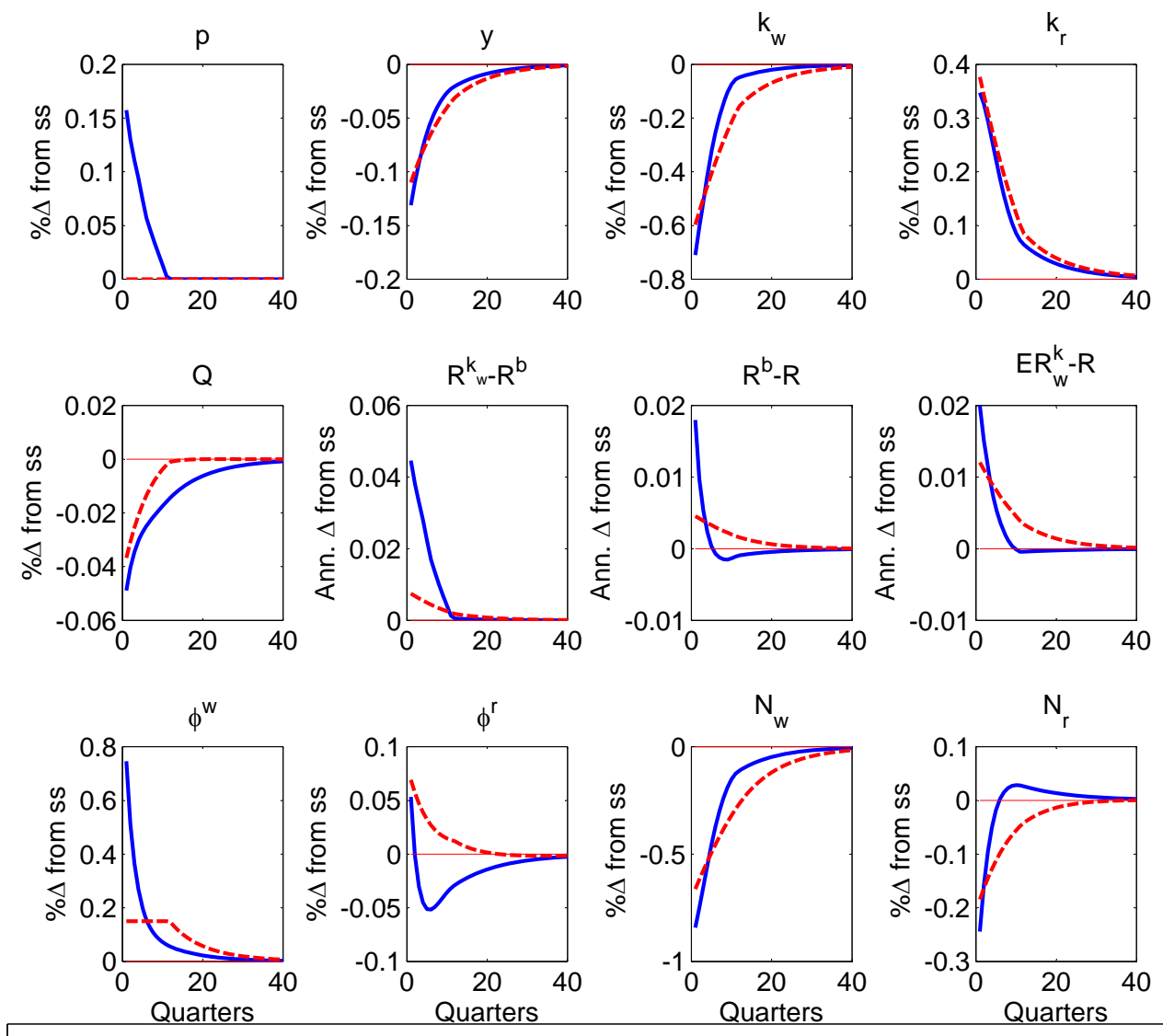

- Recession with Positive Run Probability ---- Recession with (slack) Leverage Restrictions

Figure 18: Macro Prudential Policy: $\phi^{w}=1.15 \phi^{s s}$

financial intermediation and thus dampening the downturn in real activity. Indeed, the more forgiving leverage restriction comes closer to mimicking the behavior of the leverage ratio in the decentralized economy, which moves countercylcially.

Figure 17 and 18 compare the response of the economy with anticipated runs to a negative $Z$ innovation, with and without macroprudential regulation. In Figure17 the regulator imposes the tighter leverage restriction, i.e. $\bar{\phi}^{w}$ is set to the steady state value of wholesale leverage, while in Figure 18 the restrictions are more lax and allow maximum regulatory leverage to exceed the steady state value by 15 percent. As mentioned, in both cases, the leverage restrictions are sufficient to prevent a run and hence avoid the recessionary effects associated to the endogenous increase in the probability of a run that characterizes the unregulated economy. This results in 
higher asset prices in the regulated economy throughout the recession. Under the less strict requirements the stimulative effect on asset prices is significantly higher, reaching about 1.5 percent after the first three years of the recession. On the other hand, by constraining the ability to leverage of the most efficient intermediaries, macroprudential policies induces a costly reallocation of assets. The balance between these two contrasting forces varies over time, in turn influencing output effects of the policy.

During the early stages of the recession, the stimulative effects of macroprudential policy are strongest because they eliminate the probability of a bank run, which in the unregulated economy is highest at this time. Under the stricter policy, the impact drop in output is very similar to the drop in the unregulated economy, while the more lax stance of policy dampens the drop in output by 2 percent and is stimulative throughout the first year of the recession. As time passes, the probability of a run becomes small in the unregulated economy, implying that the stimulative effects of policy decreases. On the other hand, the slower recovery of financial institutions' equity in the regulated economy that results from their impaired ability to leverage, implies a more persistent drag on output coming from financial misallocation. In both cases output costs associated with the policy peak at around 10 quarters into the recession and result in an additional drop in output of about 4 percent under the tighter requirements and 1.5 percent under the more lax stance.

\section{Summary and Directions for Future Research}

The financial crisis that triggered the Great Recession featured a disruption of wholesale funding markets, where banks lend to one another, as opposed to retail markets where banks obtain funds from depositors. It is essential to capture the roles and possible disruption of wholesale funding market to understand the financial crisis as well as to draw policy implications. Our goal in this Handbook Paper was to sketch a model based on the existing literature that provides a step toward accomplishing this objective. The model first accounts for how, through innovation in the efficiency of interbank loan markets, a wholesale banking sector emerges that intermediates loans using funds borrowed from retail banks. This wholesale sector bears a close resemblance to the shadow banking system featured in most descriptions of the crisis.

As we show, in "normal" times, the growth of the wholesale banking sector improves both efficiency and stability. Improved efficiency stems from the comparative advantage that wholesale banks having in managing certain types of loans. Improved stability arises because retail banks act as a buffer to absorb loans that wholesale banks sell off, in effect improving the liquidity of secondary loan markets. On the 
other hand, the growth of wholesale banking system makes the economy more vulnerable to a crisis. As occurred in practice, the high leverage of wholesale banks makes this sector susceptible to runs that can have highly disruptive effects on the economy. A contractionary disturbance that might otherwise lead to a moderate recession, can induce a run on the wholesale banking sector with devastating effects on the economy, as experienced during the Great Recession. We then describe how both lender of last resort and macroprudential policies can help reduce the likelihood of these kinds of banking crises.

Our framework also captures the buildup of safe assets prior to the crisis along with the subsequent collapse that a number of authors have emphasized (e.g. Gorton and Metrick (2012), Caballero and Farhi (2015)). The underlying mechanisms work a bit differently, in somewhat subtle ways: The "safe asset" literature points to an increased demand for safe assets as the driving force in the buildup of the shadow banking system. By making assets riskier, the crisis then reduces the ability of the shadow banking sector to create safe assets. It is this reduction in safe assets that then leads a contraction in spending, essentially for liquidity reasons. Within our framework, the increase in safe assets is a product of innovation in interbank lending markets. Indeed, this is where much of the growth in safe assets occurred. There is also a growth in households deposits as the overall banking system becomes more efficient. The crisis similarly induces a contraction in safe assets: The exact mechanism, though, is that, with an adverse shock to the net worth of banks, the probability of runs on wholesale banks becomes positive, which constrains the ability of both wholesale and retail banks to issue safe liabilities. In turn, a contraction in real activity emerges because the costs of intermediation increase, as manifested by the increase in credit spreads. In future work, it would be interesting to synthesize the role of safe assets in our framework with that in the conventional literature on this topic.

Another important area for further investigation involves the modeling of the growth of wholesale banking. Our approach was to treat this growth as the product of innovation as captured by a reduction in the agency friction in inter-bank lending markets. Among the factors we had in mind that motivate this reduction is technological improvements that permit less costly monitoring, such as the development of asset-backed securities and repo lending. Of course, more explicit modeling of this phenomenon would be desirable. Also important is integrating regulatory considerations. While financial innovation was important for the development of shadow banking, regulatory factors also played an important role. For example, tightening of capital requirements on commercial banks in conjunction with innovation in asset securitization induced movement of a considerable amount of mortgage lending 
from the retail to the wholesale banking sector. A careful integration of the roles of regulation and innovation in the development of wholesale banking would be highly desirable.

Finally, consistent with what occurred in the recent crisis, what makes the financial system within our model so vulnerable is high degree of leverage in the form of short term debt. Here we simply rule out a richer set of state-contingent financial contracts that would permit banks to hedge against the systemic risk implied by this liability structure. Why in practice we don't seem to observe the kind of seemingly desirable hedging is an important question for future research. ${ }^{44}$

\section{Appendix}

\subsection{Appendix A: Details of the Equilibrium}

From $(13,15,16,17)$, we get

$$
\begin{aligned}
\frac{V_{t}^{j}}{n_{t}^{j}} & =E_{t}\left(\Omega_{t+1}^{j} \cdot \frac{n_{t+1}^{j}}{n_{t}^{j}}\right) \\
& =E_{t}\left\{\Omega_{t+1}^{j}\left[R_{k t+1}^{j}+\left(R_{k t+1}^{j}-R_{t+1}\right) \frac{d_{t}^{j}}{n_{t}^{j}}+\left(R_{k t+1}^{j}-R_{b t+1}\right) \frac{b_{t}^{j}}{n_{t}^{j}}\right]\right\} \\
& =\nu_{k t}^{j}+\mu_{d t}^{j} \frac{d_{t}^{j}}{n_{t}^{j}}+\mu_{b t}^{j} \frac{b_{t}^{j}}{n_{t}^{j}},
\end{aligned}
$$

where

$$
\begin{aligned}
\nu_{k t}^{j} & =E_{t}\left(\Omega_{t+1}^{j} R_{k t+1}^{j}\right) \\
\mu_{d t}^{j} & =E_{t}\left[\Omega_{t+1}^{j}\left(R_{k t+1}^{j}-R_{t+1}\right)\right] \\
\mu_{b t}^{j} & =E_{t}\left[\Omega_{t+1}^{j}\left(R_{k t+1}^{j}-R_{b t+1}\right)\right] .
\end{aligned}
$$

From (13), the incentive constraint (14) can be written as

$$
V_{t}^{j} \geq \theta\left[n_{t}^{j}+d_{t}^{j}+\omega b_{t}^{j} \cdot I_{b_{t}^{j}>0}+(1-\gamma) b_{t}^{j} \cdot I_{b_{t}^{j}<0}\right],
$$

\footnotetext{
${ }^{44}$ Some efforts to address this issue include Krishnamurthy (2003), DiTella (2014), Gertler, Kiyotaki and Queralto (2012), and Dang, Gorton and Holmstorm (2012)).
} 
where $I_{b_{t}^{j}>0}=1$ if $b_{t}^{j}>0$ and $I_{b_{t}^{j}>0}=0$ otherwise, (and $I_{b_{t}^{j}<0}=1$ if $b_{t}^{j}<0$ and $I_{b_{t}^{j}<0}=0$ otherwise).

In order to save the notations, we normalize $n_{t}^{j}=1$ and suppress the suffix and time subscript. The generic choice of a bank is given by

$$
\psi=\underset{b, d}{\operatorname{Max}}\left(\nu_{k}+\mu_{d} d+\mu_{b} b\right)
$$

subject to

$$
\begin{aligned}
\theta\left[1+d+\omega b \cdot I_{b>0}+(1-\gamma) b \cdot I_{b<0}\right] \leq \nu_{k}+\mu_{d} d+\mu_{b} b, \\
d \geq 0 \\
1+d+b \geq 0 .
\end{aligned}
$$

Figure 20 and 21 depict the Feasible set and an Indifference Curve for Wholesale Bankers and Retail Bankers under our baseline.

Defining $\lambda$ and $\lambda_{k}$ as Lagrangian multipliers of the incentive constraint and the nonnegativity constraint of capital, we have the Lagrangian as

$\mathcal{L}=(1+\lambda)\left(\nu_{k}+\mu_{d} d+\mu_{b} b\right)-\lambda \theta\left[1+d+\omega b \cdot I_{b>0}+(1-\gamma) b \cdot I_{b<0}\right]+\lambda_{k}(1+d+b)$.

For the case of $b \geq 0$, we know $\lambda_{k}=0$ and the first order conditions are

$$
(1+\lambda) \mu_{b} \leq \lambda \theta \omega
$$

where $=$ holds if $b>0$, and $<$ implies $b=0$.

$$
(1+\lambda) \mu_{d} \leq \lambda \theta
$$

where $=$ holds if $d>0$, and $<$ implies $d=0$.

In the following we restrict the attention to the case of $\mu_{d}>0$, and will verify the inequality later. Thus for the case of $b>0$, we learn

$$
\begin{aligned}
& d>0, \text { if } \frac{\mu_{b}}{\mu_{d}}=\omega, \\
& d=0, \text { if } \frac{\mu_{b}}{\mu_{d}}>\omega .
\end{aligned}
$$

For the case of $b \leq 0$, the first order conditions are

$$
(1+\lambda) \mu_{b}+\lambda_{k} \geq \lambda \theta(1-\gamma)
$$




$$
\begin{aligned}
& \text { where }=\text { holds if } b<0 \text {, and }>\text { implies } b=0 . \\
& \qquad(1+\lambda) \mu_{d}+\lambda_{k} \leq \lambda \theta \\
& \text { where }=\text { holds if } d>0 \text {, and }<\text { implies } d=0 .
\end{aligned}
$$

Thus for the case of $b<0$ and $d>0$, we learn

$$
\begin{aligned}
& k>0, \text { if } \frac{\mu_{b}}{\mu_{d}}=1-\gamma \\
& k=0 \text { and } \lambda_{k}>0, \text { if } \frac{\mu_{b}}{\mu_{d}}<1-\gamma .
\end{aligned}
$$

Therefore, under (Assumption 2): $\omega+\gamma>1$, we can summarize the bank's choice as:

(i) $b>0, d=0, k>0$, if $\mu_{b}>\omega \mu_{d}$

(ii) $b>0, d>0, k>0$, implies $\mu_{b}=\omega \mu_{d}$

(iii) $b=0, d>0, k>0$, if $(1-\gamma) \mu_{d}<\mu_{b}<\omega \mu_{d}$

(iv) $b<0, d>0, k>0$, implies $\mu_{b}=(1-\gamma) \mu_{d}$

(v) $b<0, d>0, k=0$, if $\mu_{b}<(1-\gamma) \mu_{d}$.

In the steady state equilibrium, we know

$$
\frac{\mu_{b}}{\mu_{d}}=\frac{R_{k}-R_{b}}{R_{k}-R} .
$$

Because we know $R_{k}^{w} \geq R_{k}^{r}$ and $R_{b} \geq R$, we learn

$$
\frac{\mu_{b}^{w}}{\mu_{d}^{w}} \geq \frac{\mu_{b}^{r}}{\mu_{d}^{r}} .
$$

Therefore, market clearing for interbank loans implies that, if the interbank market is active wholesale bankers' choice can only be $(i)$ or $(i i)$ and retail banker's choice $(i v)$ or $(v)$. Otherwise both types must choose according to $(i i i)$ and the interbank market is inactive. That is, we have only the following possible patterns of equilibrium in the neighborhood of the steady state.

(A) Perfect Specialization with active Interbank Market: $d^{w}=0, k^{r}=0, b^{w}>$ $0>b^{r}$

(B) Perfect Specialized Retail Banks with active Interbank Market: $d^{w}>0, k^{r}=$ $0, b^{w}>0>b^{r}$ 
(C) Perfect Specialized Wholesale Banks with active Interbank Market: $d^{w}=$ $0, k^{r}>0, b^{w}>0>b^{r}$

(D) Imperfect Specialization with active Interbank Market: $d^{w}>0, k^{r}>0, b^{w}>$ $0>b^{r}$

(E) Inactive Interbank Market: $d^{w}>0, k^{r}>0, b^{w}=0=b^{r}$.

We can show that, under Assumption 2, there is no equilibrium of type (A) nor (B):

Proof) Equilibrium of type (A) and (B) require $\mu_{b}^{w} \geq \omega \mu_{d}^{w}$ and $(1-\gamma) \mu_{d}^{r} \geq \mu_{b}^{r}$. Thus

$$
\begin{aligned}
& R_{b} \leq \omega R+(1-\omega) R_{k}^{w}, \\
& R_{b} \geq(1-\gamma) R+\gamma R_{k}^{r}=(1-\gamma) R+\gamma R_{k}^{w}, \text { as } K^{r}=0 \text { in }(\mathrm{A}) \text { and }(\mathrm{B}) .
\end{aligned}
$$

This implies

$$
\omega R+(1-\omega) R_{k}^{w} \geq(1-\gamma) R+\gamma R_{k}^{w},
$$

or

$$
(\omega+\gamma-1) R \geq(\omega+\gamma-1) R_{k}^{w} .
$$

But this is a contradiction as $\omega+\gamma>1$ and $R_{k}^{w}>R$ (as $\mu_{d}^{w}>0$ under our conjecture ). Q.E.D.

\section{Equilibrium C and D: Active Interbank Market}

Suppose that $0<\mu_{b t}^{w}<\theta \omega$. We will verify this numerically after we characterize the equilibrium. Then the incentive constraint (58) holds with equality for wholesale banks. Together with Bellman equation (57), we have

$$
\begin{aligned}
\psi_{t}^{w} & =\nu_{k t}^{w}+\mu_{d t}^{w} d_{t}^{w}+\mu_{b t}^{w} b_{t}^{w} \\
& =\theta\left(1+d_{t}^{w}+\omega b_{t}^{w}\right)
\end{aligned}
$$

or

$$
\begin{aligned}
b_{t}^{w} & =\frac{1}{\theta \omega-\mu_{b t}^{w}}\left[\nu_{k t}^{w}-\theta-\left(\theta-\mu_{d t}^{w}\right) d_{t}^{w}\right] \\
\psi_{t}^{w} & =\frac{\theta}{\theta \omega-\mu_{b t}^{w}}\left[\omega \nu_{k t}^{w}-\mu_{b t}^{w}+\left(\omega \mu_{d t}^{w}-\mu_{b t}^{w}\right) d_{t}^{w}\right]
\end{aligned}
$$


Maximizing Tobin's Q, $\psi_{t}^{w}$, with respect to $d_{t}^{w} \geq 0$, we learn

$$
\begin{aligned}
& d_{t}^{w}=0, \text { if } \mu_{d t}^{w}<\frac{1}{\omega} \mu_{b t}^{w} \\
& d_{t}^{w}>0 \text { implies } \mu_{d t}^{w}=\frac{1}{\omega} \mu_{b t}^{w} .
\end{aligned}
$$

This provers Lemma 1 and the argument in the text follows for wholesale banks, noting that we normalize $n_{t}^{w}=1$ above.

Suppose also that $0<\mu_{d t}^{r}<\theta$. We will verify this numerically after we characterize the equilibrium. Then the incentive constraint (58) holds with equality for retail banks. Together with Bellman equation (57), we have

$$
\begin{aligned}
\psi_{t}^{r} & =\nu_{k t}^{r}+\mu_{d t}^{r} d_{t}^{r}+\mu_{b t}^{r} b_{t}^{r} \\
& =\theta\left[1+d_{t}^{r}+(1-\gamma) b_{t}^{r}\right] .
\end{aligned}
$$

Then we get

$$
\begin{aligned}
d_{t}^{r} & =\frac{1}{\theta-\mu_{d t}^{r}}\left\{\nu_{k t}^{r}-\theta+\left[\theta(1-\gamma)-\mu_{b t}^{r}\right]\left(-b_{t}^{r}\right)\right\}, \\
\psi_{t}^{r} & =\frac{\theta}{\theta-\mu_{d t}^{r}}\left[\nu_{k t}^{r}-\mu_{d t}^{r}+\left(\mu_{d t}^{r}-\mu_{b t}^{r}-\gamma \mu_{d t}^{r}\right)\left(-b_{t}^{r}\right)\right] .
\end{aligned}
$$

Maximizing Tobin's $\mathrm{Q}, \psi_{t}^{r}$, with respect to $k_{t}^{r} \geq 0$ and $b_{t}^{r} \leq 0$, we learn

$$
\begin{aligned}
& k_{t}^{r}>0 \text { and } b_{t}^{r}<0 \text { imply } \mu_{d t}^{r}-\mu_{b t}^{r}=\gamma \mu_{d t}^{r} \\
& k_{t}^{r}=0 \text { and } b_{t}^{r}<0 \text { if } \mu_{d t}^{r}-\mu_{b t}^{r}>\gamma \mu_{d t}^{r} .
\end{aligned}
$$

This proves Lemma 2 and the argument in the text follows for retail banks, noting that we normalize $n_{t}^{r}=1$ above.

Therefore the argument in the text follows for the aggregate equilibrium.

Equilibrium E: No Active Interbank Market $b_{t}^{w}=b_{t}^{r}=0$

From from Bellman equation and the incentive constraint of each bank $(57,58)$ with $\left(Q_{t}+f_{t}^{j} k_{t}^{j}\right) k_{t}^{j}=1+d_{t}^{j}$, we have

$$
\psi_{t}^{j}=\theta\left(Q_{t}+f_{t}^{j} k_{t}^{j}\right) k_{t}^{j}=\nu_{k t}^{j}-\mu_{d t}^{j}+\mu_{d t}^{j}\left(Q_{t}+f_{t}^{j} k_{t}^{j}\right) k_{t}^{j},
$$

or

$$
\begin{aligned}
\left(Q_{t}+f_{t}^{j} k_{t}^{j}\right) k_{t}^{j} & =\frac{\nu_{k t}^{j}-\mu_{d t}^{j}}{\theta-\mu_{d t}^{j}}, \\
\psi_{t}^{j} & =\theta \frac{\nu_{k t}^{j}-\mu_{d t}^{j}}{\theta-\mu_{d t}^{j}}
\end{aligned}
$$


The aggregate balance sheet conditions of wholesale and retail banking sectors are

$$
\begin{gathered}
Q_{t} K_{t}^{w}=\frac{\nu_{k t}^{w}-\mu_{d t}^{w}}{\theta-\mu_{d t}^{w}} N_{t}^{w}=N_{t}^{w}+D_{t}^{w} \\
\left(Q_{t}+f_{t}^{r} K_{t}^{r}\right) K_{t}^{r}=\frac{\nu_{k t}^{r}-\mu_{d t}^{r}}{\theta-\mu_{d t}^{r}} N_{t}^{r}=N_{t}^{r}+D_{t}^{r} .
\end{gathered}
$$

The recursive competitive equilibrium without bank runs consists of 24 variables aggregate quantities $\left(K_{t}^{w}, K_{t}^{r}, K_{t}^{h}, D_{t}^{w}, D_{t}^{r}, N_{t}^{w}, N_{t}^{r}, C_{t}^{b}, C_{t}^{h}, \bar{Y}_{t}, Y_{t}\right)$, prices $\left(Q_{t}, R_{t+1}, f_{t}^{r}\right)$

and bankers' franchise values and leverage multiples $\left(\Omega_{t}^{j}, R_{k t}^{j}, \nu_{k t}^{j}, \mu_{d t}^{j}, \psi_{t}^{j}\right)_{j=w, r}$ as a function of the state variables $\left(K_{t-1}^{w}, K_{t-1}^{r}, R_{t} D_{t-1}^{w}, R_{t} D_{t-1}^{r}, Z_{t}\right)$, which satisfy 24 equations $(1,4,7,8,16,18,34-39,54,55,59-61)$ where each of $(16,18,54,55,59-$ 61) contain two equations.

After finding the equilibrium, we need to check the inequalities

$$
\begin{aligned}
& \mu_{b t}^{w}<\omega \mu_{d t}^{w}, \\
& \mu_{b t}^{r}>(1-\gamma) \mu_{d t}^{r} .
\end{aligned}
$$

In the neighborhood of the steady state, it is sufficient to show

$$
(1-\omega) E_{t}\left(\frac{Q_{t+1}+Z_{t+1}}{Q_{t}}\right)+\omega R_{t+1}<\gamma E_{t}\left(\frac{Q_{t+1}+Z_{t+1}}{Q_{t}+\alpha^{r} K_{t}^{r}}\right)+(1-\gamma) R_{t+1} .
$$

\subsection{Appendix B: Steady State of the Economy without Run}

In order to characterize the steady state of $(\mathrm{C}, \mathrm{D}, \mathrm{E})$, define $x^{j}$ as the growth rate of the net worth of continuing bank $j$ in the steady state:

$$
\begin{aligned}
x^{j} & =\frac{n_{t+1}^{j}}{n_{t}^{j}}=R_{k}^{j} \frac{\left(Q+f^{j}\right) k^{j}}{n^{j}}-R_{b} \frac{b^{j}}{n^{j}}-R \frac{d^{j}}{n^{j}} \\
& =\left(R_{k}^{j}-R_{b}\right) \frac{b^{j}}{n^{j}}+\left(R_{k}^{j}-R\right) \frac{d^{j}}{n^{j}}+R_{k}^{j} .
\end{aligned}
$$

Then we have the aggregate net worth of bank $j$ as

$$
\begin{aligned}
N^{j} & =\sigma^{j} x^{j} N^{j}+W^{j} \\
& =\frac{W^{j}}{1-\sigma^{j} x^{j}} \equiv N^{j}\left(x^{j}\right),
\end{aligned}
$$


if $\sigma^{j} x^{j}<1$, which we guess and verify later. Tobin's $\mathrm{Q}$ of bank $j$ is

$$
\begin{aligned}
\psi^{j} & =\beta\left(1-\sigma^{j}+\sigma^{j} \psi^{j}\right) x^{j} \\
& =\frac{\beta\left(1-\sigma^{j}\right) x^{j}}{1-\beta \sigma^{j} x^{j}} \equiv \psi^{j}\left(x^{j}\right) .
\end{aligned}
$$

The ratio of bank loans to net worth is

$$
\begin{aligned}
\frac{Q k^{w}}{n^{w}} & =\frac{\psi^{w}\left(x^{w}\right)}{\theta \omega}-\frac{1-\omega}{\omega}\left(1+\frac{d^{w}}{n^{w}}\right), \text { if } b^{w}>0, \\
\frac{Q k^{w}}{n^{w}} & =\frac{\psi^{w}\left(x^{w}\right)}{\theta}, \text { if } b^{w}=0, \\
\frac{\left(Q+f^{r}\right) k^{r}}{n^{r}} & =\frac{\psi^{r}\left(x^{r}\right)}{\theta}-\gamma\left(-\frac{b^{r}}{n^{r}}\right) .
\end{aligned}
$$

\section{Case of Active Interbank Market: C and D}

From the condition for the retail banks, we have

$$
1-\gamma=\frac{\mu_{b}^{r}}{\mu_{d}^{r}}=\frac{R_{k}^{r}-R_{b}}{R_{k}^{r}-R},
$$

or

$$
\begin{gathered}
R_{b}=\gamma R_{k}^{r}+(1-\gamma) R . \\
x^{r}-R=\left(R_{k}^{r}-R_{b}\right) \frac{b^{r}}{n^{r}}+\left(R_{k}^{r}-R\right)\left(1+\frac{d^{r}}{n^{r}}\right) \\
=\left(R_{k}^{r}-R\right)\left[1+\frac{d^{r}}{n^{r}}+(1-\gamma) \frac{b^{r}}{n^{r}}\right] \\
=\left(R_{k}^{r}-R\right)\left[\frac{\left(Q+f^{r}\right) k^{r}}{n^{r}}+\gamma\left(-\frac{b^{r}}{n^{r}}\right)\right] \\
=\left(R_{k}^{r}-R\right) \frac{\psi^{r}\left(x^{r}\right)}{\theta} .
\end{gathered}
$$

Thus from $R=\beta^{-1}$,

$$
\begin{aligned}
& \beta\left(R_{k}^{r}-R\right)=\theta \frac{\beta x^{r}-1}{\psi^{r}\left(x^{r}\right)}=\theta \frac{\left(\beta x^{r}-1\right)\left(1-\sigma^{r} \beta x^{r}\right)}{\left(1-\sigma^{r}\right) \beta x^{r}} \equiv \varphi^{r}\left(\beta x^{r}\right), \\
& \beta\left(R_{b}-R\right)=\gamma \theta \frac{\beta x^{r}-1}{\psi^{r}\left(x^{r}\right)}=\gamma \varphi^{r}\left(\beta x^{r}\right) .
\end{aligned}
$$


Thus $R_{k}^{r}$ and $R_{b}$ are functions of only $x^{r}$ :

$$
R_{k}^{r}=R_{k}^{r}\left(x^{r}\right), R_{b}=R_{b}\left(x^{r}\right) .
$$

Differentiating log of the right hand side (RHS) of the above equation with respect to $x^{r}$, we learn

$$
\begin{aligned}
\frac{d \ln \varphi^{r}\left(\beta x^{r}\right)}{d\left(\beta x^{r}\right)} & =\frac{1}{\beta x^{r}-1}-\frac{\sigma^{r}}{1-\beta \sigma^{r} x^{r}}-\frac{1}{\beta x^{r}} \\
& \propto 1-\sigma^{r}\left(\beta x^{r}\right)^{2} \\
& >0, \text { iff } \sigma^{r}\left(\beta x^{r}\right)^{2}<1 .
\end{aligned}
$$

Thus if $\sigma^{r}\left(\beta x^{r}\right)^{2}<1, R_{k}^{r}$ and $R_{b}$ are increasing functions of only $x^{r}$ :

$$
\begin{array}{cl}
R_{k}^{r} & =R_{k}^{r}\left(x^{r}\right), R_{k}^{r \prime}(\cdot)>0, \\
R_{b} & =R_{b}\left(x^{r}\right), R_{b}^{\prime}(\cdot)>0 .
\end{array}
$$

Similarly

$$
\begin{aligned}
x^{w}-R_{b} & =\left(R_{k}^{w}-R_{b}\right)\left(1+\frac{b^{w}}{n^{w}}\right)+\left(R_{k}^{w}-R\right) \frac{d^{w}}{n^{w}} \\
& =\left(R_{k}^{w}-R_{b}\right)\left(1+\frac{b^{w}}{n^{w}}\right)+\frac{1}{\omega}\left(R_{k}^{w}-R_{b}\right) \frac{d^{w}}{n^{w}} \\
& =\left(R_{k}^{w}-R_{b}\right)\left(\frac{Q k^{w}}{n^{w}}+\frac{1-\omega}{\omega} \frac{d^{w}}{n^{w}}\right) \\
& =\left(R_{k}^{w}-R_{b}\right)\left(\frac{1}{\omega \theta} \psi^{w}-\frac{1-\omega}{\omega}\right) .
\end{aligned}
$$

Thus

$$
\begin{aligned}
R_{k}^{w}-R_{b} & =\omega \theta \frac{x^{w}-R_{b}}{\psi^{w}-\theta(1-\omega)} \\
R_{k}^{w}-R & =\frac{1}{\psi^{w}-\theta(1-\omega)}\left[\omega \theta\left(x^{w}-R\right)+\left(\psi^{w}-\theta\right)\left(R_{b}-R\right)\right] .
\end{aligned}
$$

Because

$$
\begin{aligned}
& \frac{d}{d x^{w}} \ln \left[\frac{\omega \theta\left(x^{w}-R\right)}{\psi^{w}-\theta(1-\omega)}\right] \\
& \propto \frac{1}{\beta x^{w}-1}-\frac{\sigma^{w}}{1-\sigma^{w} \beta x^{w}}-\frac{\Delta}{\Delta \beta x^{w}-\theta(1-\omega)}, \text { where } \Delta=1-\sigma^{w}+\theta(1-\omega) \sigma^{w} \\
& \propto\left(1-\sigma^{w}\right)\left[1-\sigma^{w}\left(\beta x^{w}\right)^{2}\right]-\theta(1-\omega)\left(1-\sigma^{w} \beta x^{w}\right)^{2},
\end{aligned}
$$


$R_{k}^{w}$ is an increasing function of $x^{w}$ and $x^{r}$

$$
R_{k}^{w}=R_{k}^{w}\left(x^{w}, x^{r}\right),
$$

if

$$
\begin{aligned}
\left(1-\sigma^{w}\right)\left[1-\sigma^{w}\left(\beta x^{w}\right)^{2}\right] & >\theta(1-\omega)\left(1-\sigma^{w} \beta x^{w}\right)^{2}, \\
\sigma^{r}\left(\beta x^{r}\right)^{2} & <1 .
\end{aligned}
$$

In the following we assume these conditions to be satisfied.

In the steady state, we know the rates of returns on capital for wholesale and retail banks and households are

$$
\begin{aligned}
R_{k}^{w} & =\frac{Z+Q}{Q} \\
R_{k}^{r} & =\frac{Z+Q}{Q+\alpha^{r} K^{r}} \\
R_{k}^{h} & =\frac{Z+Q}{Q+\alpha^{h} K^{h}}=R .
\end{aligned}
$$

Thus we have

$$
\begin{aligned}
Q & =\frac{Z}{R_{k}^{w}-1}, \\
\alpha^{r} K^{r} & =\frac{Z-\left(R_{k}^{r}-1\right) Q}{R_{k}^{r}}=Z \frac{R_{k}^{w}-R_{k}^{r}}{R_{k}^{r}\left(R_{k}^{w}-1\right)}, \\
\alpha^{h} K^{h} & =\frac{Z-(R-1) Q}{R}=Z \frac{R_{k}^{w}-R}{R\left(R_{k}^{w}-1\right)},
\end{aligned}
$$

and $Q, K^{r}$ and $K^{w}$ are functions of $\left(x^{w}, x^{r}\right)$.

Equilibrium C: $D^{w}=0$

Here, the market clearing condition of capital is given by

$$
\begin{aligned}
Q K^{w} & =\frac{Q k^{w}}{n^{w}} N^{w} \\
& =\frac{\psi^{w}\left(x^{w}\right)-\theta(1-\omega)}{\theta \omega} N^{w}\left(x^{w}\right) \\
& =Q\left(x^{w}, x^{r}\right)\left[\bar{K}-K^{r}\left(x^{w}, x^{r}\right)-K^{h}\left(x^{w}, x^{r}\right)\right]
\end{aligned}
$$


The market clearing condition of interbank credit is given by

$$
\begin{aligned}
B & =\left(\frac{Q k^{w}}{n^{w}}-1\right) N^{w} \\
& =\frac{\psi^{w}\left(x^{w}\right)-\theta}{\theta \omega} N^{w}\left(x^{w}\right) \\
& =\frac{1}{\gamma}\left\{\frac{\psi^{r}\left(x^{r}\right)}{\theta} N^{r}\left(x^{r}\right)-\left[Q\left(x^{w}, x^{r}\right)+\alpha^{r} K^{r}\left(x^{w}, x^{r}\right)\right] \cdot K^{r}\left(x^{w}, x^{r}\right)\right\}
\end{aligned}
$$

The equilibrium value of $\left(x^{w}, x^{r}\right)$ is given by $\left(x^{w}, x^{r}\right)$ which satisfies $(63,64)$ simultaneously.

In order to verify $\mu_{d}^{w}>0$ and $\mu_{d}^{r}>0$, it is sufficient to check the inequalities

$$
x^{w}>x^{r}>R=\beta^{-1} \text {. }
$$

For the other inequality $\mu_{b}^{w}>\omega \mu_{d}^{w}$, it is sufficient to check

$$
R_{k}^{w}-R_{b}>\omega\left(R_{k}^{w}-R\right)
$$

or

$$
(1-\omega)\left(R_{k}^{w}-R\right)>R_{b}-R .
$$

This is equivalent with

$$
(1-\omega) \frac{\beta x^{w}-1}{\psi^{w}\left(x^{w}\right)}>\gamma \frac{\beta x^{r}-1}{\psi^{r}\left(x^{r}\right)} .
$$

Equilibrium D: $D^{w}>0$

For this type of equilibrium, we need $\mu_{k b}^{w}=\omega \mu_{d}^{w}$, or

$$
R_{k}^{w}-R_{b}=\omega\left(R_{k}^{w}-R\right) .
$$

Thus

$$
\begin{aligned}
x^{w}-R & =\left(R_{k}^{w}-R\right)\left(1+\frac{d^{w}}{n^{w}}+\omega \frac{b^{w}}{n^{w}}\right) \\
& =\left(R_{k}^{w}-R\right) \frac{\psi^{w}}{\theta},
\end{aligned}
$$


Thus being similar to the expression for $\beta\left(R_{k}^{r}-R\right)$, we get

$$
\beta\left(R_{k}^{w}-R\right)=\theta \frac{\beta x^{w}-1}{\psi^{w}\left(x^{w}\right)}=\theta \frac{\left(\beta x^{w}-1\right)\left(1-\sigma^{w} \beta x^{w}\right)}{\left(1-\sigma^{w}\right) \beta x^{w}} \equiv \varphi^{w}\left(\beta x^{w}\right) .
$$

$R_{k}^{w}$ is an increasing function of $x^{w}$ if $\sigma^{w}\left(\beta x^{w}\right)^{2}<1$.

Also we learn

$$
R_{b}-R=(1-\omega)\left(R_{k}^{w}-R\right)=\gamma\left(R_{k}^{r}-R\right)
$$

or

$$
(1-\omega) \varphi^{w}\left(\beta x^{w}\right)=\gamma \varphi^{r}\left(\beta x^{r}\right),
$$

and thus $x^{r}$ is an increasing function of $x^{w}$. We can solve $Q$ and $K^{h}$ as functions of $x^{w}$ as

$$
\begin{aligned}
Q & =\frac{Z}{R_{k}^{w}-1} \\
& =\frac{\beta Z}{\varphi^{w}\left(\beta x^{w}\right)+1-\beta} \equiv Q\left(x^{w}\right), \\
K^{h} & =\frac{1}{\alpha^{h}}[\beta Z-(1-\beta) Q] \\
& =\frac{1}{\alpha^{h}} \frac{\beta Z \varphi^{w}\left(\beta x^{w}\right)}{\varphi^{w}\left(\beta x^{w}\right)+1-\beta} \equiv K^{h}\left(x^{w}\right) .
\end{aligned}
$$

We also get

$$
\begin{aligned}
K^{r} & =\frac{1}{\alpha^{r}} \frac{Z-\left(R_{k}^{r}-1\right) Q}{R_{k}^{r}}=\frac{Z}{\alpha^{r}} \frac{R_{k}^{w}-R_{k}^{r}}{R_{k}^{r}\left(R_{k}^{w}-1\right)} \\
& =\frac{1}{\alpha^{r}} \frac{\beta Z \varphi^{w}\left(\beta x^{w}\right)}{\varphi^{w}\left(\beta x^{w}\right)+1-\beta} \frac{\gamma+\omega-1}{\gamma+(1-\omega) \varphi^{w}\left(\beta x^{w}\right)} \\
& =\frac{\gamma+\omega-1}{\gamma+(1-\omega) \varphi^{w}\left(\beta x^{w}\right)} \frac{\alpha^{h}}{\alpha^{r}} K^{h} \equiv K^{r}\left(x^{w}\right)
\end{aligned}
$$


The capital market equilibrium is given by

$$
\begin{aligned}
Q K^{w} & =\frac{1}{\theta \omega} \psi^{w} N^{w}-\frac{1-\omega}{\omega}\left(N^{w}+D^{w}\right) \\
& =\frac{1}{\theta \omega} \psi^{w} N^{w}-\frac{1-\omega}{\omega}\left(Q K^{w}-B\right) \\
& =\frac{1}{\theta} \psi^{w} N^{w}+(1-\omega) B \\
& =\frac{1}{\theta} \psi^{w} N^{w}+\frac{1-\omega}{\gamma}\left[\frac{\psi^{r}}{\theta} N^{r}-\left(Q+\alpha^{r} K^{r}\right) K^{r}\right] \\
& =Q\left(\bar{K}-K^{h}-K^{r}\right) .
\end{aligned}
$$

Thus

$$
\begin{aligned}
& \frac{\psi^{w}}{\theta} N^{w}+\frac{1-\omega}{\gamma} \frac{\psi^{r}}{\theta} N^{r} \\
& =\frac{\psi^{w}}{\theta}\left[N^{w}+\frac{\beta x^{r}-1}{\beta x^{w}-1} N^{r}\right],(\because(66)) \\
& =Q\left[\bar{K}-K^{h}-K^{r}+\frac{1-\omega}{\gamma} \frac{Q+\alpha^{r} K^{r}}{Q} K^{r}\right] \\
& =Q\left[\bar{K}-K^{h}-K^{r}+\frac{1-\omega}{\gamma} \frac{R_{k}^{w}}{R_{k}^{r}} K^{r}\right] \\
& =Q\left[\bar{K}-K^{h}-\frac{\gamma+\omega-1}{\gamma+(1-\omega) \varphi^{w}\left(\beta x^{w}\right)} K^{r}\right],
\end{aligned}
$$

or

$$
\begin{aligned}
& \frac{\psi^{w}\left(x^{w}\right)}{\theta}\left[N^{w}\left(x^{w}\right)+\frac{\beta x^{r}-1}{\beta x^{w}-1} N^{r}\left(x^{r}\right)\right] \\
& =Q\left(x^{w}\right)\left[\bar{K}-K^{h}\left(x^{w}\right)-\frac{\gamma+\omega-1}{\gamma+(1-\omega) \varphi^{w}\left(\beta x^{w}\right)} K^{r}\left(x^{w}\right)\right] .
\end{aligned}
$$

The equilibrium is given by $\left(x^{r}, x^{w}\right)$ which satisfies $(66,67)$.

We need to check $D^{w}>0$, or

$$
0<\left(\frac{\psi^{w}}{\theta \omega}-\frac{1-\omega}{\omega}\right) N^{w}-\frac{1}{\theta} \psi^{w} N^{w}-\frac{1-\omega}{\gamma}\left[\frac{\psi^{r}}{\theta} N^{r}-\left(Q+\alpha^{r} K^{r}\right) K^{r}\right],
$$

or

$$
\gamma\left[\frac{\psi^{w}\left(x^{w}\right)}{\theta}-1\right] N^{w}\left(x^{w}\right)>\omega\left[\frac{\psi^{r}\left(x^{r}\right)}{\theta} N^{r}\left(x^{r}\right)-\left[Q\left(x^{w}\right)+\alpha^{r} K^{r}\left(x^{w}\right)\right] \cdot K^{r}\left(x^{w}\right)\right] .
$$




\section{Equilibrium E: No Active Interbank Market}

We have for $j=w, r$ that

or

$$
\begin{gathered}
\frac{\left(Q+f^{j}\right) k^{j}}{n^{j}}=\frac{\psi^{j}\left(x^{j}\right)}{\theta} \\
x^{j}-R=\left(R_{k}^{j}-R\right) \frac{\left(Q+f^{j}\right) k^{j}}{n^{j}}=\left(R_{k}^{j}-R\right) \frac{\psi^{j}\left(x^{j}\right)}{\theta},
\end{gathered}
$$

or

$$
R_{k}^{j}-R=\theta \frac{x^{j}-R}{\psi^{j}\left(x^{j}\right)}
$$

$$
R_{k}^{j}=R_{k}^{j}\left(x^{j}\right), R_{k}^{j \prime}(\cdot)>0
$$

if $\sigma^{w}\left(\beta x^{j}\right)^{2}<1$. Thus

$$
\begin{aligned}
Q & =Q\left(x^{w}\right), Q^{\prime}(\cdot)<0 \\
K^{h} & =K^{h}\left(x^{w}\right), K^{h \prime}(\cdot)>0 .
\end{aligned}
$$

The aggregate capital of retail banks satisfies

$$
\begin{aligned}
Q K^{r} & =Q \frac{Z-\left(R_{k}^{r}-1\right) Q}{\alpha^{r} R_{k}^{r}}=Q\left(x^{w}\right) \frac{Z}{\alpha^{r}} \frac{R_{k}^{w}\left(x^{w}\right)-R_{k}^{r}\left(x^{r}\right)}{R_{k}^{r}\left(x^{r}\right)\left[R_{k}^{w}\left(x^{w}\right)-1\right]} \\
& =\frac{\psi^{r}\left(x^{r}\right)}{\theta} N^{r}\left(x^{r}\right)
\end{aligned}
$$

The capital market clearing condition is

$$
\begin{aligned}
Q K^{w} & =\frac{\psi^{w}\left(x^{w}\right)}{\theta} N^{w}\left(x^{w}\right) \\
& =Q\left(x^{w}\right)\left[\bar{K}-K^{r}\left(x^{r}, x^{w}\right)-K^{h}\left(x^{w}\right)\right]
\end{aligned}
$$

The equilibrium is given by $\left(x^{r}, x^{w}\right)$ which satisfies $(68,69)$.

\subsubsection{Appendix C: Anticipated Bank Run Case}

Here we describe the conditions determining agents policy functions in the case of anticipated runs. As in the text, we focus on the case in which variation in $Z_{t+1}$ is negligible. Moreover, we follow the notation by which for any given variable $\tilde{\xi}_{t}$

$$
E_{t}^{*}\left(\widetilde{\xi}_{t+1}\right)=\left(1-p_{t}\right) \xi_{t+1}+p_{t} \xi_{t+1}^{*}
$$

where $\xi_{t+1}^{*}$ is the value taken by $\tilde{\xi}_{t+1}$ when a run occurs. 


\subsubsection{Households}

Households optimal choices of capital holdings and deposits are given by

$$
\begin{aligned}
& E_{t}^{*}\left(\tilde{\Lambda}_{t, t+1}\right) R_{t+1}=1 \\
& E_{t}^{*}\left(\tilde{\Lambda}_{t, t+1} \tilde{R}_{k t+1}^{h}\right)=1
\end{aligned}
$$

\subsubsection{Retail Bankers}

The conditions in Lemma 2 that guarantee that retail banks are constrained are now modified as follows:

Lemma $3 b_{t}^{r}<0, k_{t}^{r}>0$ and the incentive constraint is binding iff

$$
0<E_{t}^{*}\left[\tilde{\Omega}_{t+1}^{r}\left(\tilde{R}_{k t+1}^{r}-R_{t+1}\right)\right]=\frac{1}{\gamma} E_{t}^{*}\left[\tilde{\Omega}_{t+1}^{r}\left(\tilde{R}_{b t+1}-R_{t+1}\right)\right]<\theta .
$$

The optimal choice of leverage is

$$
\phi_{t}^{r}=\frac{E_{t}^{*}\left(\tilde{\Omega}_{t+1}^{r}\right) R_{t+1}}{\theta-E_{t}^{*}\left[\tilde{\Omega}_{t+1}^{r}\left(\tilde{R}_{k t+1}^{r}-R_{t+1}\right)\right]} .
$$

\subsubsection{Wholesale Bankers}

The optimization problem of wholesale banks when bank runs are anticipated is complicated by the fact that the banker can avoid bankruptcy by reducing its leverage in case a run materializes. Here we derive conditions under which he does not wish to do this. For simplicity, we focus on the problem of a wholesale banker that only funds himself in the interbank market.

In this case we can derive a threshold level for leverage, $\phi_{t}^{w M}$, under which the banker will survive a bank run, which is given by

$$
\bar{R}_{b t+1}=R_{f, t+1} \equiv \frac{E_{t}^{*}\left(\tilde{\Omega}_{t+1}^{r} \tilde{R}_{\gamma, t+1}^{r}\right)}{E_{t}^{*}\left(\tilde{\Omega}_{t+1}\right)}=R_{k t+1}^{w *} \frac{\phi_{t}^{w M}}{\phi_{t}^{w M}-1}
$$

where

$$
\tilde{R}_{\gamma, t+1}^{r} \equiv \gamma \tilde{R}_{k t+1}^{r}+(1-\gamma) R_{t+1}
$$

and $R_{f, t+1}$ is the risk free interbank rate that satisfies equation (44) with $x_{t+1}^{w}=1$. 
The objective function of wholesale bankers displays a kink at $\phi_{t}^{w M}$, so that in order to derive their optimal leverage choice we need to study separately the optimal choice in the region where leverage is high enough to induce bankruptcy when a run happens, $\left[\phi_{t}^{w M}, \infty\right)$, and in the region where bankruptcy is avoided even if a run happens, $\left[0, \phi_{t}^{w M}\right]$. As long as wholesale bankers objective is strictly increasing in leverage in both of these regions, the incentive constraint holds with equality.

In the bankruptcy region, $\left[\phi_{t}^{w M}, \infty\right)$, (45) with deterministic $Z_{t+1}$ is simplified to

$$
\bar{R}_{b t+1}\left(\phi_{t}^{w}\right)=R_{\gamma, t+1}^{r}+\frac{p_{t}}{1-p_{t}} \frac{\Omega_{t+1}^{r *}}{\Omega_{t+1}^{r}}\left(R_{\gamma, t+1}^{r *}-\frac{\phi_{t}^{w}}{\phi_{t}^{w}-1} R_{t+1}^{w *}\right) .
$$

Then the objective function of a wholesale bank with one unit of networth is given by

$$
\begin{aligned}
\psi^{w}\left(\phi_{t}^{w}\right) & =\left(1-p_{t}\right)\left\{\Omega_{t+1}^{w}\left[\phi_{t}^{w}\left(R_{k t+1}^{w}-\bar{R}_{b t+1}\left(\phi_{t}^{w}\right)\right)+\bar{R}_{b t+1}\left(\phi_{t}^{w}\right)\right]\right\} \\
& =\left(1-p_{t}\right) \Omega_{t+1}^{w}\left[\phi_{t}^{w}\left(R_{t+1}^{w}-R_{\gamma, t+1}^{r}\right)+R_{\gamma, t+1}^{r}\right] \\
& +p_{t} \Omega_{t+1}^{w} \frac{\Omega_{t+1}^{r *}}{\Omega_{t+1}^{r}}\left[\phi_{t}^{w}\left(R_{k, t+1}^{w *}-R_{\gamma, t+1}^{r *}\right)+R_{\gamma, t+1}^{r *}\right]
\end{aligned}
$$

which is strictly increasing in $\phi_{t}^{w}$ if and only if

$$
\left(1-p_{t}\right)\left(R_{k t+1}^{w}-R_{\gamma, t+1}^{r}\right)+p_{t} \frac{\Omega_{t+1}^{r *}}{\Omega_{t+1}^{r}}\left(R_{k t+1}^{w *}-R_{\gamma, t+1}^{r *}\right)>0
$$

Notice that condition (70) is implied by the condition that guarantees that retail bankers are constrained, $E_{t}^{*}\left[\tilde{\Omega}_{t}^{r}\left(\tilde{R}_{k t+1}^{r}-R_{t+1}\right)\right]>0$, together with the fact that retail bankers are less efficient at intermediating capital than wholesale bankers $\alpha^{r}>$ 0 :

$$
\begin{aligned}
& \left(1-p_{t}\right)\left(R_{k t+1}^{w}-R_{\gamma, t+1}^{r}\right)+p_{t} \frac{\Omega_{t+1}^{r *}}{\Omega_{t+1}^{r}}\left(R_{k t+1}^{w *}-R_{\gamma, t+1}^{r *}\right) \\
& >\left(1-p_{t}\right)\left(R_{k t+1}^{r}-R_{\gamma, t+1}^{r}\right)+p_{t} \frac{\Omega_{t+1}^{r *}}{\Omega_{t+1}^{r}}\left(R_{k, t+1}^{r *}-R_{\gamma, t+1}^{r *}\right) \\
& =\frac{(1-\gamma)}{\Omega_{t+1}^{r}} E_{t}^{*}\left\{\tilde{\Omega}_{t}^{r}\left(\tilde{R}_{k t+1}^{r}-R_{t+1}\right)\right\}>0
\end{aligned}
$$

In the region where the banker is able to avoid bankruptcy even when a run happens, $\left[0, \phi_{t}^{w M}\right]$, the objective is instead

$$
\begin{aligned}
& \psi^{w, n}\left(\phi_{t}^{w}\right)=E_{t}^{*}\left\{\tilde{\Omega}_{t+1}^{w}\left[\phi_{t}^{w}\left(\tilde{R}_{k t+1}^{w}-R_{f, t+1}\right)+R_{f, t+1}\right]\right\} \\
& \begin{array}{c}
=\left(1-p_{t}\right)\left\{\Omega_{t+1}^{w}\left[\phi_{t}^{w}\left(R_{k t+1}^{w}-R_{f, t+1}\right)+R_{f, t+1}\right]\right\} \\
+p_{t}\left\{\Omega_{t+1}^{w *}\left[\phi_{t}^{w}\left(R_{k t+1}^{w *}-R_{f, t+1}\right)+R_{f, t+1}\right]\right\}
\end{array}
\end{aligned}
$$


and the condition that guarantees that the objective is strictly increasing in $\phi_{t}^{w}$ in this region is

$$
E_{t}^{*}\left[\tilde{\Omega}_{t+1}^{w}\left(\tilde{R}_{k t+1}^{w}-R_{f, t+1}\right)\right]>0 .
$$

Given this we can modify the conditions in Lemma 1 as follows:

Lemma 4: Under the conditions of Lemma 3, the incentive constraint is binding iff

$$
\begin{aligned}
0 & <E_{t}^{*}\left[\tilde{\Omega}_{t+1}^{w}\left(\tilde{R}_{k t+1}^{w}-R_{f, t+1}\right)\right] \\
\theta \omega & >\left(1-p_{t}\right)\left(R_{k t+1}^{w}-R_{\gamma, t+1}^{r}\right)+p_{t} \frac{\Omega_{t+1}^{r *}}{\Omega_{t+1}^{r}}\left(R_{k t+1}^{w *}-R_{\gamma, t+1}^{r *}\right) .
\end{aligned}
$$

\subsection{Appendix D:Measurement}

We use data from the Flow of Funds in order to construct empirical counterparts of the financial flows in the simplified intermediation process described in Figure 1. The first step in constructing our time series is a definition of the wholesale and retail sector within the broad financial business sector.

Our classification is based on the sectors and instruments reported in the Flow of Funds. We use the liability structure of the different sectors included in the "Financial Business" sector of the Flow of Funds in order to aggregate them into a Retail sector, a Wholesale sector and Others. To do this, we proceed in two steps: we first classify the funding instruments in the flow of funds into four categories that we name Retail Funding, Wholesale Funding, Intermediated Assets and Other Instruments; then we assign financial intermediaries to the Retail/Wholesale sector if the funding instruments they mostly rely on belong to the Retail/Wholesale category.

Table 6 describes the four categories of funding we use. The labels in parentheses 
are the identifiers in the Flow of Funds.

Table 6: Classification of Instruments in the Flow of Funds

\begin{tabular}{|c|c|}
\hline Retail Funding & $\begin{array}{l}\text { Checkable Deposits and Currency (L.204) } \\
\text { Time and Saving Deposits (L.205) } \\
\text { Money Market Mutual Fund Shares (L.206) } \\
\text { Mutual Fund Shares (L.214) }\end{array}$ \\
\hline \multirow[t]{2}{*}{ Wholesale Funding } & $\begin{array}{lc} & \text { Repurchase Agreements (L.207) } \\
\text { Short Term } & \text { Security Credit (L.224) } \\
& \text { Financial Open Market Paper (L.208) } \\
& \text { Agency/GSE backed Securities (L.210) }\end{array}$ \\
\hline & \begin{tabular}{ll}
\multirow{2}{*}{ Long Term } & Financial Corporate Bonds (L.212) \\
& Retail Loans to Wholesale (L.215)
\end{tabular} \\
\hline Intermediated Assets & $\begin{array}{c}\text { Non Financial Corporate Bonds (L.212) } \\
\text { Non Financial Equity (L.213) } \\
\text { Non Financial Open Market Paper (L.208) } \\
\text { Retail loans to non financial (L.215) } \\
\text { Mortgages (L.217) } \\
\text { Consumer Credit (L.222) } \\
\text { Other Loans (L.216) }\end{array}$ \\
\hline Other Types of Funding & All other instruments in the Flow of Funds \\
\hline
\end{tabular}

The criterion we use to define the above categories is the composition of demand and supply for each instrument. Instruments that are supplied by financial intermediaries and demanded by households fall in the Retail category, while instruments that are mainly traded among financial intermediaries are included in Wholesale Funding. Intermediated Assets consist of all of the claims issued by domestic non financial business and households. Others is a residual category.

To define our Retail and Wholesale sectors, we start by excluding some types of intermediaries from the ones that we are trying to study in our model economy. These are the intermediaries listed in the "Others" category in Table 7 below. The remaining financial intermediaries appearing in the Flow of Funds are included in the Retail/Wholesale sector if they mostly rely on Retail/Wholesale funding. The 
resulting aggregation is described in Table 7.

\begin{tabular}{||l||c||}
\hline \hline \multicolumn{2}{||c||}{ Table 7:Aggregation of Financial Sectors in the Flow of Funds } \\
\hline \hline \multirow{3}{*}{ Retail Sector } & Private Depository Institutions (L.110) \\
& Money Market Mutual Funds (L.121) \\
Wholesale Sector & Mutual Funds (L.122) \\
\hline \hline & Security Brokers Dealers (L.129) \\
& ABS Issuers (L.126) \\
& Real Estate Investment Trusts (L.128) \\
& Finance Companies (L.127) \\
& Funding Corporations (L.131) \\
& Holding Companies (L.130) \\
\hline \hline \multirow{3}{*}{ Other Intermediaries } & Monetary Authority (L.109) \\
& Private and Public Pension Funds (L.117) \\
& Insurance Companies (L.115-116) \\
& Government (L.105-106) \\
& Rest of the World (L.132) \\
\hline \hline Households & L.101 \\
\hline \hline Firms & L.102 \\
\hline \hline
\end{tabular}

Given this we construct the following measures:

1. $K_{t}^{h}, K_{t}^{r}, K_{t}^{w}$

The intermediation shares are constructed by computing aggregate short and long positions of Households, Retail Banks and Wholesale banks in the markets that make up the Intermediated Assets category in Table 6. The matrix below describes each sectors' activity in each market. If sector $J$ has a long/short position in market $X$ the corresponding entry is given by $X_{+}^{J} / X_{-}^{J}$. If sector $J$ has both long and short positions in market $X$, the corresponding entry also displays its net position, $X_{n e t}^{J}(+) / X_{n e t}^{J}(-)$. 


\begin{tabular}{|c|c|c|c|c|c|c|}
\hline Markets & $\begin{array}{l}\text { Bonds } \\
\text { L.212 }\end{array}$ & $\begin{array}{l}\text { Equity } \\
L .213\end{array}$ & $\begin{array}{l}\text { Comm } \\
\text { Paper } \\
\text { L.208 }\end{array}$ & $\begin{array}{l}\text { Loans } \\
L .215\end{array}$ & $\begin{array}{c}\text { Mortgages } \\
\text { L.208 }\end{array}$ & $\begin{array}{c}\text { Consumer } \\
\text { Credit } \\
L .222\end{array}$ \\
\hline $\begin{array}{c}\text { Sectors } \\
\text { Retail } \\
\text { Banks }\end{array}$ & $\begin{array}{c}\mathrm{BO}_{+}^{R} \\
\mathrm{BO}_{-}^{R} \\
\mathrm{BO}_{n e t}^{R}(+)\end{array}$ & $\begin{array}{c}\mathrm{EQ}_{+}^{R} \\
\mathrm{NA} \\
? \\
\end{array}$ & $\begin{array}{c}\mathrm{CP}_{+}^{R} \\
\mathrm{CP}_{-}^{R} \\
\mathrm{CP}_{n e t}^{R}(+)\end{array}$ & $\mathrm{L}_{+}^{R}$ & $\mathrm{M}_{+}^{R}$ & $\mathrm{CC}_{+}^{R}$ \\
\hline $\begin{array}{c}\text { Wholesale } \\
\text { Banks }\end{array}$ & $\begin{array}{c}\mathrm{BO}_{+}^{W} \\
\mathrm{BO}_{-}^{W} \\
\mathrm{BO}_{n e t}^{W}(-)\end{array}$ & $\begin{array}{c}\mathrm{EQ}_{+}^{W} \\
\mathrm{NA} \\
?\end{array}$ & $\begin{array}{c}\mathrm{CP}_{+}^{W} \\
\mathrm{CP}_{-}^{W} \\
\mathrm{CP}_{n e t}^{W}(-)\end{array}$ & $\mathrm{L}_{-}^{W}$ & $\mathrm{M}_{+}^{W}$ & $\mathrm{CC}_{+}^{W}$ \\
\hline Other Item & $\begin{array}{c}\mathrm{BO}_{+}^{O} \\
\mathrm{BO}_{-}^{O} \\
\mathrm{BO}_{\text {net }}^{O}(+)\end{array}$ & $\begin{array}{c}\mathrm{EQ}_{+}^{O} \\
\mathrm{NA} \\
? \\
\end{array}$ & $\begin{array}{c}\mathrm{CP}_{+}^{O} \\
\mathrm{CP}_{-}^{O} \\
\mathrm{CP}_{n e t}^{O}(+)\end{array}$ & $\mathrm{L}_{-}^{O}$ & $\mathrm{M}_{+}^{O}$ & $\mathrm{CC}_{+}^{O}$ \\
\hline Households & $\mathrm{BO}_{+}^{H}$ & $\mathrm{EQ}_{+}^{H}$ & $\begin{array}{l}0 \\
0\end{array}$ & $\mathrm{~L}_{-}^{H}$ & $\mathrm{M}_{-}^{H}$ & $\mathrm{CC}_{-}^{H}$ \\
\hline Firms & $\mathrm{BO}_{-}^{F}$ & $\mathrm{EQ}_{-}^{F}$ & $\begin{array}{c}\mathrm{CP}_{+}^{F} \\
\mathrm{CP}_{-}^{F} \\
\mathrm{CP}_{\text {net }}^{F}(-)\end{array}$ & $\mathrm{L}_{-}^{F}$ & $\begin{array}{c}\mathrm{M}_{+}^{F} \\
\mathrm{M}_{-}^{F} \\
\mathrm{M}_{\text {net }}^{F}(-)\end{array}$ & $\mathrm{CC}_{+}^{F}$ \\
\hline
\end{tabular}

We make several assumptions in order to conduct our measures.

First, in the markets for bonds and commercial paper, some positions are potentially inconsistent with our intermediation model. This is because some sectors within the retail category are short in these markets and some in wholesale are long, $\mathrm{BO}_{-}^{R}>0, \mathrm{CP}_{-}^{R}>0, \mathrm{BO}_{+}^{W}>0$ and $\mathrm{CP}_{+}^{W}>0$. This allows for the possibility that retail banks were borrowing from wholesale in these markets. However, we rule out this possibility in constructing our measures for two reasons: given the heavy reliance on these types of instruments in financial transactions among industries within the respective categories and among financial firms within the same industry, it is reasonable to assume that the vast majority of these offsetting positions were actually arising from cross holdings among firms within the same category; moreover, the actual size of $\mathrm{BO}_{-}^{R}$ and $\mathrm{CP}_{-}^{R}$ with respect to $\mathrm{BO}_{-}^{W}$ and $\mathrm{CP}_{-}^{W}$ was very small, i.e. $\frac{C P_{-}^{R}}{C P_{-}^{W}} \simeq .1 \%$ and $\frac{C P_{-}^{R}}{C P_{-}^{W}} \simeq 3 \%$ in 2007 . This implies that we can safely work with the net positions for wholesalers and retailers.

Given the assumptions we make in these markets we can construct model consistent measures from bonds and commercial paper data by assuming that households lend to non financial firms, which is part of $K^{h}$, while retail banks (and Other intermediaries) lend to both Wholesale banks, which is part of $B$, 
and firms, which is part of $K^{r} \cdot{ }^{45}$ We also assume that portfolio weights on non financial and financial issued instruments in these markets are the same for retail banks and other intermediaries. ${ }^{46}$ That is, letting $\digamma_{b o}^{i, F}$ and $\digamma_{c p}^{i, F}$ be the proportions of lender's $i^{\prime} s$ holdings of bonds and commercial paper that are issued by non financial firms, we have

$$
\digamma_{b o}^{H, F}=1 ; \digamma_{b o}^{R, F}=\left(\frac{B O_{-}^{F}-B O_{+}^{H}}{B O_{-}^{F}+B O_{n e t}^{W}-B O_{+}^{H}}\right) ;{ }^{47}
$$

Similarly for commercial paper: $\digamma_{c p}^{H, F}=0 ; \digamma_{c p}^{R, F}=\frac{C P_{-}^{F}}{C P_{-}^{F}+C P_{n e t}^{W}}$

Second, for corporate equities the Flow of Funds does not report a disaggregated measure of equity issued by individual industries or the type of equity held by the various industries. Since we use this market only in measuring $K^{i}$, we simply assume that each sector holds a scaled version of the same equity portfolio consisting of the three sectors for which we have issuance data: Foreign equities, Financial Business equities and Non Financial Business Equities, denoted by $E Q^{R O W}, E Q^{F I N}$ and $E Q^{N F I}$ respectively. That is, in order to compute how many funds flow to non financial firms from each other sector we simply scale their total equity holdings by

$$
\eta=\frac{E Q^{N F I}}{E Q^{N F I}+E Q^{F I N}+E Q^{R O W}}
$$

Given this we can compute

$$
\begin{gathered}
K_{t}^{h}=\eta E Q^{H}+B O_{+}^{H} \\
K_{t}^{r}=\eta E Q^{R}+\digamma_{b o}^{R, F} B O_{n e t}^{R}+\digamma_{c p}^{R, F} C P_{n e t}^{R} \\
+L_{-}^{F}+L_{-}^{H}+M_{+}^{R}+C C_{+}^{R}
\end{gathered}
$$

\footnotetext{
${ }^{45}$ The Households' sector in the Flow of Funds is a residual category that includes Hedge Funds, private equity funds and personal trusts, which are interemediaries that our model does not directly capture. In any case, households' intermediation in bonds and commercial paper market is a small component of houseold intermediation so that very little would change if we instead made different assumptions about households positions in these markets.

${ }^{46}$ We include long positions of non-financial firms in the commercial paper within intermediation performed by "Others".

${ }^{47}$ Notice that we attribute all household's lending in this market, $B O_{+}^{H}$, to "nonfinancial loans" $K^{h}$; we then allocate retail bankers supply of funds in this market to non financial loans, $K^{r}$ proportionally to the weight of non financial firms demand for funds that is not met by households, $B O_{-}^{F}-B O_{+}^{H}$, in the total demand for funds that is not met by housheolds, $B O_{-}^{F}+B O_{n e t}^{W}-B O_{+}^{H}$
} 


$$
K_{t}^{W}=\eta E Q^{W}+M_{+}^{W}+C C_{+}^{W}
$$

2. $B, D$

$B$ is simply computed as wholesale net borrowing in all of the short term wholesale instruments: Repo, Commercial Paper, Agency Debt and Security credit. $D$ is given by Households and non financial Business holdings of retail funding instruments.

3. Leverage multiple for broker dealers, finance companies and GSE

We compute financial leverage multiple for these three sectors by dividing total financial assets by financial assets minus financial liabilities plus equity investment by holding companies. We do not have a measure of nonfinancial assets in the flow of funds so the leverage multiple reported here overstates financial leverage multiple that would include non financial assets in the computation. We compute average leverage multiple by using time varying weights corresponding to the relative sizes of these three sectors as measured by total financial assets.

\subsection{Appendix E: Computation}

It is convenient for computations to introduce the ex-ante optimal values of surviving bankers at time $t$ in the two sectors:

$$
\begin{gathered}
\bar{V}_{t}^{w}=\left[1-\sigma+\sigma \theta\left(1-\omega+\omega \phi_{t}^{w}\right)\right] \frac{N_{t}^{w}-W^{w}}{\sigma^{w}}= \\
=\Omega_{t}^{w} \frac{N_{t}^{w}-W^{w}}{\sigma^{w}} \\
\bar{V}_{t}^{r}=\left[1-\sigma+\sigma \theta \phi_{t}^{r}\right] \frac{N_{t}^{r}-W^{r}}{\sigma^{r}} \\
=\Omega_{t}^{r} \frac{N_{t}^{r}-W^{r}}{\sigma^{r}}
\end{gathered}
$$

Let the state of the economy if a run has not happened be denoted by $x=$ $\left(N^{w}, N^{r}, Z\right)$, and the state in case a run has happened be denoted by $x^{*}=\left(0, N^{r}, Z\right)$. We use time iteration in order to approximate the functions

$$
\left\{\mathbf{Q}(x), \mathbf{C}^{h}(x), \overline{\mathbf{V}}^{r}(x), \overline{\mathbf{V}}^{w}(x), \mathbf{\Gamma}(x)\right\} \quad x \in\left[W^{w}, \bar{N}^{w}\right] \times\left[W^{r}, \bar{N}^{r}\right] \times[(.95) Z, Z]
$$

and

$$
\left\{\mathbf{Q}^{*}(x), \mathbf{C}^{h *}\left(x^{*}\right), \overline{\mathbf{V}}^{r *}\left(x^{*}\right), \mathbf{\Gamma}^{*}\left(x^{*}\right)\right\} \quad x^{*} \in\{0\} \times\left[W^{r}, \bar{N}^{r}\right] \times[(.95) Z, Z]
$$


where $\boldsymbol{\Gamma}(x)$ and $\boldsymbol{\Gamma}^{*}\left(x^{*}\right)$ are the laws determining the stochastic evolution of the state (See below).

The computational algorithm proceeds as follows:

1. Determine a functional space to use for approximating equilibrium functions. (We use piecewise linear).

2. Fix a grid of values for the state in case no run happens $G \subset\left[W^{w}, \bar{N}^{w}\right] \times$ $\left[W^{r}, \bar{N}^{r}\right] \times[.95,1]$ and for the state in case a run happens $G^{*} \subset\{0\} \times$ $\left[W^{r}, \bar{N}^{r}\right] \times[.95,1]$.

3. Set $j=0$ and guess initial values for

$$
N R P o l_{t, j}=\left\{Q_{t, j}(x), C_{t, j}^{h}(x), \bar{V}_{t, j}^{r}(x), \bar{V}_{t, j}^{w}(x), \Gamma_{t, j}(x)\right\}_{x \in G}
$$

and

$$
\operatorname{RPol}_{t, j}=\left\{Q_{t, j}^{*}(x), C_{t, j}^{h *}\left(x^{*}\right), \bar{V}_{t, j}^{r *}\left(x^{*}\right), \Gamma_{t, j}^{*}\left(x^{*}\right)\right\}_{x^{*} \in G^{*}}
$$

The guess for $\Gamma_{t, j}(x)$ involves guessing $\left\{p_{t, j}(x), N_{t, j}^{r \prime}(x), N_{t, j}^{w \prime}(x), N_{t, j}^{r \prime *}(x), Z^{\prime}(x)\right\}$ which implies

$$
\Gamma_{t, j}(x)=\left\{\begin{array}{cc}
\left(N_{t, j}^{w \prime}(x), N_{t, j}^{r \prime}(x), Z^{\prime}(Z)\right) & \text { w.p. } 1-p_{t, j}(x) \\
\left(0, N_{t, j}^{r \prime *}(x), Z^{\prime}(Z)\right) & \text { w.p. } p_{t, j}(x)
\end{array} .\right.
$$

We denote by $x_{t, j}^{\prime N R}(x)=\left(N_{t, j}^{w \prime}(x), N_{t, j}^{r \prime}(x), Z^{\prime}(Z)\right)$ the state evolution if there is no run in the following period and $x_{t, j}^{\prime R}(x)=\left(0, N_{t, j}^{r \prime *}(x), Z^{\prime}(Z)\right)$ the evolution if a run happens in the following period.

Similarly the guess for $\Gamma_{t, j}^{*}\left(x^{*}\right)$ involves guessing $\left\{\hat{N}_{t, j}^{r \prime}\left(x^{*}\right), Z^{\prime}(Z)\right\}$ which implies

$$
\Gamma_{t, j}^{*}\left(x^{*}\right)=\left(\left(1+\sigma^{w}\right) W^{w}, \hat{N}_{t, j}^{r \prime}\left(x^{*}\right), Z^{\prime}(Z)\right)
$$

4. Assume that $N R P o l_{t, j}$ and $R P o l_{t, j}$ have been found for $j \leq i<M$ where $\mathrm{M}$ is set to 10000. To find $N R P o l_{t, i+1}$ and $R P o l_{t, i+1}$ first use $N R P o l_{t, i}$ and $R P o l_{t, i}$ to find functions in the approximating space that take on these values on the grid, e.g. $\mathbf{Q}_{i}:\left[W^{w}, \bar{N}^{w}\right] \times\left[W^{r}, \bar{N}^{r}\right] \times[.95,1] \rightarrow \mathbf{R}$ is the price function that satisfies $\mathbf{Q}_{i}(x)=Q_{t, i}(x)$ for each $x \in G$. 
5. Derive $N R P$ ol $_{t, i+1}$ and $R P$ ol $_{t, i+1}$ by assuming that from time $t+1$ onwards equilibrium outcomes are determined according to the functions associated to NRPol,$i$ and $R$ Pol $_{t, i}$ found in step 4 :

\section{- NO RUN SYSTEM}

At any point $x_{t}=\left(N_{t}^{w}, N_{t}^{r}, Z_{t}\right) \in G$ the system determining $\left\{\phi_{t}^{w}, \phi_{t}^{r}, B_{t}, Q_{t}, C_{t}^{h}, K_{t}^{h}, K_{t}^{r}\right\}$ is given by

$$
\begin{gathered}
\theta\left[1-\omega+\omega \phi_{t}^{w}\right] N_{t}^{w}=\beta\left(1-\mathbf{p}_{i}\left(x_{t}\right)\right) \overline{\mathbf{V}}_{i}^{w}\left(\mathbf{x}_{i}^{\prime N R}\left(x_{t}\right)\right) \\
\left(\phi_{t}^{w}-1\right) N_{t}^{w}=B_{t} \\
\phi_{t}^{w} N_{t}^{w}=Q_{t}\left(1-K_{t}^{r}-K_{t}^{h}\right) \\
\theta \phi_{t}^{r} N_{t}^{r}=\beta\left[\left(1-\mathbf{p}_{i}\left(x_{t}\right)\right) \overline{\mathbf{V}}_{i}^{r}\left(\mathbf{x}_{i}^{\prime N R}(x)\right)+\mathbf{p}_{i}\left(x_{t}\right) \overline{\mathbf{V}}_{i}^{r *}\left(\mathbf{x}_{i}^{\prime R}(x)\right)\right] \\
\phi_{t}^{r} N_{t}^{r}=\left(Q_{t}+\alpha^{r} K_{t}^{r}\right) K_{t}^{r}+(1-\gamma) B_{t} \\
C_{t}^{h}+\frac{\left(1-\sigma_{w}\right)\left(N_{t}^{r}-W^{w}\right)}{\sigma_{w}}+\frac{\left(1-\sigma_{r}\right)\left(N_{t}^{r}-W^{r}\right)}{\sigma_{r}}+\frac{\alpha^{h}\left(K_{t}^{h}\right)^{2}}{2}+\frac{\alpha^{r}\left(K_{t}^{r}\right)^{2}}{2}= \\
\left.\left.Z_{t}\left(1+Z_{t}\right)+\tilde{\mathbf{Q}}_{i}\left(\boldsymbol{\Gamma}_{i}(x)\right)\right)\right\}=Q_{t}+\alpha^{h} K_{t}^{h}+W^{r}+W^{w}=
\end{gathered}
$$

where $E_{i}$ is the expectation operator associated with the stochastic realization of a run according to $\mathbf{p}_{i}$ and tildes denote random variables whose values depend on the realization of the sunspot. For instance,

$$
\tilde{\mathbf{C}}_{i}^{h}\left(\boldsymbol{\Gamma}_{i}(x)\right)=\left\{\begin{array}{cc}
\mathbf{C}_{i}^{h}\left(\mathbf{N}_{i}^{w \prime}(x), \mathbf{N}_{i}^{r \prime}(x), \mathbf{Z}^{\prime}(Z)\right) & w . p .1-\mathbf{p}_{i}(x) \\
\mathbf{C}_{i}^{h *}\left(\mathbf{N}_{i}^{r * *}(x), \mathbf{Z}^{\prime}(Z)\right) & \text { w.p. } \mathbf{p}_{i}(x)
\end{array}\right.
$$

One can then find $\left\{R_{t}, \bar{R}_{t}^{b}\right\}$ from

$$
R_{t}=\frac{1}{\beta E_{i}\left\{\frac{C_{t}^{h}}{\tilde{\mathbf{C}}_{i}^{h}\left(\boldsymbol{\Gamma}_{i}(x)\right)}\right\}}
$$




$$
\begin{aligned}
\bar{R}_{t}^{b}= & \frac{E_{i}\left\{\tilde{\boldsymbol{\Omega}}^{r}\left(\boldsymbol{\Gamma}_{i}(x)\right)\left(\gamma \frac{\left(\mathbf{z}^{\prime}\left(Z_{t}\right)+\tilde{\mathbf{Q}}_{i}\left(\boldsymbol{\Gamma}_{i}(x)\right)\right)}{Q_{t}+\alpha^{r} K_{t}^{r}}+(1-\gamma) R_{t}\right)\right\}}{\left(1-\mathbf{p}_{i}\left(x_{t}\right)\right) \boldsymbol{\Omega}^{r}\left(\mathbf{x}_{i}^{\prime N R}\left(x_{t}\right)\right)} \\
& -\frac{-\mathbf{p}_{i} \Omega^{r *}\left(x_{i}^{\prime R}\left(x_{t}\right)\right)\left(\frac{\left(\mathbf{z}^{\prime}\left(Z_{t}\right)+\tilde{\mathbf{Q}}_{i}\left(\boldsymbol{\Gamma}_{i}(x)\right)\right)}{Q_{t}} \frac{\phi_{t}^{w}}{\phi_{t}^{t}-1}\right)}{\left(1-\mathbf{p}_{i}\left(x_{t}\right)\right) \boldsymbol{\Omega}^{r}\left(\mathbf{x}_{i}^{\prime N R}\left(x_{t}\right)\right)}
\end{aligned}
$$

where

$$
\tilde{\mathbf{\Omega}}^{r}\left(\boldsymbol{\Gamma}_{i}(x)\right)=\left\{\begin{array}{cc}
\sigma^{r} \frac{\overline{\mathbf{V}}_{i}^{r}\left(\mathbf{N}_{i}^{w \prime}(x), \mathbf{N}_{i}^{r \prime}(x), \mathbf{Z}^{\prime}(Z)\right)}{\mathbf{N}_{i}^{w \prime}(x)-W} & \text { w.p. } 1-\mathbf{p}_{i}(x) \\
\sigma^{r} \frac{\overline{\mathbf{V}}_{i}^{r *}\left(\mathbf{N}_{i}^{r \prime *}(x), \mathbf{Z}^{\prime}(Z)\right)}{\mathbf{N}_{i}^{w \prime}(x)-W} & \text { w.p. } \mathbf{p}_{i}(x)
\end{array}\right.
$$

and finally $\left\{\bar{V}_{t}^{r}, \bar{V}_{t}^{w}, \Gamma_{t}\right\}$ are given by

$$
\begin{gathered}
\bar{V}_{t}^{w}=\left[1-\sigma+\sigma \theta\left(1-\omega+\omega \phi_{t}^{w}\right)\right] \frac{N_{t}^{w}-W^{w}}{\sigma^{w}} \\
\bar{V}_{t}^{r}=\left[1-\sigma+\sigma \theta \phi_{t}^{r}\right] \frac{N_{t}^{r}-W^{r}}{\sigma^{r}} \\
\Gamma_{t}=\left\{\begin{array}{cc}
\left(N_{t+1}^{w}, N_{t+1}^{r}, Z^{\prime}(Z)\right) & w \cdot p \cdot 1-p_{t} \\
\left(0, N_{t+1}^{r *}, Z^{\prime}(Z)\right) & w \cdot p \cdot p_{t}
\end{array}\right.
\end{gathered}
$$

where

$$
\begin{gathered}
N_{t+1}^{w}=\sigma^{w} N_{t}^{w}\left[\phi_{t}^{w}\left(\frac{\mathbf{Z}^{\prime}\left(Z_{t}\right)+\mathbf{Q}_{i}\left(\mathbf{x}_{i}^{\prime N R}(x)\right)}{Q_{t}}-\bar{R}_{t}^{b}\right)+\bar{R}_{t}^{b}\right]+W^{w} \\
N_{t+1}^{r}=\sigma^{r}\left(\left[\mathbf{Z}^{\prime}\left(Z_{t}\right)+\mathbf{Q}_{i}\left(\mathbf{x}_{i}^{\prime N R}(x)\right)\right] K_{t}^{r}+B_{t} \bar{R}_{t}^{b}-D_{t} R_{t}\right)+W^{w} \\
N_{t+1}^{r *}=\sigma^{r}\left(\left[Z^{\prime}\left(Z_{t}\right)+\mathbf{Q}_{i}^{*}\left(\mathbf{x}_{i}^{\prime R}(x)\right)\right]\left(K_{t}^{r}+K_{t}^{w}\right)-D_{t} R_{t}\right)+W^{w} \\
p_{t}=\left[1-\frac{\frac{Z^{\prime}\left(Z_{t}\right)+\mathbf{Q}_{i}^{*}\left(\mathbf{x}_{i}^{\prime R}(x)\right)}{Q_{t}}}{\bar{R}_{b t}} \cdot \frac{\phi_{t}^{w}}{\phi_{t}^{w}-1}\right]
\end{gathered}
$$

- RUN SYSTEM

Analogously at a point $x_{t}^{*}=\left(0, N_{t}^{r}, Z_{t}\right) \in G^{*}$ the system determining $\left\{\phi_{t}^{r *}, Q_{t}^{*}, C_{t}^{h *}, K_{t}^{h *}\right\}$ is given by

$$
\theta \phi_{t}^{r *} N_{t}^{r}=\beta \overline{\mathbf{V}}_{i}^{r}\left(\boldsymbol{\Gamma}_{i}^{*}\left(x_{t}^{*}\right)\right)
$$




$$
\begin{gathered}
\phi_{t}^{r *} N_{t}^{r}=\left(Q_{t}^{*}+\alpha^{r} K_{t}^{r *}\right) K_{t}^{r *} \\
\beta\left\{\frac{C_{t}^{h *}}{\mathbf{C}_{i}^{h}\left(\boldsymbol{\Gamma}_{i}^{*}\left(x_{t}^{*}\right)\right)}\left(Z^{\prime}\left(Z_{t}\right)+\mathbf{Q}_{i}\left(\boldsymbol{\Gamma}_{i}^{*}\left(x_{t}^{*}\right)\right)\right)\right\}=Q_{t}^{*}+\alpha^{h} K_{t}^{h *} \\
C_{t}^{h *}+\frac{\left(1-\sigma_{r}\right)}{\sigma_{r}}\left(N_{t}^{r}-W^{r}\right)+\frac{\alpha^{h}}{2}\left(K_{t}^{h *}\right)^{2}+\frac{\alpha^{r}}{2}\left(1-K_{t}^{h *}\right)^{2}=Z_{t}\left(1+W^{h}\right)+W^{r}
\end{gathered}
$$

and $\left\{R_{t}^{*}, \bar{V}_{t}^{r *}, \Gamma_{t}^{*}\right\}$ are given by

$$
\begin{gathered}
R_{t}^{*}=\frac{1}{\beta E_{i}\left\{\frac{C_{t}^{h *}}{\mathbf{C}_{i}^{h}\left(\boldsymbol{\Gamma}_{i}^{*}\left(x_{t}^{*}\right)\right)}\right\}} \\
\bar{V}_{t}^{r *}=\left[1-\sigma+\sigma \theta \phi_{t}^{r *}\right] \frac{N_{t}^{r}-W^{r}}{\sigma^{r}} \\
\Gamma_{i}^{*}\left(x^{*}\right)=\left(\left(1+\sigma^{w}\right) W^{w}, \hat{N}_{t+1}^{r}, Z^{\prime}(Z)\right) \\
\hat{N}_{t+1}^{r}=\sigma^{r} N_{r}^{r}\left[\phi_{t}^{r *}\left(\frac{Z^{\prime}\left(Z_{t}\right)+\mathbf{Q}_{i}\left(\boldsymbol{\Gamma}_{i}^{*}\left(x_{t}^{*}\right)\right)}{Q_{t}}-R_{t}^{*}\right)+R_{t}^{*}\right]+W^{r}
\end{gathered}
$$

6. Compute the maximum distance between $N R \operatorname{Pol}_{t}=\left\{Q_{t}, \bar{V}_{t}^{r}, \bar{V}_{t}^{w}, C_{t}^{h}, p_{t}, N_{t+1}^{r}, N_{t+1}^{w}, N_{t+1}^{r *}\right\}$ and $N R P o l_{t, i}$

$$
d N R=\max _{x_{t} \in G} \max \left|N R \operatorname{Pol}_{t}-N R \operatorname{Rol}_{t, i}\right|
$$

and similarly for $R \operatorname{Pol}_{t}=\left\{Q_{t}^{*}, \bar{V}_{t}^{r *}, C_{t}^{h *}, \hat{N}_{t+1}^{r}\right\}$ and $R P o l_{t, i}$

$$
d R=\max _{x_{t} \in G^{*}} \max \left|R \operatorname{Pol}_{t}-R P \operatorname{Pol}_{t, i}\right|
$$

if $d N R$ and $d R$ are small enough, in our case $e-6$, set

$$
\begin{aligned}
N R \text { Pol }_{t, i+1} & =N \text { RPol }_{t, i} \\
\operatorname{RPol}_{t, i+1} & =\text { RPol }_{t, i}
\end{aligned}
$$

Otherwise set

$$
\begin{gathered}
\operatorname{NRPol}_{t, i+1}=\alpha N \operatorname{RPol}_{t, i}+(1-\alpha) \text { NRPol }_{t} \\
\text { RPol }_{t, i+1}=\alpha \text { RPol }_{t, i}+(1-\alpha) \text { RPol }_{t}
\end{gathered}
$$

where $\alpha \in(0,1)$. 


\section{References}

[1] Adrian, T., Ashcraft, A., 2012. Shadow Banking: A review of the Literature. Palgrave Dictionary of Economics.

[2] Adrian, T., Colla, P., and Shin, H., 2012. Which Financial Frictions? Paring the Evidence from Financial Crisis of 2007-9. Forthcoming in NBER Macroeconomic Annual.

[3] Adrian, T., and H. Shin. 2010. Changing Nature of Financial Intermediation and Financial Crisis of 2007-2009. Annual Review of Economics: 603-618.

[4] Allen, F., and Gale, D., 2007. Understanding Financial Crises. Oxford University Press.

[5] Angeloni, I., and E. Faia, 2013, Capital Regulation and Monetary Policy with Fragile Banks, Journal of Monetary Policy 60, 3111-382.

[6] Begenau, J., 2015. Capital Requirements, Risk Choice, and Liquidity Provision in a Business Cycle Model, Harvard Business School Working Paper, n 15-072.

[7] Bernanke, B., 2010. Causes of the Recent Financial and Economic Crisis. Statement before the Financial Crisis Inquiry Commission, Washington, September 2 .

[8] Bernanke, B., and Gertler, M., 1989. Agency Costs, Net Worth and Business Fluctuations. American Economic Review 79, 14-31.

[9] Bianchi, J., 2011. Overborrowing and Systemic Externalities in the Business Cycle. American Economic Review 101, 3400-3426.

[10] Bianchi, J., and Mendoza, E., 2013. Optimal Time-Consistent Macroprudential Policy, NBER Working Paper 19704

[11] Bigio, S., 2015. Financial Risk Capacity, Working Paper.

[12] Boissay F., F. Collard, and F. Smets, 2013, Booms and Systemic Banking Crises, mimeo.

[13] Brunnermeier, M. K., and M. Oemke. 2013 Maturity Rat Race. Journal of Finance, 68: 483-521. 
[14] Brunnermeier, M. K., and Pedersen, L., 2009. Market Liquidity and Funding Liquidity. Review of Financial Studies 22, 2201-2238.

[15] Brunnermeier, M. K., and Sannikov, Y., 2014. A Macroeconomic Model with a Financial Sector. American Economic Review 104, 379-421.

[16] Caballero, R., and Farhi, E., 2015. The Safety Trap, Working Paper.

[17] Chari, V., and Kehoe, P., 2015. Bailouts, Time Inconsistency, and Optimal Regulation: A Macroeconomic View, Federal Reserve Bank of Minneapolis, Research Department Staff Report 481.

[18] Christiano, L., and Ikeda, D., 2014. Leverage Restrictions in a Business Cycle Model, in Macroeconomic and Financial Stability: Challenges for Monetary Policy, Conference Volume, XVI Annual Conference of the Central bank of Chile.

[19] Cole, H. and T. Kehoe, 2000, Self-fulfilling Debt Crises, Review of Economic Studies 67, 91-161

[20] Cooper, R. and T. Ross, 1998, Bank Runs: Liquidity Costs and Investment Distortions, Journal of Monetary Economics 41, 27-38.

[21] Covitz, D., N. Liang and G. Suarez. 2013. Evolution of a Financial Crisis: Collapse of the Asset-Backed Commercial Paper Market. Journal of Finance, 68: $815-$

[22] Curdia, V., and M. Woodford. 2010. Credit Spreads and Monetary Policy. Journal of Money, Credit and Banking, 42(6), 3-35.

[23] Dang, T., Gorton, G., and Holmstrom, B., 2012. Ignorance, Debt and Financial Crises, Working Paper.

[24] Diamond, D., and Dybvig, P., 1983. Bank Runs, Deposit Insurance, and Liquidity. Journal of Political Economy 91, 401-419.

[25] Di Tella, S., 2014. Uncertainty Shocks and Balance Sheet Recessions, Working Paper.

[26] Eggertsson, G., and P. Krugman. 2012. Debt, Deleveraging, and Liquidity Trap. Quarterly Journal of Economics, 1469-1513.

[27] Ennis, H. and T. Keister, 2003, Economic Growth, Liquidity and Bank Runs, Journal of Economic Theory 109, 220-245. 
[28] Farhi, E., and Tirole, J., 2012. Collective Moral Hazard, Maturity Mismatch and Systemic Bailouts, American Economic Review, 102(1), 60-93.

[29] Farhi, E., and Werning, I., 2015. A Theory of Macroprudential Policies in the Presence of Nominal Rigidities, Working Paper.

[30] Farmer, R., 1999. The Macroeconomics of Self-Fulfilling Prophecies. MIT Press.

[31] Ferrante, F. 2015a. A Model of Endogenous Loan Quality and the Collapse of the Shadow Banking System. Finance and Economics Discussion Series 2015-021, Federal Reserve Board.

[32] Ferrante, F. 2015b. Risky Mortgages, Bank Leverage and Credit Policy, Working Paper.

[33] Friedman, M., and Schwartz, A., 1963. A Monetary History of the United States, 1867-1960. Princeton University Press.

[34] Garleanu, N., Panageas, S., and Yu, J., 2015. Financial Entanglement: A theory of Incomplete Integration, Leverage, Crashes and Contagion, American Economic Review, 105(7), 1979-2010.

[35] Geanakoplos, J. and H., Polemarchakis, 1986. Existence, Regularity, and Constrained Suboptimality of Competitive Allocations When the Asset Market Is Incomplete, in W. Heller, R. Starr and D. Starret (eds.), Uncertainty, Information, and Communication: Essays in Honor of K. J. Arrow, Vol III, Cambridge University Press.

[36] Gertler, M., and Karadi, P., 2011. A Model of Unconventional Monetary Policy, Journal of Monetary Economics, January.

[37] Gertler, M., and Kiyotaki, N., 2010. Financial Intermediation and Credit Policy in Business Cycle Analysis. In Friedman, B., and Woodford, M. (Eds.), Handbook of Monetary Economics. Elsevier, Amsterdam, Netherlands.

[38] Gertler, M., Kiyotaki, N., and Queralto, A., 2012. Financial Crises, Bank Risk Exposure and Government Financial Policy, Journal of Monetary Economics 59, S17-S34.

[39] Gertler, M., N. Kiyotaki. 2015. Banking, Liquidity and Bank Runs in an Infinite Horizon Economy, American Economic Review, forthcoming. 
[40] Gilchrist, S., and E. Zakrajsek. 2012. Credit Spread and Business Cycle Fluctuations, American Economic Review.

[41] Giroud, X., and H., Mueller. 2015. Firm Leverage and Unemployment During the Great Recession, mimeo.

[42] Goldstein, I., and A. Pauzner. 2005. Demand-Deposit Contracts and the Probability of Bank Runs. Journal of Finance 60, 1293-1327.

[43] Gorton, G., 2009. Information, Liquidity and the (Ongoing) Panic of 2007, American Economic Review, Papers and Proceedings, vol. 99, n. 2, 567-572.

[44] Gorton, G., 2010. Slapped by the Invisible Hand: The Panic of 2007. Oxford University Press.

[45] Gorton, G., Metrick, A., 2012. Who Ran on Repo? NBER Working Paper 18455.

[46] Gorton, G., Metrick, A., 2015. The Safe Asset Share, American Economic Review, Papers and Proceedings, 102(3), 101-106.

[47] Guerrieri, V., and G. Lorenzoni. 2011. Credit Crises, Precautionary Savings and the Liquidity Trap. NBER Working Paper 17583.

[48] Gurley, J., and E. Shaw. 1960. Money in Theory of Finance. Washington, D.C.: Brookings Institution.

[49] He, Z. and A. Krishnamurthy, 2013. Intermediary Asset Pricing, American Economic Review.

[50] He, Z. and A. Krishnamurthy, 2014. A Macroeconomic Framework for Quantifying Systemic Risk. Working Paper, University of Chicago and Stanford University.

[51] Holmstrom, B. and J. Tirole, 1997, Financial Intermediation, Loanable Funds and the Real Sector, The Quarterly Journal of Economics, Vol.112, No. 3, 663691

[52] Holmstrom, B. and J. Tirole, 2011. Inside and Outside Liquidity. MIT Press.

[53] Kacperczyk, M., and P. Schnabl. 2010. When Safe Proved Risky: Commercial Paper during the Financial Crisis of 2007-2009. Journal of Economic Perspectives, 24(1), 29-50. 
[54] Kiyotaki, N., and Moore, J., 1997. Credit Cycles. Journal of Political Economy $105,211-248$.

[55] Korinek, A., and Simsek, A., 2015. Liquidity Trap and Excessive Leverage, Working Paper.

[56] Krishnamurthy, A., 2003. Collateral Constraints and the Amplification Mechanism, Journal of Economic Theory, vol 111, Issue 2, 277-292.

[57] Krishnamurthy, A., S. Nagel and D. Orlov. 2014. Seizing Up Repo. Journal of Finance. Forthcoming.

[58] Lorenzoni, G., 2008. Inefficient Credit Boom. Review of Economic Studies 75, $809-833$.

[59] Martin, A., D. Skeie and E.L. Von Thadden. Repo Runs. Review of Financial Studies, 27: 957-989.

[60] Martin, A., D. Skeie and E.L. Von Thadden. Fragility of Short-Term Secured Funding. Journal of Economic Theory, 149: 15-42.

[61] McCabe, P., 2010. The Cross Section of Money Market Fund Risks and Financial Crises. Finance and Economics Discussion Series 2010-51, Federal Reserve Board.

[62] Mendoza, E. 2010. "Sudden Stops, Financial Crises, and Leverage. American Economic Review 100, 1941-1966.

[63] Midrigan, T., and T. Philippon, 2011. A Macroeconomic Framework for Quantifying Systemic Risk. NBER Working Paper 19885.

[64] Morris, S. and H.S. Shin. 1998. Unique Equilibrium in a Model of Self-Fulfilling Currency Attacks. American Economic Review 88, 587-97.

[65] Parlatore, C., 2015. Fragility in Money Market Funds: Sponsor Support and Regulation. Working Paper.

[66] Phillipon, T. 2013. Has the U.S. Finance Industry Become Less Efficient?

[67] Pozsar, Z., Adrian, T., Ashcraft, A. and Boesky, H., 2013. Shadow Banking, Federal Reserve Bank of New York Economic Policy Review, Volume 19, Number 2 . 
[68] Robatto, R. 2014, Financial Crises and Systematic Bank Runs in a Dynamic Model of Banking, Working Paper, University of Wisconsin-Madison.

[69] Uhlig, H., 2010, A Model of a Systemic Bank Run, Journal of Monetary Economics $57,78-96$. 


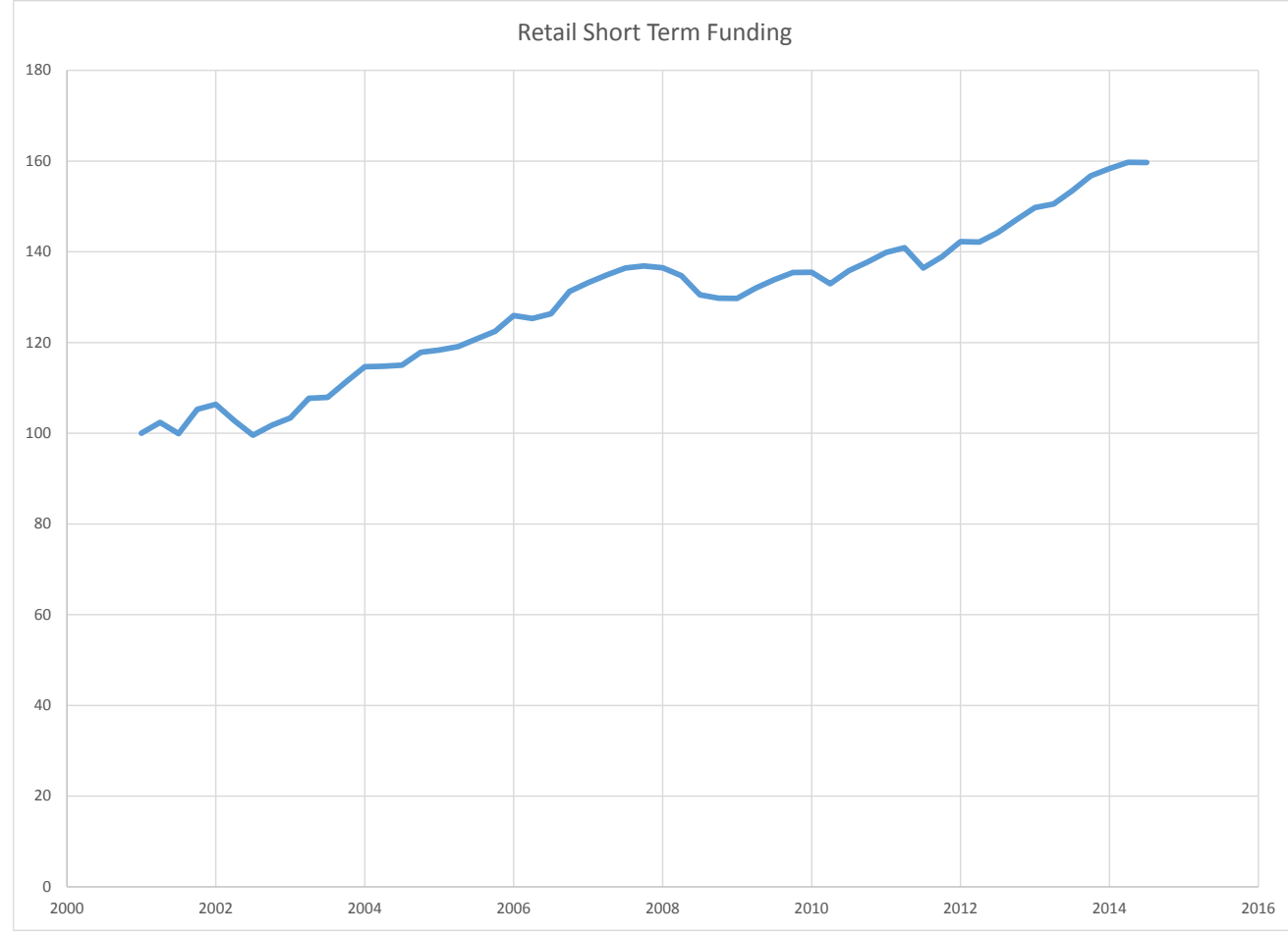

Figure 19: Retail short term Funding

The graph shows the logarithm of the real value outstanding. Nominal values from Flow of Fnds are deflated using the CPI and normalized so that the log of the normalized value of retail short term funding in 2001 is equal to 100 


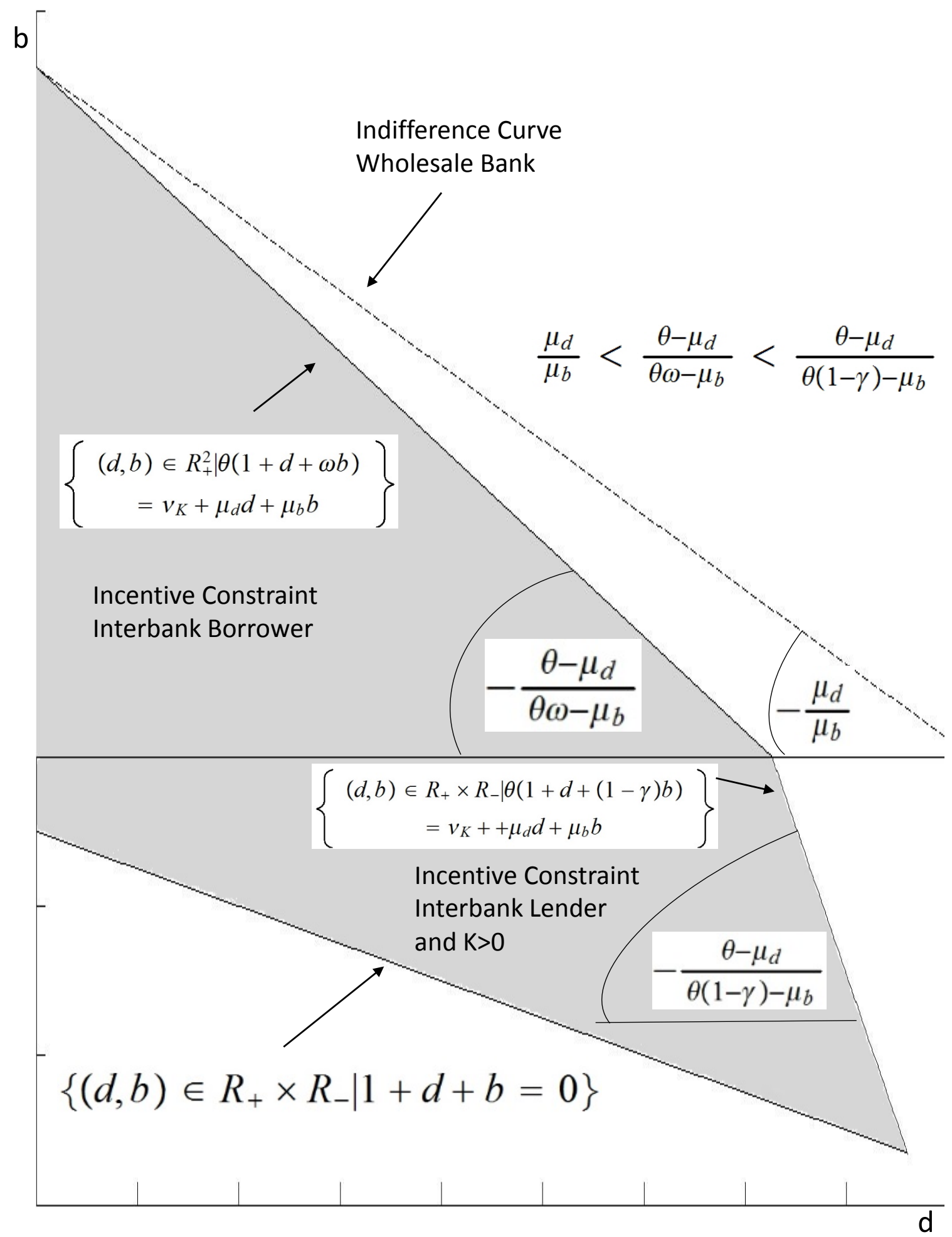

Figure 20: Wholesale9 9 anker's Optimization 


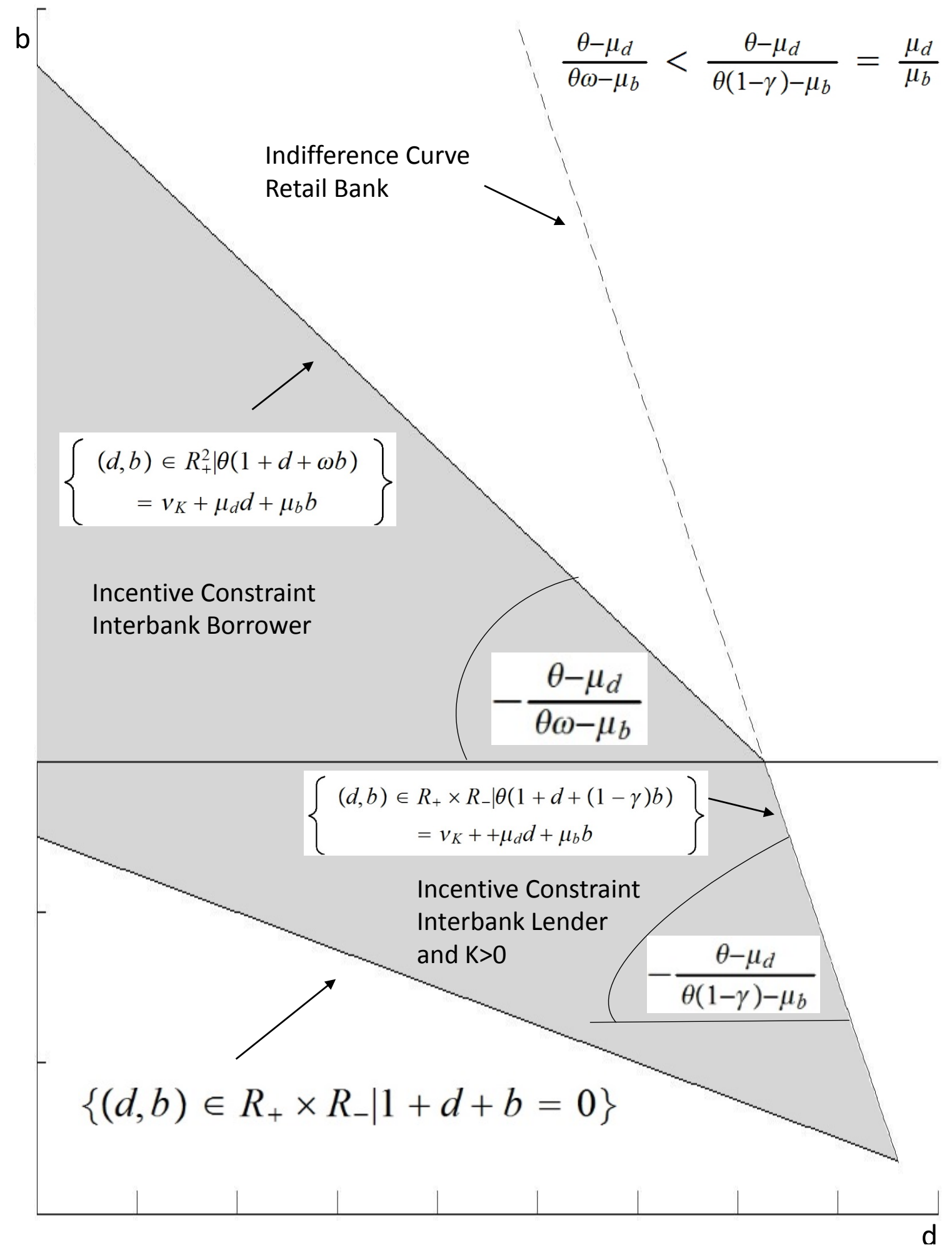

Figure 21: Retail Bahker's Optimization 